\title{
Free Movement of Inventors: Open-Border Policy and Innovation in Switzerland*
}

\author{
Gabriele Cristelli ${ }^{\dagger} \quad$ Francesco Lissoni ${ }^{\ddagger}$
}

\author{
November 2020 \\ (Revised April 2021)
}

\begin{abstract}
We study the innovation effects of the Agreement on the Free Movement of Persons (AFMP), signed by Switzerland and the EU in 1999. Using geocoded patent data, complemented by matched inventor-immigrant-census records, we identify a large number of cross-border inventors (CBIs), commuters from neighbouring countries working in Swiss R\&D labs. We show that, during the AFMP implementation phase, the influx of CBIs increased differentially across regions at different driving distances from the border, causing a $24 \%$ increase in patents, mostly due to large and medium patent holders (as opposed to very large ones) and to inventor teams mixing CBIs and natives. We do not detect any adverse effect on native inventors and show that Swiss incumbent inventors collaborating with CBIs increased their productivity. Our evidence suggests complementarity between CBIs' and Swiss incumbents' knowledge assets.
\end{abstract}

JEL Classification: F22, J61, O31, O33

Keywords: Immigration, Innovation, Patents, Inventors, Free Movement of Persons

${ }^{*}$ We thank Mike Andrews, Andreas Beerli, Enrico Berkes, David Card, Raj Choudhury, Fabrizio Colella, Gaétan de Rassenfosse, Kirk Doran, Carsten Fink, Dominique Foray, Ina Ganguli, Patrick Gaulé, Albrecht Glitz, Megan MacGarvie, Matt Marx, Ernest Miguelez, Abhishek Nagaraj, Markus Nagler, Michele Pezzoni, Ariell Reshef, Maria Roche, Michael Siegenthaler, Valerio Sterzi, Otto Toivanen, Rainer Widmann, and Kenneth Younge for helpul comments. We are grateful to Michael Siegenthaler for sharing his data on the Swiss Border Regions and to James Feigenbaum and Julio Raffo for their advice on data linkage techniques. We received very useful comments by seminar participants at the Max Planck Institute for Innovation and Competition, the NBER Productivity Lunch, Université du Luxembourg, Université de Strasbourg, University of Manchester, Swinburne University, and WIPO; as well as by participants to the 2018 CEPII-EPFL Workshop on Migration Innovation and the Knowledge Economy, the EPIP 2018 Conference, the 2019 Wharton Conference on Migration, Organizations, and Management, and the 2019 Workshop on Innovation, Technological Change, and International Trade at TUM Heilbronn. We are grateful to the Swiss State Secretariat for Migration, the Swiss Federal Institute of Intellectual Property, and the Swiss Federal Statistical Office for supporting our project. Andrea Vismara provided excellent research assistance. Lissoni acknowledges financial support from the French National Research Agency (TKC project - reference: ANR-17-CE26-0016) and the French National Center for Scientific Research (InSHS-CNRS, programme de soutien à la mobilité internationale-2018). All errors are ours.

$\dagger$ École Polytechnique Fédérale de Lausanne, Chair of Economics and Management of Innovation.

Email: gabriele.cristelli@epfl.ch

‡GREThA UMR CNRS 5113, Université de Bordeaux and ICRIOS, Bocconi University, Milan.

Email: francesco.lissoni@u-bordeaux.fr 


\section{Introduction}

International migration is a key topic of current public debate. A rising anti-immigration sentiment conditions immigration policies in many destination countries (Card et al., 2005; Dustmann and Preston, 2006; Alesina et al., 2018). A prominent example is Brexit, in which hostility towards the Freedom of Movement of Workers principle, a pillar of the EU, has played an important role (Becker et al., 2017). A large literature in economics has sought to understand how immigration affects receiving economies. Among studies casting a positive light on the phenomenon are those suggesting that immigration can sustain innovation in destination countries (Hunt and Gauthier-Loiselle, 2010; Kerr, 2020; Burchardi et al., 2020; Arkolakis et al., 2020).

As observed by Kerr et al. (2017), most causal evidence on the relationship between immigration and innovation is limited to the United States. It either refers to historical episodes (Moser et al., 2014; Doran and Yoon, 2020; Moser and San, 2020) or to countryspecific policy shocks, most notably those concerning the issuing of H-1B visas to highskilled workers (Kerr and Lincoln, 2010; Hunt, 2011; Peri et al., 2015; Glennon, 2020). The production of comparable evidence for other geographical and policy contexts is lagging behind, which limits generalization. Studies on Europe, in particular, are largely based on cross-firm, -regional, or -country variation in the workforce's ethnic composition or immigrant presence, and its association with various measures of innovation (Ozgen et al., 2013; Parrotta et al., 2014; Bosetti et al., 2015; Nathan, 2015).

Our understanding of the mechanisms via which immigration may sustain innovation is also limited. Some studies have investigated the role of immigrants' positive self-selection into R\&D-oriented careers (Hunt, 2011); others that of cultural diversity (survey by Kemeny, 2017), while many more have focused on knowledge diffusion (e.g., Choudhury and Kim, 2019 or Bahar et al., 2020; survey by Lissoni, 2018). We also deal with the diffusion, but first notice that it lends itself to quite different interpretations. One is that of diffusion as mobility, with immigrants bringing and putting to use their own knowledge assets, but not necessarily passing them on to natives (as in historical studies of itinerant craftsmen and engineers in early modern Europe: Belfanti, 2004; 
Hilaire-Pérez and Verna, 2006). Another considers diffusion as knowledge transfer, with interpersonal transmission from more to less expert individuals playing a decisive role (as in more recent studies of European scientists' migration to the United States: Moser et al., 2014; Ganguli, 2015). Both interpretations, however, should be revisited in the light of the contemporary importance of teamwork in innovation and the relatively young age of many high-skilled immigrants. Present-day immigrant scientists and inventors are carriers of specialist knowledge assets that need to be combined with others, due to the increasing division of R\&D labor (Jones, 2009). At the same time, most of them move at an early age, when they may have much-in-demand experimental skills or theoretical notions, but not much to teach to the R\&D staff they join (d'Aiglepierre et al., 2020). We suspect that complementarity between their knowledge assets and the natives' is what really matters, along with their deployment in teamwork.

In this paper, we study the effects of the Agreement on the Free Movement of Persons (AFMP), an open-border immigration policy signed by Switzerland and the European Union in 1999. We exploit a quasi-experimental setting generated by regional differences in the AFMP implementation to evaluate its impact on Swiss regional innovative performance and the individual productivity of incumbent inventors in different regions. We also inspect the composition of inventor teams and discuss immigrant-native interactions.

Despite its small size, Switzerland is an innovation powerhouse. From 2013 to 2019 it ranked first worldwide in terms of patent applications per million inhabitants and it currently ranks twelfth for employment intensity of full-time researchers (Researchers FTE/Population). ${ }^{1}$ At the same time, a sizeable share of its researchers are foreign nationals, such as those that composed over a third of its inventor workforce in 2001-2010 (versus 12\% in the UK and 16\% in the US; Miguelez and Fink, 2017). These immigrants are employed in the R\&D laboratories of Swiss multinationals such as Novartis and ABB or foreign ones like IBM, Google, and Merck; and also work for less visible domestic firms of all sizes.

As for the AFMP, it can be regarded as both a major episode in the progressive

\footnotetext{
1Sources: European Patent Office (EPO) Annual Reports: https://www.epo.org/about-us/ annual-reports-statistics/annual-report.html; and Global Innovation Index 2020: https://www . wipo . int/global_innovation_index/en/2020/ (last visit: November 2020).
} 
expansion of Free Movement in Europe and a natural experiment. As demonstrated by Beerli et al. (2021), during its implementation phase (1999-2007), the AFMP induced a sudden labor supply shock for some regions of Switzerland, but not for others, the difference depending on distance from the country's international borders. The regions very close to a border crossing, in particular, experienced a disproportionate increase in the number of cross-border commuters, the first category of visa holders for which restrictions were removed.

Our paper studies in depth the impact of the AFMP-induced immigration shock on innovation. We rely on an original dataset of 65,333 patent applications filed at the European Patent Office (EPO) between 1990 and 2012 to protect inventions resulting from Swiss-located R\&D activities. By comparing personal and company addresses reported on patent applications, we identify a large number of Cross-Border Inventors (CBIs), namely inventors with residence in commuting zones across the border but working in Switzerland. For a subset of relatively recent years (2002-2012), we validate this patent-based definition of CBIs by comparing it to a census-based one, which we obtained by matching foreign inventors with personal records on immigrant permit holders from the Swiss Central Migration Information System (ZEMIS), an administrative database covering the entire immigrant population in Switzerland.

We first show that the AFMP led to a large increase in the number of CBIs, but only for regions close to the international border. We argue that this differential effect is due only to CBIs' preference for shorter commutes and not to any unobserved trend affecting both innovation and immigration. This creates a powerful treatment-control setting, which we exploit to establish the causal effect of immigration on regional innovation. Using a difference-in-differences approach, we estimate an increase in patenting of around $24 \%$ during the first eight years after the signing of the AFMP, mostly due to mixed CBI-Swiss inventor teams. We also find that this effect is due not only to giant multinational conglomerates, which may have lobbied for and anticipated the AFMP, but also and predominantly to other large and medium-sized patent applicants. In addition, it is mostly due to incumbent firms in the CBI-impacted regions (which patented both before and after the shock), and not only to new firms or firms moving to the area in order to 
profit from the increased supply of inventors. None of these regional changes occurs at the detriment of Swiss-resident inventors.

Beyond regional and quantitative effects, we investigate individual and qualitative ones. First, we find that incumbent Swiss-resident inventors in the CBI-impacted regions increased their patenting productivity by about $12 \%$ in the post-AFMP period. This result is driven solely by collaborations with CBIs, that is, by additional patents produced by mixed teams of CBIs and incumbent inventors. This result suggests that the AFMP shock was a source of foreign skills and knowledge that complemented those of natives. This may have allowed the latter to work on a larger number of inventive projects, thanks both to a finer division of labor (more R\&D teams, more recombination of team members) and the availability of new knowledge inputs.

We provide evidence supporting this interpretation in two steps. First, we find that the AFMP increased the number of distinct co-inventors working with the average incumbent inventor in a treated region. Second, we consider all citations by incumbent inventors' patents to prior art from the CBIs' countries of origin, and find that - in the post-AFMP period and in the treated regions - they increase by roughly $26 \%$. Both effects are exclusively due to patents listing at least one CBI among the inventors. This provides evidence of complementarity between CBIs and Swiss inventors, while at the same time excluding any learning dynamics, such as CBIs passing on their knowledge to their local colleagues. We find no sign of an increase in patent quality, whether measured by the number of forward citations or their grant status.

Our paper is closely related to Beerli et al. (2021), who first exploited the quasiexperimental features of the AFMP introduction for cross-border workers to study its impact on Switzerland. They find no adverse effects on Swiss workers' labor market outcomes and positive effects on the size and productivity of skill-intensive incumbent firms. Based on survey data, they also report a positive effect of the AFMP on Swiss firms' innovative performance. Our paper differs in the following ways. First, using the full set of patents filed by Swiss firms at the EPO, we quantify Beerli et al.'s firm-level innovation findings at the regional level. Second, we establish a direct relationship between the patenting surge and the immigration of foreign inventive labor, i.e., the cross- 
border inventors. Third, we make use of information on inventor teams and inventions' technological attributes to study incumbent Swiss-resident inventors' productivity and investigate the mechanism behind the patenting boost.

More generally, our paper is related to studies that examine migration policy shocks. Kerr and Lincoln (2010) exploit time variations in US H-1B visa caps, and find that they affect ethnic patenting in highly H-1B-dependent locations, with no adverse effects on natives but, at the same time, no evidence of spillovers. Our results are similar, although based on more direct evidence of geographical variation in foreign talent dependence. In addition, we find that, contrary to what some authors have suggested for H-1B visaholders (see discussion by Kerr, 2020), CBIs in Switzerland do not work exclusively for foreign multinationals. Doran et al. (2020) examine the 2006 and 2007 H-1B visa lotteries and find negligible effects on patenting for firms winning additional visas, at the cost of some crowding-out of natives. Our results contrast with theirs, as we find that at least one specific category of Swiss firms, the incumbent medium-sized ones, gained considerably from the inflow of foreign inventors. Nor we find any indication of displacement. While Doran et al. (2020; p. 3) also state that "many H-1Bs are not in scientific industries, and [...] perform jobs (e.g. technical support) that would not be expected to lead to innovations...", our findings suggest that the high-skilled immigrants attracted as the result of the AFMP integrated fully in the host innovation system.

As for studies based on historical shocks, our results are in accordance with those providing evidence of innovation slowdowns following immigration restrictions, such as the quotas for Eastern and Southern Europeans, which the United States introduced in the 1920s (Doran and Yoon, 2020; Moser and San, 2020). However, we do not find any evidence of interpersonal knowledge transfer, as for German Jewish chemists who arrived in the US in the 1930s (Moser et al., 2014) or Soviet scientists immigrating in the early 1990s (Ganguli, 2015). This may be due to the rather short time frame of our study, but also, and more importantly, to the different type of immigrants examined. In the cited studies, these were senior scholars or practitioners in their fields, while in ours they are predominantly first-time inventors. We also do not detect any adverse effect on the productivity of incumbent inventors, as found for American mathematicians after 
the influx of Soviet peers by Borjas and Doran (2012). This might be due to the higher elasticity of labor demand in industrial $R \& D$ relative to academic settings.

Finally, our research connects to studies investigating the presence of productivity peer effects among scientists and inventors, such as Azoulay et al. (2010), Waldinger (2012), Borjas and Doran (2015), and Jaravel et al. (2018). While we find positive peer effects for Swiss-resident inventors collaborating with CBIs, these do not last beyond the end of the collaboration. This is another indication of the absence of any knowledge transmission or learning mechanism.

We proceed as follows. In Section 2 we provide some essential information on Swiss migration laws, before and after the AFMP. Section 3 describes our data collection methodology and the resulting dataset. Section 4 outlines our quasi-experimental setting and describes the cross-border inventors' supply shock. Section 5 presents the econometric analysis and discusses its results. Section 6 concludes.

\section{The Swiss Immigration System and the AFMP}

The inflow of foreign workers in Switzerland is regulated by an employer-based system: only workers with a job offer are eligible to apply for an entry permit. Due to the peculiar geography of Switzerland, which is surrounded by the three largest EU countries, with densely populated areas on both sides of the border, permits for cross-border workers are as important as those for resident immigrants.

Resident immigrants are foreigners working and residing anywhere in Switzerland. Their entry permit can be either a "B", valid for five years, or a "L", valid for one year. After 10 years of uninterrupted stay in Switzerland, a resident immigrant may request a permit " $\mathrm{C}$ ", with unlimited validity. Cross-border workers are foreign commuters to cities like Basel, Geneva, and other Swiss cities close to the international border. They hold a work permit "G", which is regulated by a set of bilateral treaties with Austria, France, Germany, and Italy. ${ }^{2}$ The treaties designate the across-the-border areas whose residents are eligible to apply for the permit and, until 2007, also designated the Swiss "border

\footnotetext{
${ }^{2}$ The Principality of Liechtenstein also borders Switzerland, but we disregard it due to its extremely small size.
} 
regions" (BRs), in which they were allowed to seek employment. ${ }^{3}$

On June 21st, 1999, Switzerland and the EU signed the Agreement on the Free Movement of Persons (AFMP). Gradually implemented during the subsequent years, the AFMP lifted all restrictions to immigration from the EU to Switzerland (and vice versa). Its negotiation had started in 1994, as part of a series of treaties regulating EU-Swiss relationships after Switzerland's failed attempt to join the Union in 1992, due to the negative outcome of a referendum. The result of the negotiations remained in doubt until common ground was found in 1998 and introduction of the AFMP was certain only after the "yes" prevailed - rather narrowly - at a confirmatory referendum held in 2000. For these reasons, anticipatory behaviour by firms expecting to gain from the AFMP, especially small ones, is unlikely.

Before the AFMP implementation, work permits for both cross-border workers and resident immigrants were limited and subject to nationality-based quotas. Sponsoring employers had to go through a costly and time-consuming application process, which included demonstrating that they had searched and failed to find a native worker with the required skills. Cross-border workers were obliged to respect additional restrictions. First, they were required to have resided in the across-the-border designated areas for at least six months before applying for a G-permit. Second, they had to commute back to their countries of residence on a daily basis. Third, their work permits had to be renewed every year and were tied to a specific employer. Fourth, they could only work in a BR.

The AFMP progressively lifted these restrictions and cross-border commuters were the first immigrant category to be affected. Immediately after the signing of the treaty in 1999, the procedures for firms to hire G-permit holders were informally simplified. Then, after its official introduction on June 1st, 2002, the duration of G-permits was extended to five years and no longer tied to a specific employer. In addition, the compulsory

\footnotetext{
${ }^{3}$ The treaties were signed in 1928 with Italy, 1946 with France, 1970 with Germany, and 1973 with Austria. The treaties with Germany and Austria indicate precisely in which cities and/or districts commuters must reside. For France and Italy, the treaties simply mention residence at no more than $10 \mathrm{~km}$ from the border. As for the definition of BRs, those close to Germany and Austria are once again defined at the district level, while those adjacent to France and Italy simply follow the $10 \mathrm{~km}$ limit (State Secretariat for Migration, https://www.sem.admin.ch/sem/de/home/publiservice/ weisungen-kreisschreiben/auslaenderbereich.html). For BRs, we rely on the list used by Beerli et al. (2021).
} 
daily commute was transformed into a weekly one and the six-month across-the-border residence requirement was dispensed with. In 2004 all residual restrictions for G-permit holders in BRs were dropped, while the non-border regions (NBRs) still remained under a separate regime. In 2007, EU15 and EFTA nationals gained full freedom to work in Switzerland without distinction between BRs and NBRs, even for G-permit holders. Resident immigrants also experienced a gradual relaxation of immigration restrictions, starting in 2002, but with no differences between Swiss BRs and NBRs. ${ }^{4}$

In summary, the AFMP introduction laid down the conditions for a geographically heterogeneous labor supply shock: stronger in the BRs, to which cross-border workers were admitted, and weaker in the NBRs, which admitted only resident immigrants. Even more importantly, the shock was asymmetric also within the BRs, due to cross-border workers' preference for very short commutes, which resulted in them choosing to work almost exclusively in locations easily reachable from an international border crossing. We exploit this variation for a difference-in-differences study of the shock on Switzerland's innovation performance, focusing on cross-border workers who appear as inventors on patents. We come back to this in Section 4.

\section{Dataset construction and the Cross-Border Inventors}

Our main data source is the Worldwide Patent Statistical Database (Patstat), version 2017b. ${ }^{5}$ Despite their well-known limitations, patent statistics are an invaluable measure of inventive activities in R\&D-intensive economies such as Switzerland's (Griliches, 1990; Nagaoka et al., 2010). Patent documents, in particular, provide rich information on the inventions they protect as well as on the inventors' and applicants' identity and location.

We extract from Patstat all the patent applications filed at the European Patent Office (EPO), whether granted, under examination, or rejected (for ease of exposition we will often refer to all of them simply as "patents"). One reason for focusing on EPO patents is that they contain accurate information on the address of both inventors and applicants,

\footnotetext{
${ }^{4}$ Figure A1 in the Appendix illustrates the AFMP implementation timeline, by region and immigrant category. By EU15 we mean the European Union member countries in 2004, while EFTA stands for European Free Trade Area, which in 1999 included Norway, Iceland, and Liechtenstein.

${ }^{5}$ See: https://www.epo.org/searching-for-patents/business/patstat.html (last visit: November 2020).
} 
which we need for geolocalization purposes (Breschi and Lissoni, 2004). At the same time, filing through EPO represents a convenient way for Swiss companies to obtain patent protection at the continental level. ${ }^{6}$

We consider all patents with priority dates comprised between 1990 and 2012. This time frame ensures a decade of observations both before and after the AFMP signing. Second, we retain all patents including at least one inventor with a Swiss address $(66,881$ patents), regardless of the applicant's address. To these, we add those by applicants with a Swiss address and no Swiss addresses for the inventors, but at least one inventor with an address in a G-permit designated area in Austria, France, Germany, or Italy (2,487 patents). Third, we assign each patent to the location where the inventive activity presumably took place and filter out those originating from outside Switzerland. Contextually, we identify the inventors with a likely status of cross-border workers (Cross-Border Inventors, or CBIs). We distinguish them both from the inventors working and residing in Switzerland (or "Swiss-resident inventors", whether Swiss nationals or not) and other inventors collaborating with a Swiss R\&D lab from abroad, that is without any connection to the Swiss labor market. Our final sample thus includes all patents by Swiss-resident inventors and/or CBIs, assigned to the Swiss location where the inventive activity presumably took place. In the following we provide some important, although succinct, methodological information on this heavy data preparation effort. All details can be found in Appendix B.

\subsection{Inventor and applicant disambiguation}

Patstat data come with unique identifiers for both inventors and patent applicants, but they are quite inaccurate (they contain too many false negatives, implying low recall rates). Further disambiguation is necessary to track both individuals and firms over time and across locations.

\footnotetext{
${ }^{6}$ Swiss companies seeking patent protection in one or more European countries can file their patents directly at the EPO or first at the Swiss Federal Institute of Intellectual Property (IGE) (or another national office) and subsequently extend them. Most extensions pass again through the EPO. All these cases are captured by our data. We miss only the patents which Swiss companies do not extend to Europe or otherwise bypass the EPO. We believe these cases not to be many, and that in any event their omission cannot bias our results. On the relationship between patent offices, such as the IGE and the EPO, see Eaton et al. (2004) and Guellec and Van Pottelsberghe (2007).
} 
We disambiguated inventors using the algorithm proposed by Pezzoni et al. (2014) and already used by Breschi et al. (2017), Kogler et al. (2017), Akcigit et al. (2018) and Ferrucci and Lissoni (2019). As for the disambiguation of applicants, we employed the unique identifiers produced by Du Plessis et al. (2009). These are widely used by Patstat users, but still exhibit low recall. In particular, we know that different divisions of the same company are often treated as separate entities. For this reason, we manually checked all applicants with at least 20 patents, which include the majority of suspect cases. Altogether, they amount to 412 initial entities and account for roughly $60 \%$ of the total patents in our data set (see Table B2 in the Appendix). For each of them we consulted the companies' websites as well as several online resources containing business history information, verifying their company or group affiliation. Table B3 in the Appendix provides some examples of the type of patent applicants we inspected and shows how we fixed their identifiers. ${ }^{7}$

\subsection{RED locations}

Patent data do not explicitly report the address of the R\&D laboratories (or other facilities) that produced the inventions they protect. They only include the address of the patent applicant and the inventors. Hence, we must deduce the presumed location of the invention sources from either one or both addresses (to which we often refer as "R\&D location"). This is a crucial task, since geographic variation plays a key role in our analytical framework.

With regard to the applicant's address, the larger the company, the more likely it is that it coincides with the company's headquarters or its intellectual property division. These may be located in different cities than those hosting the company's R\&D laboratories and in the case of multinationals not even the countries may coincide. As for the inventors' address, the most common practice followed by patent attorneys is to report their home one, which we expect to be relatively close to their workplace. In these cases, the inventor

\footnotetext{
${ }^{7}$ On the importance and technicalities of inventor disambiguation see Appendix B and Raffo and Lhuillery (2009); Li et al. (2014). As for the low recall rate of applicants in Patstat, this concerns especially large industrial groups and multi-divisional companies. Examples in Switzerland include local multinationals, such as ABB, Nestlé, Novartis, and Roche, as well as foreign ones, such as Alstom, BASF, DuPont, Google, IBM, and Merck.
} 
and applicant addresses differ. When they coincide, it is because the attorney preferred to use the applicant address for the inventors too. ${ }^{8}$

Based on these considerations, we infer each applicant's R\&D location(s) from the distribution of its inventor addresses, with the applicant addresses playing an auxiliary role. We work at the level of Spatial Mobility regions (MS regions, from the French "Mobilité Spatiale"). They consist of agglomerations of municipalities defined by the Swiss Federal Statistical Office as travel-to-work areas for micro-regional analyses (Schuler et al., 2005). MS regions are large enough to track inventors' commutes to work and are also ideal units of analysis for our econometric analysis, due to their heterogeneity in terms of G-permit holders' presence (see Section 4).

In synthesis, we proceed as follows. We use the Google Maps Geolocation API to geocode each Swiss address and assign it to an MS region. For each applicant, we calculate the frequency distribution across MS regions of all its inventor-patent instances, obtaining one or more candidate R\&D locations. We first consider applicants with a single candidate, which we retain as the one and only relevant R\&D location. Together, these account for $18 \%$ of all patents in the data set. We then consider applicants with multiple candidates and with at least 20 patents (mostly large, multi-plant corporations), for which we extensively search the companies' websites and other online resources. In this way, we manually identify as many of their R\&D laboratories as possible (some of which are presently dismissed, but were active during our observation period). We then retain only the candidate R\&D locations that match them. These account for about $55 \%$ of all patents in the data set. For the remaining applicants with multiple candidates, but fewer than 20 patents ( $27 \%$ of total patents), we retain only one R\&D location, corresponding to the MS region with the highest number of inventor-patent instances. In this case, we perform no systematic manual checking, except for dubious cases (such as when the number of patents in two or more candidate locations are close). Last, we look for any false R\&D location to filter out. These correspond to applicants whose patents never

\footnotetext{
${ }^{8}$ For example, the municipality of Rüschlikon (Zurich) hosts one of IBM's 12 global research labs. Out of all IBM's 603 patents in our dataset, only one mentions it in the applicant's address. All others indicate the IBM's headquarters in Armonk, NY. In contrast, $80 \%$ of the inventors' addresses indicate municipalities around Zurich.
} 
report a Swiss address or have any known Swiss-based facility, and yet hold a few patents with one or more Swiss-based inventors. They are typically due to collaboration between a Swiss academic and a foreign research institution; or a Swiss-based inventor consulting internationally. ${ }^{9}$

These procedures result in a final sample of 65,333 patents, 12,211 applicants and 35,956 inventors. Most patents correspond to only one R\&D location (62,377 patents, approximately $96 \%$ of the total). The others may correspond to more than one location because their applicant has multiple $R \& D$ facilities and the inventors appearing on the patent are located in different MS regions. In these cases, we assign each inventor to one or another R\&D location, by simply picking the closest to the inventor's address.

\subsection{Cross-border inventors}

We define as Cross-Border Inventors (CBIs) all inventors who, according to patent information, reside in a G-permit designated area in Austria, France, Germany, or Italy, and work in a nearby Swiss R\&D location (MS region). ${ }^{10}$ We define instead as "resident inventors" all those with a Swiss address. We cannot distinguish between Swiss natives and foreign nationals (holders of B, C or L permits). In this way, we count 4,507 CBIs, associated to 7,563 applications and 935 applicants; and 54,316 Swiss-residents, associated to 62,654 applications and 12,193 applicants. As for the remaining inventors, those with a foreign address but unlikely to be CBIs, we consider them as external collaborators (international inventors), not employed in Switzerland. Unlike CBIs and resident inventors, they are not of primary interest for our analysis, and we take them into account only when necessary.

Figure 1 shows the distribution of CBIs across Switzerland's neighboring countries. Colored polygons indicate municipalities where CBIs reside, varying in color intensity

\footnotetext{
${ }^{9}$ We search and eliminate the former by looking at keywords such as "university" or "foundation" in the applicants' names (134 applicants, with 379 patents). As for the latter, we search online for corporate information and eliminate all those for which no Swiss-based R\&D facility is ever mentioned (42 applicants, with 3,656 patents).

${ }^{10}$ For each G-permit designated area we consider as "near" all the MS regions in cantons with the same official languages, which we know to be spoken across the border. The only exceptions are the MS regions in the cantons of Bern, Fribourg, Grisons, and Valais, which have two or more official languages, and the cantons of Basel-Stadt and Basel-Landschaft, which share borders with both France and Germany. In those cases, we opted for a conservative definition strictly based on the G-permit designated areas' geographic proximity to avoid false positives. See Table B5 for the complete pairwise list of G-permit designated areas and "nearby" MS regions.
} 
according to the number of CBIs they host. All municipalities are located at a short distance from the border. Those with the highest proportion of CBIs are, in general, immediately adjacent to it. Germany hosts the largest share, followed by France and, some way behind, Austria and Italy.

For the 2002-12 period we validate our patent-based CBI definition with one based on administrative records, namely those of the Swiss Central Migration Information System (ZEMIS). These provide data on all foreigners working and/or residing in Switzerland, including their permit types (with issue and renewal dates), as well as their addresses, nationalities, and dates of birth. Using a supervised machine learning strategy first proposed by Feigenbaum (2016), we name-match all the inventor and ZEMIS records and identify as CBIs all matches holding a G-permit. We also classify as foreign resident inventors all the matches with permits other than "G" and as Swiss nationals all the non-matches. Figure $\mathrm{C} 2$ in the Appendix compares the number of CBIs identified with the two methods in each year (patent-based, solid black line; ZEMIS-based, dashed gray line). The two figures are strikingly close, which speaks in favour of the accuracy of the patent-based definition. Appendix Figure C3 compares the spatial distribution of CBIs identified with the two methods, again finding them to be very similar. ${ }^{11}$

Using ZEMIS biographical information we can characterize CBIs versus other immigrant inventors, albeit only for the post-AFMP period. Panels (a) and (b) in Appendix Figure C4 confirm that most CBIs are either German or French citizens, and that they are disproportionately active in chemical and pharmaceutical technologies. Panels (c) and (d) indicate that CBIs generally enter the Swiss innovation system early on in their careers and have a high probability of integrating into it permanently. Only $12 \%$ of them obtained a permit after having filed a patent abroad, while the modal entry age is 30 years, two years below the average age of first-time inventors indicated by the literature (Jones, 2009; Breschi et al., 2020). After their first filing for a Swiss-based R\&D lab, about half of CBIs patent at least once again in Switzerland. Compared to CBIs, resident foreign inventors are both less experienced when they enter Switzerland and less likely to patent

\footnotetext{
${ }^{11}$ Appendix E provides all details on the matching algorithm. While this would have been the ideal way to define CBI status for the entire database, we could not adopt it, as ZEMIS records start after the AFMP was signed.
} 
more than once afterwards. ${ }^{12}$

\section{Quasi-Experimental Setting}

As discussed in Section 2, G-permit holders (including CBIs) were the first immigrant category to experience a progressive relaxation of immigration restrictions after the AFMP was signed. In addition, until 2007, G-permits were granted only to employees of firms located in BRs. The most intuitive empirical approach would then be to compare BRs to NBRs, before and after the AFMP. This strategy would exploit the exogenous exposure of BRs to CBIs' influx, entirely determined by a legal change, rather than any economic force simultaneously driving the local performance and the influx of CBIs. However, a close look at the data reveals that the majority of CBIs work predominantly in a subset of the BRs, namely those located at very short commuting times from their residences in neighbouring countries. Other locations inside the BRs, despite admitting G-permit holders, are not as attractive or not attractive at all, as longer commutes offset the wage benefit of working in Switzerland.

Figure 2 shows the relationship between driving times from the closest international border crossing and the share of CBIs relative to total inventors, for both BRs and NBRs, before and after the AFMP ratification. CBI shares are strongly positively correlated with border proximity. The BRs situated at up to 10 minutes from the border crossing exhibit by far the largest shares, both pre- and post-AFMP. They are followed by other BRs regions, those at up to 20 minutes from the border crossing, which also visibly increase their CBI share in the post-AFMP period. More distant BRs and all the NBRs both exhibit very small CBI shares and do not increase them much. ${ }^{13}$

These observations suggest that distance from the border should be considered as the key source of exogenous geographic variation in CBI presence, more important than the administrative distinction between BRs and NBRs. Accordingly, we set up the following

\footnotetext{
${ }^{12}$ In the Appendix we confirm this difference by regressing the immigrant inventors' probability of patenting more than once as a function of their permit type and other control variables (Table D1).

${ }^{13}$ Each MS region's driving time is defined as the average driving time between its municipalities and their closest international border crossing. Table B6 in the Appendix reports an alternative measure, based on centroids, and shows that differences are negligible. All driving times are calculated with the Google Maps Directions API. We obtained the border crossings' locations from Hennerberger and Ziegler (2011).
} 
difference-in-differences exercise. We restrict our analysis only to the BRs and elect as treated group all those at no more than a 20-minute drive from the border (henceforth: 020-BRs). All the other BRs, at more than 20-minutes from the border (20plus-BRs), constitute the control group (see map in Figure 3). As for the NBRs, we include them in the control group only in robustness checks, whose results we report in the Appendix (with no change in our results).

One key advantage of this identification strategy is that the 20plus-BRs constitute a better control for 020-BRs than the NBRs, especially in terms of innovation activities. As an example, consider the four largest Swiss cities, Zurich, Geneva, Basel, and Lausanne. All of them fall into a BR, with Basel and Geneva right on an international border and Zurich and Lausanne at 28 and 34-minute drives from the closest one respectively. These four cities are Switzerland's leading economics centers, concentrate most of its patenting activity, and host its top research universities. Table 1 provides general evidence from our dataset. It shows how, in the pre-AFMP period, the 20plus-BRs were very close to the 020-BRs in terms of average number of patent filings and inventors, while the NBRs reported much lower values.

In addition, the number of CBIs active in the 20plus-BRs and in 020-BRs, while different, followed a similar trend before the AFMP and subsequently started diverging. The three lines in Figure 4 report yearly figures for all groups of regions, including, for the sake of completeness, the NBRs. We observe that, before 1999 the number of CBIs in our treated and control groups differ, but were increasing at the same moderate pace. Between 1999 and 2002, the growth rate in the 020-BRs then increases sharply, while that in the 20plus-BRs does not change. This differing trend persists until 2005. Then, the 020-BRs revert to their early trend, with the 20plus-BRs never filling the (much increased) gap. The number of CBIs in the NBRs remains negligible throughout the observation interval. All these counts refer to our patent-based definition of CBIs. For validation, Figure 4 also reports the same counts for the ZEMIS-based definition, for all the available years (that is, after 2002). We notice that, once again, the patent-based and ZEMIS-based counts are very similar, in all groups of regions. 


\section{Innovation Effects of the AFMP}

\subsection{Regional innovation}

For our regional analysis, we organize the dataset in a panel of MS regions, which we observe yearly from 1990 to 2012. We then compare treated and control regions over time, based on an event-study approach. Formally, we estimate the following equation:

$$
E\left[y_{m, t} \mid X_{m, t}\right]=\exp \left[\alpha+\sum_{t=1990}^{2012} \beta_{t} * I(\text { year }=t) \times \text { Treated }_{m}+\gamma_{m}+\phi_{t}\right]
$$

where $y_{m, t}$ is an innovation outcome for MS region $m$ in year $t ; I($ year $=t)$ is a dummy variable taking value 1 in year $t$ and 0 otherwise (with 1999 as the reference year); Treated $_{m}$ is a dummy variable equal to 1 for the 020-BRs and 0 for the 20plus-BRs; $\gamma_{m}$ are regional fixed effects, capturing time-invariant unobserved characteristics of a given MS region; and $\phi_{t}$ are year fixed effects, which account for time-variant shocks common to all MS regions. Our parameters of interest are the $\beta_{t}$, which measure the yearly difference in the mean of $y$ between treated and control regions. If the AFMP introduction and subsequent CBI influx had any effect on the regional outcome considered, we expect it to be detectable starting from 2000, i.e., one year after the start of the AFMP implementation period. In other words, we expect estimates for $\beta_{t}$ to be positive and significant for and only for $t \geq 2000 .^{14}$

When useful, we also employ an equivalent fixed-effects difference-in-differences regression, in which we compare two periods, pre- and post-AFMP :

$$
E\left[y_{m, t} \mid X_{m, t}\right]=\exp \left[\alpha+\beta\left(A F M P_{t} \times \text { Treated }_{m}\right)+\gamma_{m}+\phi_{t}\right]
$$

In this case, $A F M P_{t}$ is a dummy variable taking value 1 from 2000 onwards. The other variables are identical to those in Equation (1). Here, the parameter of interest $\beta$

\footnotetext{
${ }^{14}$ Notice that we assume a one-year delay between the introduction of the AFMP and the first signs of its effect. Indeed, this is what we observe in Figure 4 for the number of CBIs. It also corresponds to what the literature indicates as the modal "invention gestation lag", dating from the start of an R\&D project (including the recruitment of new staff) up to its first patent output (Hall et al., 1986; de Rassenfosse and Jaffe, 2018).
} 
identifies the average effect of the AFMP introduction on the treated regions over the entire post-AFMP period.

We follow other econometric studies of innovation and science (e.g., Henderson and Cockburn, 1994, Blundell et al., 1995, Azoulay et al., 2019, Catalini et al., 2020) and produce pseudo-maximum-likelihood (PML) estimations, based on Hausman et al.'s (1984) Poisson fixed-effects model. Regarding inference, we calculate PML robust standard errors clustered at the MS-region level, accounting for potential biases due to serial correlation (Bertrand et al., 2004).

Panel (a) in Figure 5 reports our estimation results for Equation 1. The black circles and vertical dashed bars correspond, respectively, to the estimated $\hat{\beta}_{t}$ and their $95 \%$ confidence intervals. For $t<2000$ all $\hat{\beta}_{t}$ are close to zero and display no trend. This implies that, before the AFMP, the patenting output of treated and control MS regions did not diverge and evolved in a similar manner. At $t \geq 2000$, the $\hat{\beta}_{t}$ first increase then also become statistically significant (starting in 2002). This trend reverts in 2007, when all regions finally implement the AFMP. ${ }^{15}$

We interpret these results as evidence that, after the AMFP was signed, the R\&D locations in the 020-BRs progressively increased their patenting output relative to the control ones, thanks to the inflow of CBIs. This interpretation, however, faces two possible objections. First, the rise in patenting in the 020-BRs could be due to new firms setting up their R\&D labs in the 020-BRs, or to firms from the 20plus-BRs relocating there, to profit from the possibility of recruiting the CBIs. Such circumstances would raise an identification issue in our exercise, namely the impossibility of retaining the 20plus-BRs as controls for the 020-BRs, due to the changes in the structural conditions caused by the AFMP itself. Second, our results could be driven by a very small number of large firms, particularly chemical and pharmaceutical giants (such as Novartis, Roche, BASF or DuPont). These companies hold a disproportionate share of patents in our sample, run world-class R\&D labs in the 020-BRs, and might have lobbied influentially in favour of

\footnotetext{
${ }^{15}$ We opted for a graphical report of our estimation results for Equation 1 for readability reasons. For the full list of estimated coefficients and standard errors, plus diagnostics, see Table D2 in the Appendix. See also the same table for the next event-study plots in this section.
} 
the AFMP, while preparing to recruit large numbers of CBIs after its signing. ${ }^{16}$

We tackle these two objections as follows. First, we run our estimations again for a reduced sample of firms, namely those with patents both before and after the AFMP introduction, to which we refer as "incumbent" applicants. While a small number of such applicants have or used to have R\&D labs in both the 020-BRs and the 20plus-BRs, only three of them opened up one after 2000 (and produced little more than a hundred patents in such new labs). Second, we identify the "top" applicants in our sample as those in the 99.9th percentile of the inventive workforce distribution, and re-run our regressions after dropping them. ${ }^{17}$

Panels (b) and (c) in Figure 5 report our event-study results for the two reduced samples. The plot in panel (b) is strikingly similar to panel (a), and suggests that our baseline results owe much more to the incumbent firms in the 020-BRs benefiting from the influx of CBIs, than to other firms changing location to profit from it. As for panel (c), it shows that our results are robust to the exclusion of "top" applicants.

We revisit and synthesize the results obtained so far by estimating Equation 2 for both our full sample and the same selected sub-samples that we just described. Table 2 reports our results. It also reports the results for a set of regressions with a slightly altered period breakdown, which limits the post-AFMP period to 2007. In the baseline regressions for the full sample (column 1), the estimated parameter for $A F M P_{t} \times$ Treated $_{m}$ $(\hat{\beta})$ is positive, but not significant. This is due to the non-persistence of the effect beyond 2007. In fact, when we drop all years after 2007 (column 2), the estimated coefficient becomes significant, albeit rather weakly ( $p$-value $=0.055)$. When considering only the incumbent applicants (columns 3 and 4), the size and significance of the estimated $\hat{\beta}$ increase remarkably. The same occurs when excluding the top applicants (columns 5 and 6). When we combine the two restrictions (columns 7 and 8) we get the strongest results. Overall, these findings suggest that it is precisely the incumbent firms, and above

\footnotetext{
${ }^{16}$ In the context of US H-1B visa legislation, Kerr et al. (2014) find lobbying to be associated with firm size.

${ }^{17}$ Inventive workforce is defined as the total number of inventors associated to a given applicant. We count 23 "top" applicants, who have 51 R\&D locations and one third of the total patents in our sample (18,852 patents). All of them are large corporations, either Swiss or foreign ones with R\&D sites in Switzerland. Figure C6 in the Appendix shows that firms with a large inventive workforce are also large in terms of sales and employees.
} 
all those with less political leverage, which explain our results.

These estimates imply that the AFMP impact has been not only statistically significant, but also quantitatively remarkable. For example, the coefficient in column (2) indicates a $24 \%$ increase in patent applications for 020-BRs during the first eight years of the AFMP period. ${ }^{18}$ If one considers that the average MS region produced around 196 patents in the eight years preceding the AFMP, this implies an average treatment effect of 47 additional patents for an MS region.

Our results so far indicate that the CBI's supply shock induced by the AFMP caused an increase in treated regions' patenting activity. We now turn our attention to the mechanisms underlying the patenting surge. We first observe that, both before and after the AFMP, no less than $80 \%$ of the patents signed by one or more CBIs was co-signed by a Swiss-resident inventor, most often a Swiss national (see Figure C7 in the Appendix). We then investigate how much of the CBIs' impact on their host regions' patent output depends on such interactions. To do so, we distinguish between patents associated with teams including at least one CBI (CBI-in-Team) and patents associated with teams composed only of resident inventors (Resident-only team). We then run separate eventstudy regressions for the two types of patents, whose results are reported in Figure 5, panel (d). Black circles show the estimated parameters for the CBI-in-team patents, while gray squares indicate resident-only teams. After the AFMP introduction, it is mainly the former that become positive and significant, indicating a sharp and persisting increase in patents on inventions by or in collaboration with CBIs. ${ }^{19}$

Finally, we check for any evidence of Swiss resident inventors being displaced by CBIs, as a consequence of the AFMP. To do so, we once again estimate Equation 1, but with $y_{m, t}$ now equal to the number of Swiss resident inventors active in each region and year. Figure 6 reports our results. In panel (a), for the full sample, the estimated $\hat{\beta}_{t}$ are positive and statistically significant in the period immediately after the AFMP signing.

\footnotetext{
${ }^{18}$ The calculations rest on the interpretation of $\exp (\hat{\beta})-1$ as elasticities. For column (2) in Table 2: $[\exp (0.213)-1] \cdot 100 \approx 24 \%$.

${ }^{19}$ Notice that we obtain these results by operating the CBI-in-team vs. resident-only distinction only for patents in the 020-BRs. This is to maintain the same 20plus-BRs control group as in the baseline regression in Figure 5 panel (a). Table D6 in the Appendix provides equivalent evidence based on separate estimations of Equation 2 for the two types of patents groups.
} 
We can see that the number of Swiss-resident inventors decreases only after 2007, along with the general patenting activity. In panel (b) we report, overlapped, the results for three subsamples: one considering only incumbent applicants, one excluding the top applicants, and a combination of both. In all three cases, the estimated $\hat{\beta}_{t}$ are generally positive in the same period, although almost never statistically significant. We consider this evidence as indicative of the absence of any major displacement effect. If anything, this might suggest a possible crowding-in effect, mostly driven by top applicants. ${ }^{20}$

\subsection{Incumbent inventors' productivity}

We further investigate the immigration-innovation transmission mechanisms by focusing on individual inventors. In particular, we consider the "incumbent" Swiss-resident inventors, namely the Swiss nationals and foreign residents patenting at least once in the pre-AFMP period. We follow them in the post-AFMP years, and proceed in two steps. First, we test whether their probability of continuing to patent after the AFMP depends on their location in either a treated or untreated region. Second, for those who keep patenting, we test whether their post-AFMP productivity is affected by their location. Before proceeding, we further restrict our sampling to the inventors who never move from a $020-B R$ to a 20 plus-BR (or vice versa). ${ }^{21}$

Our first step is based on a cross section of 14,616 inventors (5,781 active in 020-BRs and 8,835 in 20 plus-BRs) and 26,892 patents, i.e., about $51 \%$ of all those filed in the observed regions between 1990-2012. ${ }^{22}$ We estimate the following probit model:

$$
\operatorname{Pr}\left[y_{i}=1 \mid X_{i}\right]=\Phi\left[\alpha+\text { Breated }_{i}+\delta X_{i}+\gamma M S \text {-region }_{i}+\psi \text { Tech-class }_{i}+\varepsilon_{i}\right]
$$

where $y_{i}$ is a dummy variable taking value 1 if inventor $i$ patents at least once in the post-AFMP period. Treated ${ }_{i}$ is the main regressor, and consists of a dummy equal to 1 if inventor $i$ 's R\&D location in the pre-AFMP period is in a 020-BR (to abbreviate, we will

\footnotetext{
${ }^{20}$ For the detailed estimation results, see Table D9 in the Appendix.

${ }^{21}$ Incumbent inventors with more than one patent and at least one in both a 020-BR and a 20plus-BR, which we exclude, number 905 . Notice that the restriction does not apply to inventors with labs in different MS regions, but always within either the 020-BR or 20plus-BR group.

${ }^{22}$ In the Appendix we extend the sample to 3,792 incumbent inventors with patents only in the NBRs, and our results do not change (see Table D11).
} 
often refer to "treated" versus "non-treated" inventors). $X_{i}$ is a vector of inventor-level controls, including the number of years during which inventor $i$ was active in the preAFMP period, the total number of co-inventors inventor $i$ has worked with during the pre-AFMP period, and the inventive workforce size of inventor $i$ 's associated applicant in the pre-AFMP period. We include dummies for the MS regions and for the technological classes where the inventor has been active in the pre-AFMP period. ${ }^{23}$

Table 3 reports our results. We find that the treated inventors' probability of patenting in the post-AFMP period is not lower, and is possibly higher, than that for non-treated ones. The result holds whether we consider all inventors (column 1) or exclude those associated with the Top applicants (column 2). Due to the different specializations of firms in the treated and non-treated regions and the disproportionate presence of CBIs in pharmaceutical and chemical technology fields, we also run regressions focusing only on those technologies, respectively in columns 3 and 4, finding, respectively, positive or null effects of the AFMP.

We build upon this result and proceed to the second step. We focus on the incumbent inventors who were active both before and after the AFMP introduction, for a total of 2,076 individuals (to whom we refer as "persistent" inventors), 777 of whom are located in the 020-BRs (1,299 in the 20plus-BRs). By construction, these are highly productive inventors: considering both the pre- and post-AFMP periods, those in the 020-BRs produce on average 9.68 patents (7.41 for those in the 20plus-BRs), that is many more than the 2.48 average patents for all incumbent inventors and the 1.96 for all resident ones. In all likelihood, these are experienced members of the R\&D laboratories to which they belong, possibly with leading roles (Appendix Table C1 reports detailed descriptive statistics).

Panel (a) in Figure 7 reports the average number of patents per year for the persistent inventors in both the 020-BRs and 20plus-BRs, for the entire observation period. We notice that the trends for the two groups substantially overlap in the pre-AFMP period, and then diverge, only to converge again after 2007. This suggests an increase of productivity for persistent inventors exposed to the influx of CBIs. We test this intuition by means of a

\footnotetext{
${ }^{23}$ We use 35 technology classes introduced by Schmoch (2008) and based on International Patent Classification (IPC) technology codes.
} 
difference-in-differences regression. Specifically, we estimate:

$$
E\left[y_{i, j, m, t} \mid X_{i, j, m, t}\right]=\exp \left[\alpha+\beta\left(A F M P_{t} \times \text { Treated }_{m}\right)+\theta_{i}+\xi_{j}+\gamma_{m}+\phi_{t}\right]
$$

where $y_{i, j, m, t}$ is the patenting output of inventor $i$, associated with applicant $j$ and located in MS-region $m$, in year $t$. $A F M P_{t}$ is a dummy variable taking value 1 after 1999 and Treated $_{m}$ is a dummy variable taking value 1 if inventor $i$ is located in a 020-BR, while $\phi_{t}$ are year fixed effects. Inventor fixed effects $\theta_{i}$ control for any unobserved time-invariant characteristics of $i$; the same for applicant fixed effects $\left(\xi_{j}\right)$ and MS-region ones $\left(\gamma_{m}\right)$.

Table 4 reports our results. In column (1) the estimated coefficient for the AFMP $\times$ Treated interaction term is positive and statistically significant, albeit only at $90 \%$. Its value is equivalent to a patenting productivity increase of around $12 \%$ for persistent inventors located in the 020-BRs, in the post-AFMP period. In column (2) we run the same regression, excluding from the dependent variable all patents with a CBI as co-inventor. We do not detect any effect of the AFMP introduction on individual productivity. Taken together, these estimates suggest that the positive productivity effect experienced by inventors in the treated regions is directly linked (and entirely due) to their interaction with one or more CBIs. This excludes any productivity spillover to other inventors, even those in the same firm or region. ${ }^{24}$

Our explanation for these findings is that CBIs have distinctive competencies, complementary to domestic ones, which allow the persistent inventors in the 020-BRs to join (or assemble) more inventor teams and pursue a greater number of R\&D projects. We support this interpretation in two ways. First, we show that after the AFMP introduction, persistent inventors in the 020-BRs collaborate with a larger number of distinct co-inventors than those in the untreated regions, most of them being CBIs. Second, we show that the patents with incoming CBIs as co-inventors cite different prior art than those without them. In particular, they cite many more patents filed in the CBIs' countries of origin.

\footnotetext{
${ }^{24}$ In Table D12 we report the results of a falsification test, where we replicate each regression in Table 4, limiting the sample to the pre-AFMP period and testing a "placebo AFMP" in 1994. We do not find any evidence of pre-trends.
} 
Panels (b) and (c) in Figure 7 provide descriptive evidence in this regard. Panel (b) shows that, in each year of the pre-AFMP period, the persistent inventors in the 020BRs and 20plus-BRs worked on average with the same number of distinct co-inventors. The trends diverge in the post-AFMP period, when persistent inventors in the 020-BRs increase the number of co-inventors relative to their homologues in the 20plus-BRs. Panel (c) shows that in the pre-AFMP period, the average number of citations to prior art from Austria, France, Germany and Italy (the CBIs' countries of origin) was roughly the same for the patents by persistent inventors in 020-BRs and 20plus-BRs. Again, in the post-AFMP period divergence sets in, with patent applications by inventors in the 020-BRs tripling their average number of citations to such prior art, and only a moderate increase in the 20plus-BRs.

We strengthen this evidence by means of regression analysis. Columns (3) to (6) in Table 4 reports the estimation results for two specifications of Equation 4 with, as dependent variables, respectively the per-year number of distinct co-inventors and the per-year number of citations to CBI-countries' prior art (divided by the number of patents filed by inventor $i$ in the same year). In both baseline specifications (columns 3 and 5 ) the coefficient $\hat{\beta}$ for $A F M P \times$ Treated is positive and significant. This implies a $14 \%$ increase in the number of distinct co-inventors and a $26 \%$ increase in the number of citations to CBI-countries' prior art, for persistent inventors in the 020-BRs during the post-AFMP period. When we exclude any patent resulting from a direct collaboration with CBIs (column 4 and 6) the estimated coefficients shrink and lose statistical significance. We interpret these results as supporting the idea that CBIs have distinctive competences that are demonstrated in their inventions, but not in their co-inventors' patents after their collaboration stint.

We complete our analysis by examining the quality of persistent inventors' patents, pre- and post-AFMP. In the economic and legal literature on patents, quality refers either to the technological importance of the patented invention (Lanjouw and Schankerman, 2004) or to the soundness of the application and granting procedure (Hall et al., 2004). We focus on the first of these two meanings, for which a widely accepted measure is the number of citations a patent receives by subsequent ones (forward citations; Jaffe and 
de Rassenfosse, 2017). In particular, we consider the citations received up to five years after the patent's priority date. As an alternative measure of an invention's importance, we employ information on whether, following application, a patent is ultimately granted.

Appendix Figure C8 reports descriptive evidence. We detect no divergence in trends in the post-AFMP period for either indicator, which suggests that patent quality neither decreased nor increased as a consequence of the migration shock (both the drop in citations after 2008 and the overall declining trend for grant rates are statistical artifacts due to right-truncation in the data). This evidence is confirmed, in the Appendix, by Table D14, which reports the estimated results for various specifications of Equation 4, with the two quality indicators as dependent variables.

\section{Conclusions}

We have studied the impact of immigration on domestic innovation, focusing on the Agreement on the Free Movement of Persons (AFMP), which progressively opened Switzerland's borders to EU citizens after its signing in 1999. Exploiting quasi-experimental regional variations in the influx of Cross-Border Inventors (CBIs) following the AFMP, we document how such CBIs boosted patenting in the regions where they started working.

Our findings contribute to the general literature on migration and innovation by investigating the mechanisms linking the two. In particular, we highlight the importance of direct collaborations between immigrant and Swiss-resident (mostly native) inventors, through which the latter both increased their productivity and gained access to the former's knowledge assets (without necessarily acquiring them). Coupled with the absence of any displacement effect, this result suggests that immigrant inventors in the Swiss innovation system are complementary to natives. This echoes more general findings by Peri and Sparber (2009) and Peri (2012) on the imperfect substitutability of natives and immigrants at the production level. It also suggests that high-skilled immigration may play a key role in easing the "burden of knowledge", whose weight on R\&D activities worldwide has been growing for decades (Jones, 2009). As the increasingly complex processes of scientific discovery and technological invention require more and more specialized knowledge inputs, the division of labor within R\&D teams also needs 
to increase. The free movement of inventors has helped Switzerland in this sense, by augmenting at the same time the supply of suitable team members and the variety of knowledge assets they provide. Further research could investigate whether this is also the case for STEM immigration into the United States, via student or H-1B visa channels.

Our findings are policy-relevant. First, the Free Movement principle is both a pillar of the European integration process and the object of hot political controversies. In Switzerland, the "stop mass immigration" referendum initiative of 2014 called successfully for the re-introduction of immigration quotas (Salvatore, 2016; Dibiasi et al., 2018). In view of the resistance put up by the Federal Government to implement them, and renegotiate its treaties with the EU, a new "limitation initiative" brought Swiss voters to the urns in September 2020, and narrowly lost. Our results suggest that a win could have been very costly in terms of innovation. Second, we put at center stage the cross-border commuting phenomenon, which is an important feature of intra-European migration flows, due to the large number of travelling-to-work areas spanning national borders. Our results for Switzerland, suggest that cross-border inventors may play a role in other small and medium-sized R\&D-intensive economies, such as Belgium, Denmark, the Netherlands, or Sweden, as well as in some border regions of larger countries, such as Alsace in France and Baden-Württemberg in Germany.

Further research can build upon ours either by concentrating only on Switzerland or by targeting other countries in Europe. Concerning Switzerland, it would be ideal to complement our ZEMIS data for immigrant inventors with similar data for Swiss citizens. In that way, one could compare not only natives' and immigrants' productivity in terms of patents, but also salary, mobility, and job profiles. We could also observe both natives and immigrants not only at the time of patenting, but throughout their careers (in Switzerland). Concerning the rest of Europe, one could investigate which countries have benefited from joining the Free Movement Area as much as Switzerland; and whether the United Kingdom, which is leaving it, is at risk of losing out. 


\section{References}

Akcigit, U., S. Caicedo, E. Miguelez, S. Stantcheva, and V. Sterzi (2018): “Dancing with the stars: Innovation through interactions," NBER WP 24466, National Bureau of Economic Research.

Alesina, A., A. Miano, and S. Stantcheva (2018): "Immigration and redistribution," NBER WP 24733, National Bureau of Economic Research.

Arkolakis, C., S. K. Lee, And M. Peters (2020): “European Immigrants and the United States? Rise to the Technological Frontier," Mimeo.

Azoulay, P., C. Fons-Rosen, and J. S. Graff Zivin (2019): “Does science advance one funeral at a time?" American Economic Review, 109, 2889-2920.

Azoulay, P., J. S. Graff Zivin, ANd J. Wang (2010): "Superstar extinction," The Quarterly Journal of Economics, 125, 549-589.

Bahar, D., P. Choudhury, AND H. Rapoport (2020): "Migrant inventors and the technological advantage of nations," Research Policy, 103947.

Becker, S. O., T. Fetzer, And D. Novy (2017): “Who voted for Brexit? A comprehensive district-level analysis," Economic Policy, 32, 601-650.

Beerli, A., J. Ruffner, M. Siegenthaler, ANd G. Peri (2021): “The abolition of immigration restrictions and the performance of firms and workers: evidence from Switzerland," American Economic Review, 111, 976-1012.

Belfanti, C. M. (2004): “Guilds, patents, and the circulation of technical knowledge: Northern Italy during the early modern age," Technology and culture, 45, 569-589.

Bertrand, M., E. Duflo, and S. Mullainathan (2004): “How much should we trust differences-in-differences estimates?" The Quarterly Journal of Economics, 119, 249-275.

Blundell, R., R. GRiffith, and J. V. Reenen (1995): “Dynamic count data models of technological innovation," The Economic Journal, 105, 333-344.

Borjas, G. J. And K. B. Doran (2012): “The collapse of the Soviet Union and the productivity of American mathematicians," The Quarterly Journal of Economics, 127, 1143-1203.

- (2015): "Which peers matter? The relative impacts of collaborators, colleagues, and competitors," Review of Economics and Statistics, 97, 1104-1117. 
Bosetti, V., C. Cattaneo, and E. Verdolini (2015): “Migration of skilled workers and innovation: A European perspective," Journal of International Economics, 96, 311-322.

BREsCHI, S. AND F. Lissoni (2004): "Knowledge networks from patent data," in Handbook of quantitative science and technology research, ed. by H. F. Moed, W. Glänzel, and U. Schmoch, Springer.

Breschi, S., F. Lissoni, AND E. Miguelez (2017): "Foreign-origin inventors in the USA: testing for diaspora and brain gain effects," Journal of Economic Geography, 17, 1009-1038.

- (2020): “Return Migrants' Self-Selection: Evidence for Indian Inventors," in The Roles of Immigrants and Foreign Students in US Science, Innovation, and Entrepreneurship, ed. by I. Ganguli, S. Kahn, and M. MacGarvie, Univ. of Chicago Press.

Burchardi, K. B., T. Chaney, T. A. Hassan, L. Tarquinio, and S. J. Terry (2020): "Immigration, Innovation, and Growth," NBER WP 27075, National Bureau of Economic Research.

Card, D., C. Dustmann, and I. Preston (2005): “Understanding attitudes to immigration: The migration and minority module of the first European Social Survey," CReAM Discussion Paper No 03/05, Centre for Research and Analysis of Migration.

Catalini, C., C. Fons-Rosen, and P. Gaulé (2020): “How Do Travel Costs Shape Collaboration?" Management Science, 66, 3340-3360.

Choudhury, P. AND D. Y. Kim (2019): “The ethnic migrant inventor effect: Codification and recombination of knowledge across borders," Strategic Management Journal, 40, 203-229.

Correia, S., P. Guimarães, ANd T. Zylkin (2020): "Fast Poisson estimation with highdimensional fixed effects," The Stata Journal, 20, 95-115.

D'Aiglepierre, R., A. David, C. Levionnois, G. Spielvogel, M. Tuccio, and E. Vickstrom (2020): "A global profile of emigrants to OECD countries: Younger and more skilled migrants from more diverse countries," Tech. rep., OECD Publishing.

De Rassenfosse, G. And A. B. Jaffe (2018): “Econometric evidence on the depreciation of innovations," European Economic Review, 101, 625-642.

Dibiasi, A., K. Abberger, M. Siegenthaler, ANd J.-E. Sturm (2018): “The effects of policy uncertainty on investment: Evidence from the unexpected acceptance of a far-reaching referendum in Switzerland," European Economic Review, 104, 38-67. 
Doran, K. AND C. Yoon (2020): "Immigration and invention: Evidence from the quota acts," Mimeo.

Doran, K. B., A. Gelber, ANd A. Isen (2020): “The Effects of High-Skilled Immigration Policy on Firms: Evidence from Visa Lotteries," Mimeo.

Du Plessis, M., B. V. Loox, X. Song, and T. Magerman (2009): “Data production methods for harmonized patent indicators: Assignee sector allocation," EUROSTAT Working Paper and Studies.

Dustmann, C. And I. Preston (2006): "Is immigration good or bad for the economy? Analysis of attitudinal responses," Research in Labor Economics, 24, 3-34.

Eaton, J., S. Kortum, And J. Lerner (2004): “International Patenting and the European Patent Office: A Quantitative Assessment," in Patents, Innovation and Economic Performance OECD Conference Proceedings: OECD Conference Proceedings, OECD Publishing.

Feigenbaum, J. J. (2016): “Automated census record linking: A machine learning approach," Mimeo.

FERRUCCI, E. AND F. Lissoni (2019): "Foreign inventors in Europe and the United States: Diversity and Patent Quality," Research Policy, 48, 103774.

GANGULI, I. (2015): "Immigration and ideas: What did Russian scientists ?bring? to the United States?" Journal of Labor Economics, 33, S257-S288.

GLENNON, B. (2020): "How do restrictions on high-skilled immigration affect offshoring? Evidence from the H-1B program," NBER WP 27538, National Bureau of Economic Research.

Griliches, Z. (1990): "Patent Statistics as Economic Indicators: A Survey," Journal of Economic Literature, 28, 1661-1707.

Guellec, D. and B. Van Pottelsberghe (2007): The economics of the European patent system: IP policy for innovation and competition, Oxford University Press.

Hall, B. H., S. Graham, D. Harhoff, and D. C. Mowery (2004): "Prospects for improving US patent quality via postgrant opposition," Innovation policy and the economy, 4, $115-143$.

Hall, B. H., Z. Griliches, and J. A. Hausman (1986): "Patents and R and D: Is There a Lag?" International Economic Review, 27, 265-283. 
Hausman, J., B. H. Hall, Z. Griliches, et Al. (1984): “Econometric Models for Count Data with an Application to the Patents-R\&D Relationship," Econometrica, 52, 909-938.

Henderson, R. AND I. CocKBURn (1994): "Measuring competence? Exploring firm effects in pharmaceutical research," Strategic management journal, 15, 63-84.

Hennerberger, F. AND A. Ziegler (2011): “Empirische Überprüfung des Auftretens von Lohndruck aufgrund des Immigrationsdrucks aus den EU17/EFTA-Mitgliedstaaten," Univ. St. Gallen WP.

Hilaire-Pérez, L. and C. Verna (2006): “Dissemination of technical knowledge in the middle ages and the early modern era: New approaches and methodological issues," Technology and culture, 47, 536-565.

Hunt, J. (2011): "Which immigrants are the most innovative and entrepreneurial? Distinctions by entry visa," Journal of Labor Economics, 29, 417-457.

Hunt, J. And M. Gauthier-Loiselle (2010): “How Much Does Immigration Boost Innovation," American Economic Journal: Macroeconomics, 2, 31-56.

Jaffe, A. AND G. De RAssenfosse (2017): "Patent citation data in social science research: Overview and best practices," Journal of the Association for Information Science and Technology, 68, 1360-1374.

Jaravel, X., N. Petkova, and A. Bell (2018): "Team-specific capital and innovation," American Economic Review, 108, 1034-73.

JoNES, B. F. (2009): "The burden of knowledge and the "death of the renaissance man": Is innovation getting harder?" The Review of Economic Studies, 76, 283-317.

KeMENY, T. (2017): "Immigrant diversity and economic performance in cities," International Regional Science Review, 40, 164-208.

Kerr, S. P., W. Kerr, Ç. Özden, and C. Parsons (2017): “High-skilled migration and agglomeration," Annual Review of Economics, 9, 201-234.

Kerr, W. R. (2020): "The Gift of Global Talent: Innovation Policy and the Economy," in Innovation Policy and the Economy, ed. by J. Lerner and S. Stern, Univ. of Chicago Press, vol. 20, 1-37.

KerR, W. R. ANd W. F. Lincoln (2010): “The Supply Side of Innovation: H-1B Visa Reforms and U.S. Ethnic Invention," Journal of Labor Economics, 28, 473-508. 
KerR, W. R., W. F. Lincoln, AND P. Mishra (2014): “The dynamics of firm lobbying," American Economic Journal: Economic Policy, 6, 343-79.

Kogler, D. F., J. Essletzbichler, ANd D. L. Rigby (2017): “The evolution of specialization in the EU15 knowledge space," Journal of Economic Geography, 17, 345-373.

Lanjouw, J. O. AND M. Schankerman (2004): "Patent quality and research productivity: Measuring innovation with multiple indicators," The Economic Journal, 114, 441-465.

Li, G.-C., R. LaI, A. D'Amour, D. M. Doolin, Y. Sun, V. I. TorviK, Z. Y. AmY, AND L. Fleming (2014): "Disambiguation and co-authorship networks of the US patent inventor database (1975-2010)," Research Policy, 43, 941-955.

Lissoni, F. (2018): “International Migration and Innovation Diffusion: An Eclectic Survey," Regional Science, 52, 702-714.

Miguelez, E. AND C. FinK (2017): "Measuring the international mobility of inventors: a new database," in The International Mobility of Talent and Innovation, ed. by C. Fink and E. Miguelez, Cambridge University Press.

Moser, P. AND S. SAN (2020): "Immigration, Science, and Invention. Evidence from the Quota Acts," Mimeo.

Moser, P., A. Voena, and F. Waldinger (2014): “German Jewish Émigrés and US Invention," American Economic Review, 104, 3222-3255.

Nagaoka, S., K. Мотоhashi, and A. Goto (2010): "Patent statistics as innovation indicator," in Handbook of the Economics of Innovation, ed. by B. H. Hall and N. Rosenberg, North-Holland.

Nathan, M. (2015): "Same difference? Minority ethnic inventors, diversity and innovation in the UK," Journal of Economic Geography, 15, 129-168.

Ozgen, C., P. NijKamp, and J. Poot (2013): "The impact of cultural diversity on firm innovation: evidence from Dutch micro-data," IZA Journal of Migration, 2, 18.

Parrotta, P., D. Pozzoli, and M. Pytlikova (2014): “Labor Diversity and Firm Productivity," European Economic Review, 66, 144-179.

PeRI, G. (2012): "The effect of immigration on productivity: Evidence from US states," Review of Economics and Statistics, 94, 348-358.

Peri, G., K. ShiH, ANd C. Sparber (2015): “STEM workers, H-1B visas, and productivity in US cities," Journal of Labor Economics, 33, S225-S255. 
Peri, G. And C. Sparber (2009): “Task specialization, immigration, and wages," American Economic Journal: Applied Economics, 1, 135-69.

Pezzoni, M., F. Lissoni, and G. Tarasconi (2014): “How to kill inventors: testing the Massacrator(C) algorithm for inventor disambiguation," Scientometrics, 101, 477-504.

Raffo, J. AND S. Lhuillery (2009): "How to play the ?Names Game?: Patent retrieval comparing different heuristics," Research policy, 38, 1617-1627.

SAlvatore, V. (2016): The free movement of persons between Switzerland and the European Union, Giappichelli Editore.

Sснмосн, U. (2008): "Concept of a Technology Classification for Country Comparisons," WIPO Technical Report.

Schuler, M., P. Dessemontet, And D. Joye (2005): “Les Niveaux Géographiques de la Suisse," Office fédéral de la statistique.

Silva, J. S. And S. Tenreyro (2011): "Poisson: Some convergence issues," The Stata Journal, $11,207-212$.

WALDINGER, F. (2012): "Peer effects in science: Evidence from the dismissal of scientists in Nazi Germany," The Review of Economic Studies, 79, 838-861. 


\section{Tables}

Table 1: MS regions descriptive statistics, by area and period

\begin{tabular}{|c|c|c|c|c|c|c|c|c|c|c|}
\hline & \multicolumn{5}{|c|}{ Pre-AFMP (1990-1999) } & \multicolumn{5}{|c|}{ Post-AFMP (2000-2012) } \\
\hline & Mean & $\mathrm{SD}$ & Median & Min & Max & Mean & SD & Median & Min & Max \\
\hline & \multicolumn{5}{|c|}{ 020-BRs } & \multicolumn{5}{|c|}{$020-B R s$} \\
\hline No. Patents & 26.00 & 34.32 & 12.5 & 0 & 184 & 47.65 & 58.27 & 25 & 0 & 343 \\
\hline No. Inventors (total) & 37.69 & 62.00 & 15 & 0 & 361 & 74.02 & 114.22 & 32 & 0 & 673 \\
\hline No. Resident inventors & 31.35 & 45.94 & 14 & 0 & 252 & 57.11 & 76.07 & 29 & 0 & 439 \\
\hline No. CBIs & 6.33 & 17.17 & 0 & 0 & 109 & 16.90 & 39.93 & 4 & 0 & 238 \\
\hline \multirow[t]{2}{*}{ Share CBIs } & 0.07 & 0.11 & 0 & 0 & 1 & 0.13 & 0.12 & 0.12 & 0 & 0.53 \\
\hline & \multicolumn{5}{|c|}{ 20plus-BRs } & \multicolumn{5}{|c|}{ 20plus-BRs } \\
\hline No. Patents & 24.48 & 36.10 & 9 & 0 & 214 & 39.02 & 63.70 & 12 & 0 & 332 \\
\hline No. Inventors (total) & 32.61 & 50.29 & 11 & 0 & 294 & 60.04 & 106.14 & 15.5 & 0 & 586 \\
\hline No. Resident inventors & 31.97 & 48.76 & 11 & 0 & 290 & 58.31 & 102.62 & 15 & 0 & 576 \\
\hline No. CBIs & 0.63 & 2.95 & 0 & 0 & 35 & 1.73 & 4.90 & 0 & 0 & 37 \\
\hline \multirow[t]{2}{*}{ Share CBIs } & 0.01 & 0.04 & 0 & 0 & 0.5 & 0.02 & 0.07 & 0 & 0 & 1 \\
\hline & \multicolumn{5}{|c|}{ NBRs } & \multicolumn{5}{|c|}{ NBRs } \\
\hline No. Patents & 9.57 & 15.66 & 4 & 0 & 89 & 15.40 & 25.40 & 7 & 0 & 141 \\
\hline No. Inventors (total) & 11.90 & 19.93 & 4 & 0 & 102 & 21.72 & 33.71 & 9 & 0 & 209 \\
\hline No. Resident inventors & 11.82 & 19.82 & 4 & 0 & 99 & 20.53 & 33.55 & 9 & 0 & 206 \\
\hline No. CBIs & 0.08 & 0.38 & 0 & 0 & 3 & 0.19 & 0.68 & 0 & 0 & 8 \\
\hline Share CBIs & 0.01 & 0.02 & 0 & 0 & 0.25 & 0.01 & 0.04 & 0 & 0 & 0.5 \\
\hline
\end{tabular}

Notes: Descriptive statistics for the MS region panel, based on the final sample of 65,333 EPO patent applications. 
Table 2: Regional patent count: Fixed-effects difference-in-differences results

\begin{tabular}{|c|c|c|c|c|c|c|c|c|}
\hline & \multicolumn{2}{|c|}{ Full sample } & \multicolumn{2}{|c|}{ Incumbents only } & \multicolumn{2}{|c|}{ No Top applicants } & \multicolumn{2}{|c|}{$\begin{array}{l}\text { No Top applicants } \\
\text { Incumbents only }\end{array}$} \\
\hline & $\begin{array}{c}\text { Baseline } \\
\text { (1) }\end{array}$ & $\begin{array}{c}\text { Until } 2007 \\
\text { (2) }\end{array}$ & $\begin{array}{l}\text { Baseline } \\
\text { (3) }\end{array}$ & $\begin{array}{c}\text { Until } 2007 \\
(4)\end{array}$ & $\begin{array}{c}\text { Baseline } \\
\text { (5) }\end{array}$ & $\begin{array}{c}\text { Until } 2007 \\
(6)\end{array}$ & $\begin{array}{l}\text { Baseline } \\
\text { (7) }\end{array}$ & $\begin{array}{c}\text { Until } 2007 \\
(8)\end{array}$ \\
\hline AFMP $\times$ Treated & $\begin{array}{c}0.140 \\
(0.1222)\end{array}$ & $\begin{array}{c}0.213^{*} \\
(0.1107)\end{array}$ & $\begin{array}{c}0.269^{*} \\
(0.1435)\end{array}$ & $\begin{array}{l}0.359^{* * *} \\
(0.1316)\end{array}$ & $\begin{array}{l}0.241^{* *} \\
(0.0999)\end{array}$ & $\begin{array}{l}0.270^{* * *} \\
(0.0938)\end{array}$ & $\begin{array}{l}0.339^{* *} \\
(0.1335)\end{array}$ & $\begin{array}{l}0.351^{* * *} \\
(0.1282)\end{array}$ \\
\hline Number of MS regions & 63 & 63 & 59 & 59 & 63 & 63 & 59 & 59 \\
\hline Observations & 1,449 & 1,134 & 1,357 & 1,062 & 1,449 & 1,134 & 1,357 & 1,062 \\
\hline Pseudo $\mathrm{R}^{2}$ & 0.88 & 0.87 & 0.87 & 0.87 & 0.83 & 0.82 & 0.78 & 0.78 \\
\hline MS region FE & $\checkmark$ & $\checkmark$ & $\checkmark$ & $\checkmark$ & $\checkmark$ & $\checkmark$ & $\checkmark$ & $\checkmark$ \\
\hline Year FE & $\checkmark$ & $\checkmark$ & $\checkmark$ & $\checkmark$ & $\checkmark$ & $\checkmark$ & $\checkmark$ & $\checkmark$ \\
\hline
\end{tabular}

Notes: ${ }^{* * *} \mathrm{p}<0.01,{ }^{* *} \mathrm{p}<0.05,{ }^{*} \mathrm{p}<0.1$. The dependent variable is the number of patents in MS-region $m$ and year $t$. The treated group includes all MS-regions in the BR whose driving distance from the closest border crossing is below or equal to 20 minutes (BR, 0-20 min). The control group includes all MS-regions in the BR whose driving distance from the closest border crossing in above 20 minutes (BR, $>20$ min). Robust standard errors clustered at the MS-region level are given in parentheses. Estimations by Poisson pseudo-maximum-likelihood (PML). Columns (1) to (4) report results for the entire dataset. Columns (5) to (8) report results excluding Top applicants' patents. Columns (3), (4), (7), and (8) report results considering only incumbent applicants' patents. In this case, the number of MS regions decreases to 59 since 4 MS regions have no incumbent applicants observable in the post-AFMP period due to the overall low number of patent applications filed in those areas in $1990-2012$. 
Table 3: Incumbent Swiss-resident inventors' patenting probability in the post-AFMP period

\begin{tabular}{lcccc}
\hline \hline & Baseline & No top applicants & Pharmaceuticals & Chemicals \\
& $(1)$ & $(2)$ & $(3)$ & $(4)$ \\
\hline Treated & $0.321^{* *}$ & -0.274 & $0.674^{* *}$ & -0.113 \\
& $(0.1244)$ & $(0.2273)$ & $(0.3345)$ & $(0.1888)$ \\
& & & & \\
Years active (pre-AFMP) & $0.085^{* * *}$ & $0.200^{* * *}$ & 0.019 & 0.020 \\
& $(0.0095)$ & $(0.0140)$ & $(0.0181)$ & $(0.0121)$ \\
& & & & \\
No. of co-inventors (pre-AFMP) & $0.047^{* * *}$ & $0.023^{* * *}$ & $0.045^{* * *}$ & $0.050^{* * *}$ \\
& $(0.0046)$ & $(0.0076)$ & $(0.0072)$ & $(0.0061)$ \\
& & & & \\
Applicant inventive workforce (pre-AFMP) & $-0.00009^{* * *}$ & $0.0003^{* *}$ & 0.00007 & $-0.00008^{*}$ \\
& $(0.00003)$ & $(0.0001)$ & $(0.00005)$ & $(0.00004)$ \\
& & & & \\
Observations & & & & 4,485 \\
Pseudo R & & 9,333 & 2,877 & 0.14 \\
\hline MS region dummies & 14,616 & 0.14 & 0.16 & $\checkmark$ \\
Tech. class dummies & 0.12 & $\checkmark$ & $\checkmark$ & $\checkmark$ \\
\hline \hline
\end{tabular}

Notes: ${ }^{* * *} \mathrm{p}<0.01,{ }^{* *} \mathrm{p}<0.05,{ }^{*} \mathrm{p}<0.1$. The dependent variable is a dummy variable equal to 1 if the focal inventor patents at least once after 1999, the post-AFMP period. Treated $i$ is a dummy equal to 1 if the focal inventor was active in BRs whose driving distance from the closest border crossing is below or equal to 20 minutes (BR, 0-20 min). Column (1) reports results for the full sample. Column (2) excludes inventors associated with "Top" applicants. Column (3) considers only inventors active in Pharmaceutical technology classes and column (4) only inventors active in Chemical technology classes (Schmoch, 2008). Robust standard errors are given in parentheses. Probit models estimated by maximum likelihood. 
Table 4: Individual productivity (patent count), number of co-inventors, and CBI-countries' prior-art citations: fixed-effects differencein-differences results, $1990-2012$

\begin{tabular}{|c|c|c|c|c|c|c|}
\hline & \multicolumn{2}{|c|}{ No. of patents } & \multicolumn{2}{|c|}{ No. of co-inventors } & \multicolumn{2}{|c|}{$\begin{array}{l}\text { No. of backward citations } \\
\text { to CBI-country prior art }\end{array}$} \\
\hline & $\begin{array}{c}\text { Baseline } \\
\text { (1) }\end{array}$ & $\begin{array}{l}\text { Excluding patents } \\
\text { with CBIs in team } \\
\text { (2) }\end{array}$ & $\begin{array}{c}\text { Baseline } \\
\text { (3) }\end{array}$ & $\begin{array}{l}\text { Excluding patents } \\
\text { with CBIs in team } \\
\text { (4) }\end{array}$ & $\begin{array}{c}\text { Baseline } \\
\text { (5) }\end{array}$ & $\begin{array}{l}\text { Excluding patents } \\
\text { with CBIs in team } \\
\text { (6) }\end{array}$ \\
\hline AFMP $\times$ Treated & $\begin{array}{c}0.113^{*} \\
(0.0598)\end{array}$ & $\begin{array}{c}0.005 \\
(0.0488)\end{array}$ & $\begin{array}{l}0.132^{* * *} \\
(0.0392)\end{array}$ & $\begin{array}{c}0.039 \\
(0.0358)\end{array}$ & $\begin{array}{l}0.228^{* * *} \\
(0.0726)\end{array}$ & $\begin{array}{c}0.063 \\
(0.0706)\end{array}$ \\
\hline Number of Inventors & 1,942 & 1,894 & 1,882 & 1,833 & 1,570 & 1,482 \\
\hline Observations & 9,887 & 9,673 & 9,570 & 9,309 & 8,526 & 8,082 \\
\hline Pseudo $R^{2}$ & 0.11 & 0.14 & 0.28 & 0.24 & 0.31 & 0.24 \\
\hline Inventor FE & $\checkmark$ & $\checkmark$ & $\checkmark$ & $\checkmark$ & $\checkmark$ & $\checkmark$ \\
\hline Applicant FE & $\checkmark$ & $\checkmark$ & $\checkmark$ & $\checkmark$ & $\checkmark$ & $\checkmark$ \\
\hline MS region FE & $\checkmark$ & $\checkmark$ & $\checkmark$ & $\checkmark$ & $\checkmark$ & $\checkmark$ \\
\hline Year FE & $\checkmark$ & $\checkmark$ & $\checkmark$ & $\checkmark$ & $\checkmark$ & $\checkmark$ \\
\hline
\end{tabular}

Notes: ${ }^{* * *} \overline{\mathrm{p}<0.01,{ }^{* *} \mathrm{p}<0.05,{ }^{*} \mathrm{p}<0.1 \text {. In columns (1) and (2) the dependent variable is the number of patents filed by inventor } i \text { in MS-region } m \text { and }}$ year $t$ for applicant $j$. In columns (3) and (4) the dependent variable is the number of distinct co-inventors collaborating with inventor $i$ in MS-region $m$ and year $t$ for applicant $j$. In columns (5) and (6) the dependent variable is the number of citations to CBI-countries' prior art made by inventor $i$ in MS-region $m$ and year $t$ for applicant $j$, divided by the number of patents filed by the inventor in the considered year. The treated group includes "persistent" inventors working in R\&D labs located in BR MS regions whose driving distance from the closest border crossing is below or equal to 20 minutes (BR, 0-20 min). The control group includes "persistent" inventors working in R\&D labs located in BR MS regions whose driving distance from the closest border crossing is above 20 minutes (BR, > $20 \mathrm{~min}$ ). Robust standard errors clustered at the MS region level are given in parentheses. Estimations by Poisson pseudo-maximum-likelihood (PML). The number of "persistent" inventors is slightly lower than our original sample as few observations are discarded to ensure the existence of the estimates (Silva and Tenreyro, 2011). Such "separated" observations can be safely dropped as they do not contribute useful information for the estimation algorithm (Correia et al., 2020). 


\section{Figures}

Figure 1: Spatial distribution of cross-border inventors (CBIs) by municipality of residence, 19902012

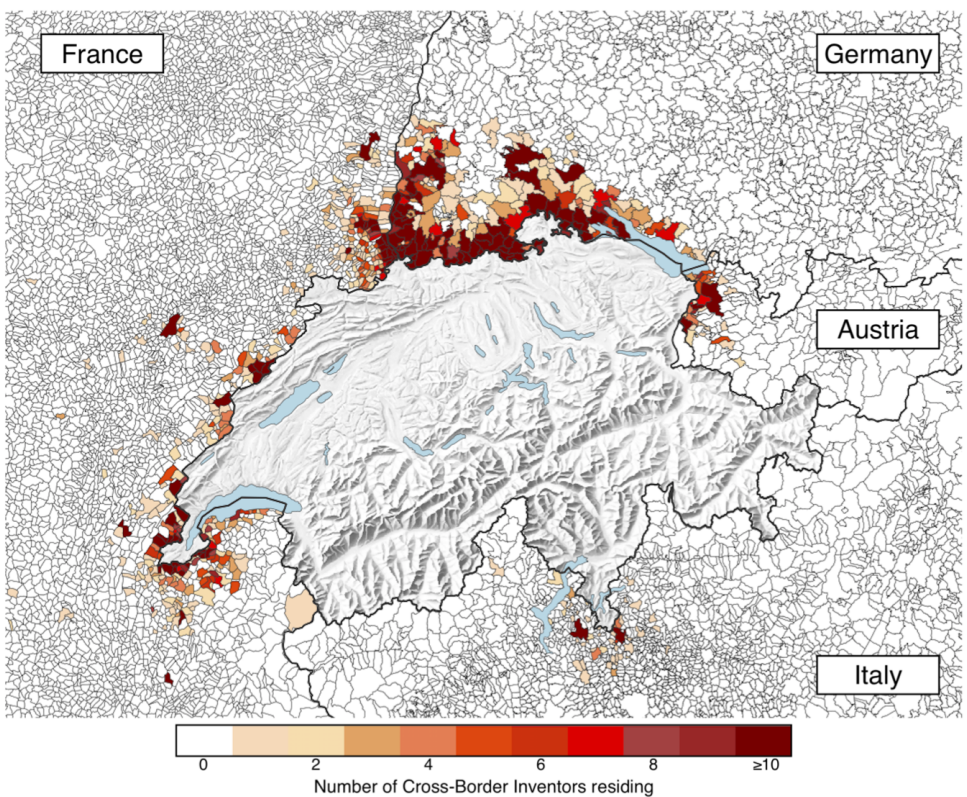

Notes: The map shows the municipalities in Austria, France, Germany, and Italy where CBIs reside, according to the address found on their patents.

Figure 2: CBIs' share of total inventors in MS regions groups by driving distance to border crossing

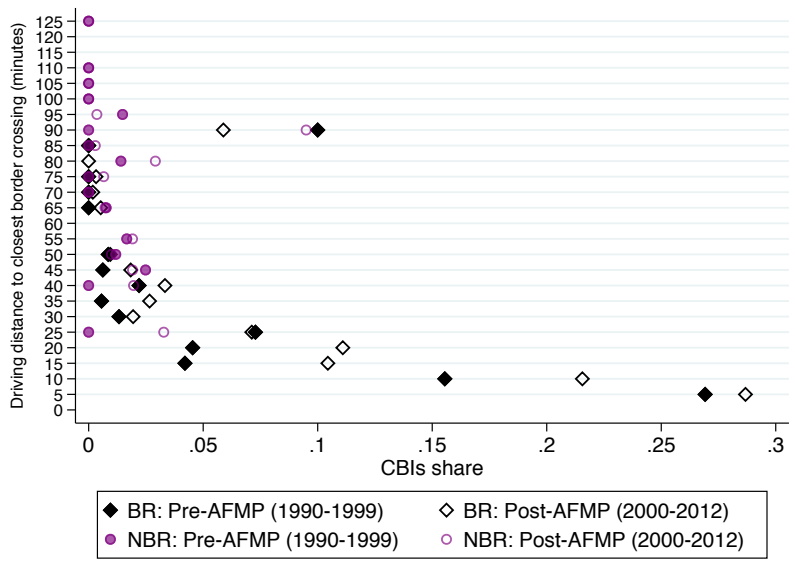

Notes: The figure shows the share of CBIs of the total of active inventors in each group of MS regions sorted according to their distance from the closest international border crossing (5-minute groups). It compares CBI shares before and after the AFMP signing and introduction. Diamond markers indicate BRs while circle markers indicate NBRs. 
Figure 3: MS regions in Switzerland: BRs (driving distance groups) and NBRs

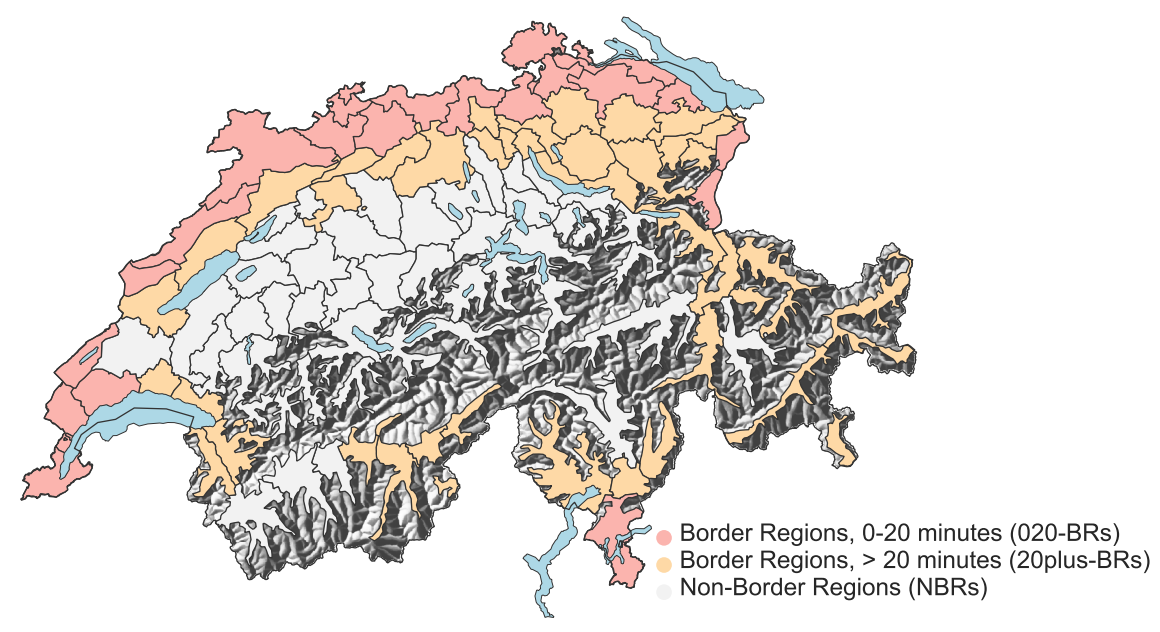

Notes: The map shows MS regions in the BR and NBR. Those in the BR are divided into two groups, according to their driving distance from the closest international border crossing. MS regions are plotted in terms of their productive areas, as defined by the Swiss Federal Statistical Office (FSO), rather than their purely political boundaries.

Figure 4: Active cross-border inventors' evolution by driving distance area

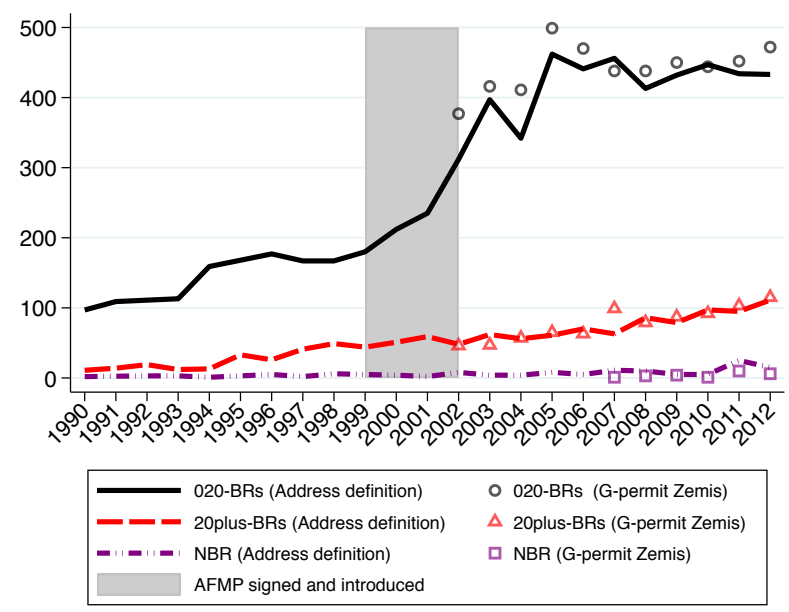

Notes: The figure shows the yearly number of active cross-border inventors by driving distance area in the Border Regions (BRs) and Non-Border Regions (NBRs). Lines indicate cross-border inventors identified with addresses found on their patents. Markers show cross-border inventors defined according to their residence permit (i.e., Permit G; Patstat-ZEMIS matched database). 
Figure 5: Regional patent count: event study results

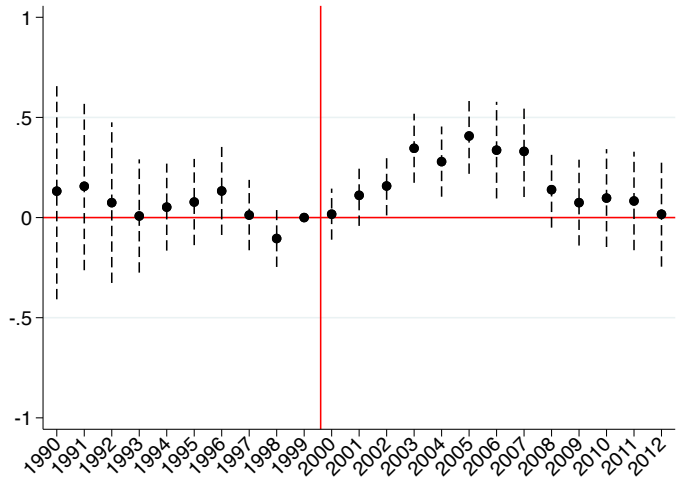

(a) Full sample

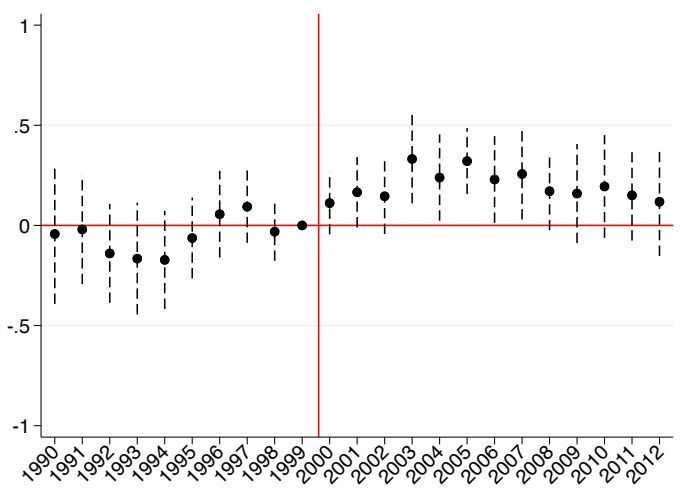

(c) No top applicants

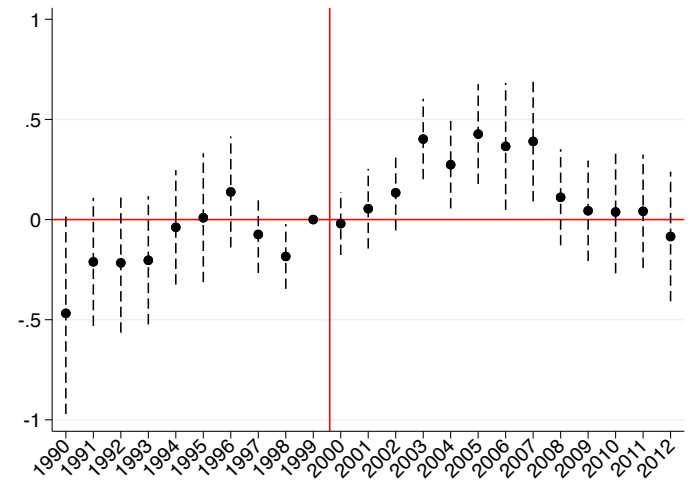

(b) Incumbent applicants only

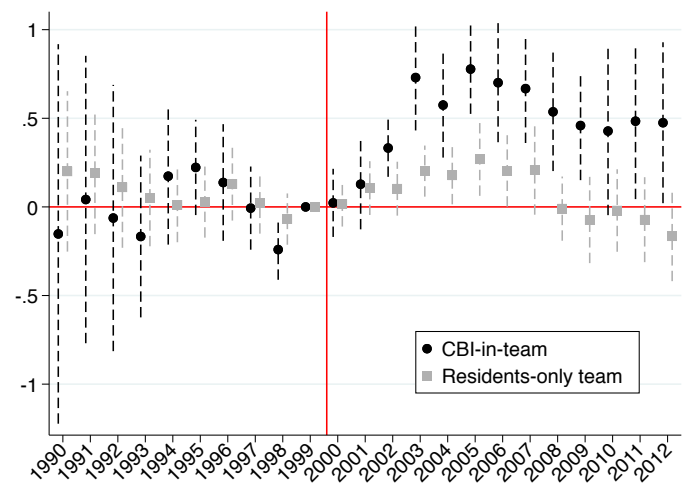

(d) CBI-in-team VS. Resident-only team patents

Notes: The dependent variable is the number of patent filings in MS-region $m$ in year $t$. The treated group includes all MS-regions in the BR whose driving distance from the closest border crossing is below or equal to 20 minutes (BR, 0-20 min). The control group includes all MS-regions in the BR whose driving distance from the closest border crossing is above 20 minutes (BR, > $20 \mathrm{~min}$ ). For the estimations in panel (a) we count all patents. For those in panel (b) we count only patents associated with "incumbent" applicants; for those in panel (c) we exclude patents associated with "top" applicants. For the estimations in panel (d) we decompose each treated MS region's yearly patent output, distinguishing between patents including at least one CBI (CBI-in-team) and patents including only resident inventors (Resident-only team) and running two separate event-study regressions. The estimated parameters related to CBI-in-team patents are shown as black circles. Those related to Resident-only team patents are shown as gray squares. All regressions include MS-region Fixed Effects and Year Fixed Effects. Vertical bars represent 95\% confidence intervals. The coefficient for our baseline year 1999 is set to zero and shown without confidence interval. Robust standard errors are clustered at the MS-region level. Estimation by Poisson pseudo-maximum-likelihood (PML). 
Figure 6: Active Swiss-resident inventors by region, event study results

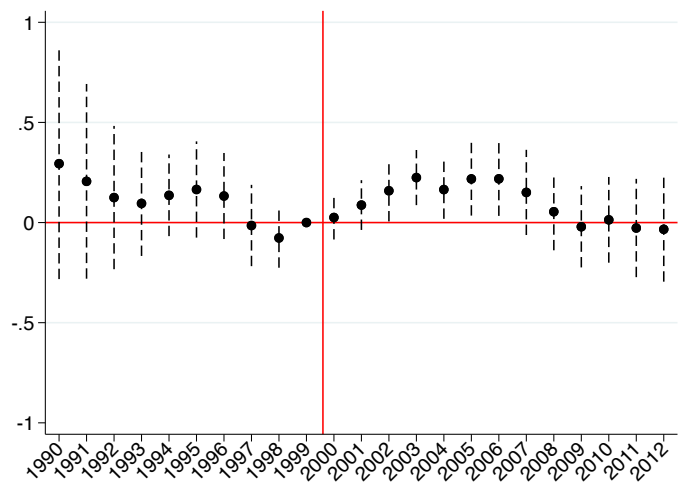

(a) Full sample

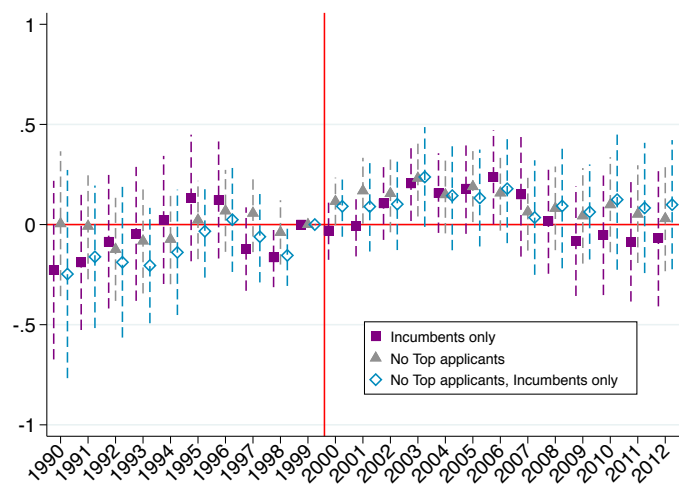

(b) Incumbents \& excluding Top applicants

Notes: The dependent variable is the number of Swiss-resident inventors active in MS-region $m$ and year $t$. The treated group includes all MS-regions in the BR whose driving distance from the closest border crossing is below or equal to 20 minutes (BR, 0-20 min). The control group includes all MS-regions in the BR whose driving distance from the closest border crossing in above 20 minutes (BR, $>20 \mathrm{~min}$ ). Panel (a) shows the estimated coefficient for the full sample. Panel (b) focuses on Incumbents and excludes Top applicants. Robust standard errors clustered at the MS-region level are given in parentheses. Estimation by Poisson pseudo-maximum-likelihood (PML). 
Figure 7: Evolution of average inventive outcomes for inventors in 020-BRs and 20plus-BRs

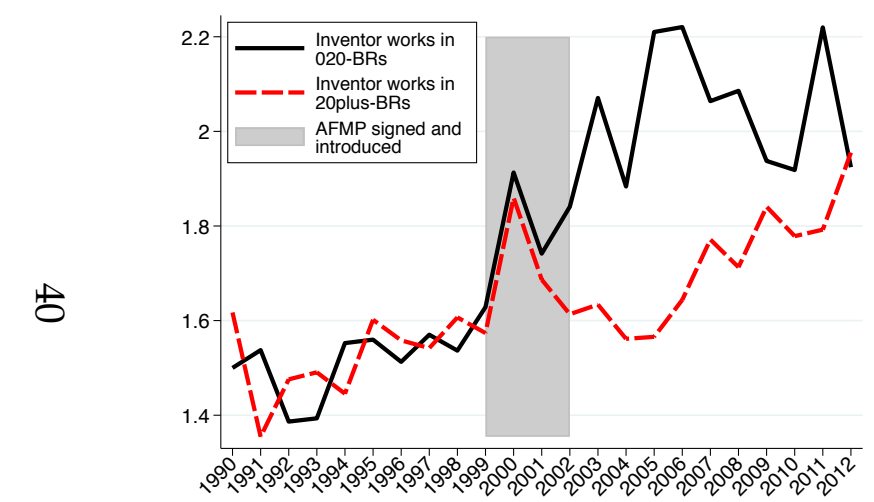

(a) No. patents

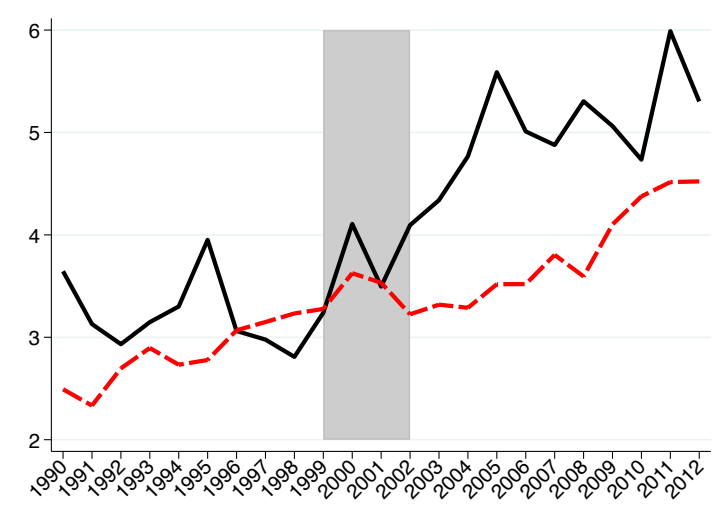

(b) No. distinct co-inventors

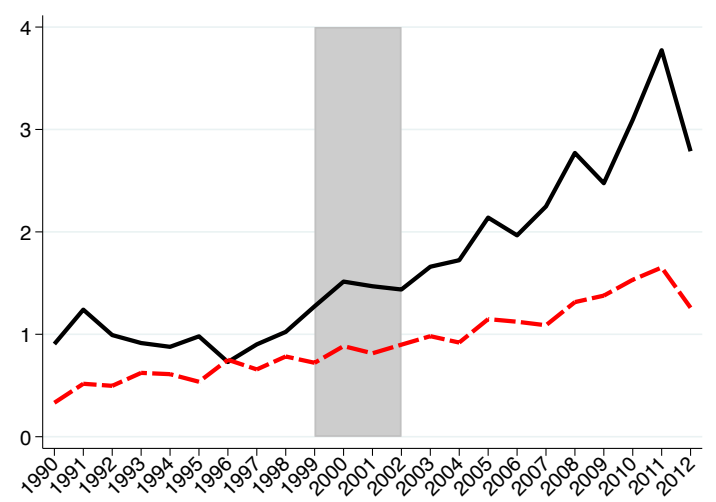

(c) Citations to CBI-country prior-art

Notes: The figure shows the average yearly productivity for inventors located in 020-BRs (solid black line) and those located in 20plus-BRs (dashed red line). Average yearly productivity is computed as the average number of patents filed by inventors in a given year in the region considered. 


\title{
Appendix for
}

\section{"Free Movement of Inventors: Open-Border Policy and Innovation in Switzerland"}

\author{
by Gabriele Cristelli and Francesco Lissoni
}

April 2021

\section{Contents}

A. The Agreement on the Free Movement of Persons (AFMP) $\ldots \ldots \ldots \ldots \ldots \ldots$ A-1

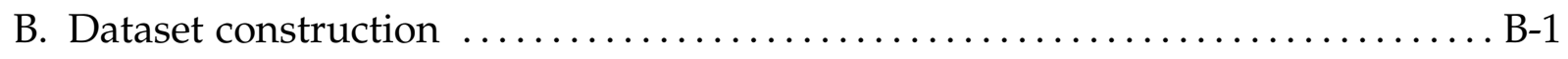

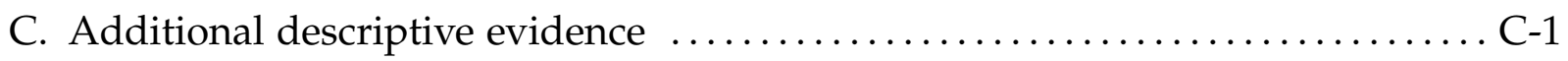

D. Additional estimations and robustness checks $\ldots \ldots \ldots \ldots \ldots \ldots \ldots \ldots \ldots$ D-1

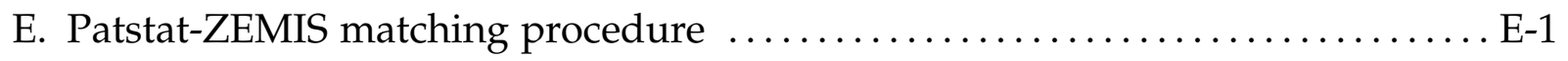




\section{A. The Agreement on the Free Movement of Persons (AFMP)}

Figure A1: Agreement on the Free Movement of Persons (AFMP) introduction timeline

Border region

(BR)
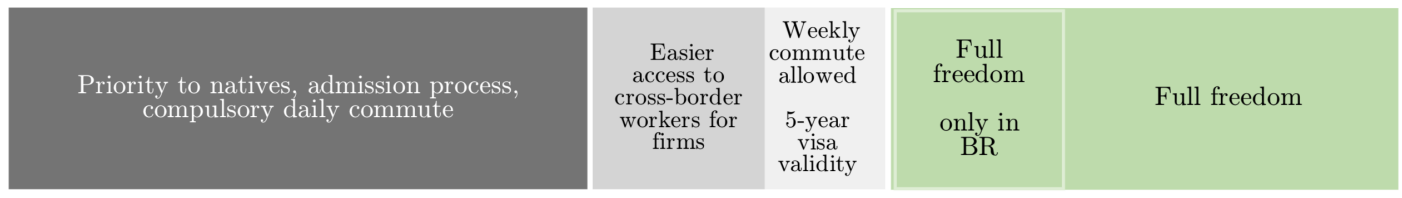

Non-border region (NBR)

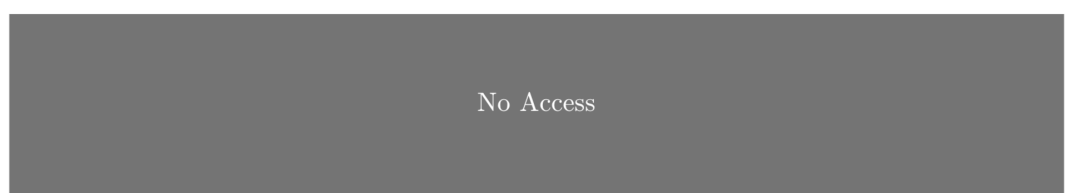

Full freedom

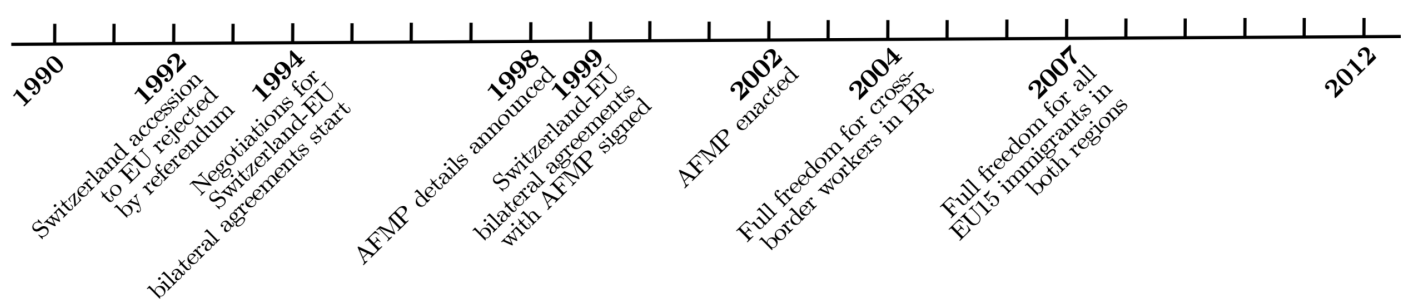

(a) Cross-border workers

Both regions
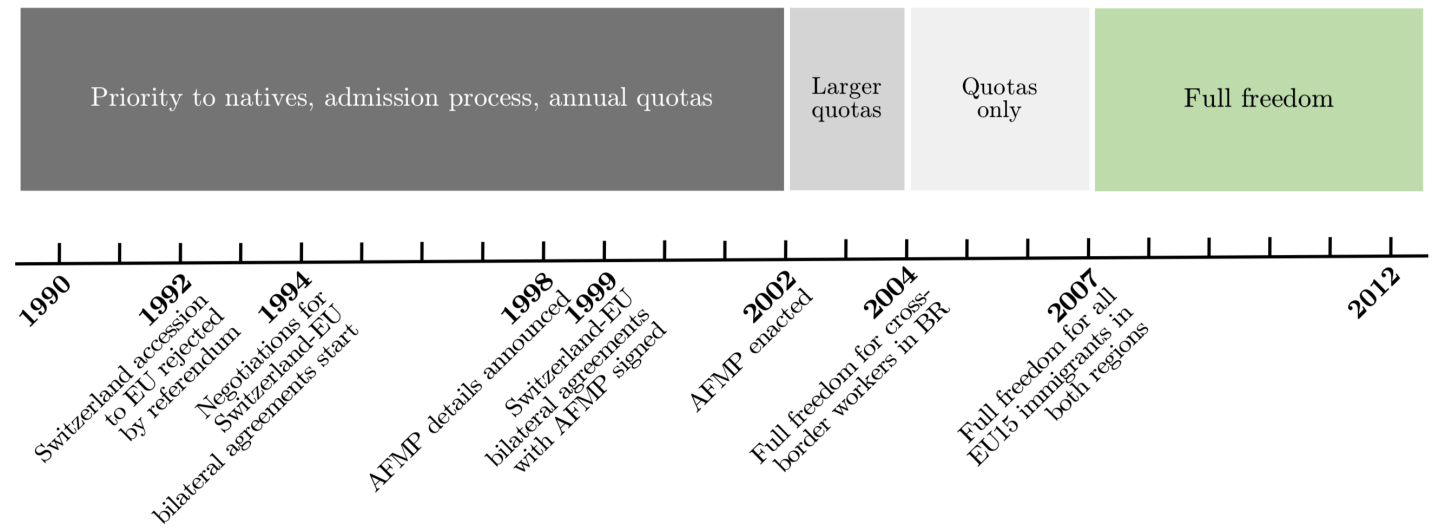

(b) Resident immigrants 


\section{B. Dataset construction}

Inventors' disambiguation. We disambiguated inventors using the algorithm proposed by Pezzoni et al. (2014). The algorithm first parses each inventor's name, surname, and address strings. Then, it selects inventor pairs (found across different patents) which could potentially be associated to the same individual, based on perfectly matching name-surname combinations or name-surname string similarity. It then filters out false positive cases using score-weighted information on common co-inventors, geographical location, and patenting technology classes, with the scores obtained from two training sets for calibration. By adjusting the scores, the algorithm can be calibrated in order to balance precision and recall. Incidentally, one of the training sets consists of inventors affiliated to the École Polytechnique Fédérale de Lausanne (EPFL), one of the two Swiss Federal Institutes of Technology, and it is highly representative of the mix of names in German, French, Italian and other languages one can find in many large R\&D labs across Switzerland. 
Table B1: G-permit-designated areas in Austria, France, Germany, and Italy

\begin{tabular}{|c|c|c|}
\hline Country & First Administrative Unit & Second Administrative Unit \\
\hline \multirow[t]{6}{*}{ Austria } & Bezirk (District) & Bundesland (State) \\
\hline & Bludenz & Vorarlberg \\
\hline & Bregenz & Vorarlberg \\
\hline & Dornbirn & Vorarlberg \\
\hline & Feldkirch & Vorarlberg \\
\hline & Landeck & Tirol \\
\hline \multirow[t]{7}{*}{ France } & Département (Department) & Région (Region) \\
\hline & Ain & Auvergne-Rhône-Alpes \\
\hline & Haute-Savoie & Auvergne-Rhône-Alpes \\
\hline & Doubs & Bourgogne-Franche-Compté \\
\hline & Jura & Bourgogne-Franche-Compté \\
\hline & Territoire de Belfort & Bourgogne-Franche-Compté \\
\hline & Haut-Rhin & Grand Est \\
\hline \multirow[t]{15}{*}{ Germany } & Landkreis (District) or Stadt (City) & Land (State) \\
\hline & Biberach & Baden-Wüerttenberg \\
\hline & Bodenseekreis & Baden-Wüerttenberg \\
\hline & Breisgau-Hochschwarzwald & Baden-Wüerttenberg \\
\hline & Freiburg & Baden-Wüerttenberg \\
\hline & Konstanz & Baden-Wüerttenberg \\
\hline & Lörrach & Baden-Wüerttenberg \\
\hline & Ravensburg & Baden-Wüerttenberg \\
\hline & Sigmaringen & Baden-Wüerttenberg \\
\hline & Schwarzwald-Baar-Kreis & Baden-Wüerttenberg \\
\hline & Tuttlingen & Baden-Wüerttenberg \\
\hline & Waldshut-Tiengen & Baden-Wüerttenberg \\
\hline & Kempten (Allgäu) & Bavaria \\
\hline & Lindau & Bavaria \\
\hline & Oberallgäu & Bavaria \\
\hline \multirow[t]{8}{*}{ Italy } & Provincia (Province) & Regione (Region) \\
\hline & Aosta & Valle d'Aosta \\
\hline & Bolzano & Trentino-Südtirol \\
\hline & Como & Lombardia \\
\hline & Lecco & Lombardia \\
\hline & Varese & Lombardia \\
\hline & Sondrio & Lombardia \\
\hline & Verbania-Cusio-Ossola & Piemonte \\
\hline
\end{tabular}

Notes: The table shows the administrative units in Austria, France, Germany, and Italy we used to select patent applications filed by Swiss-based applicants and potential cross-border inventors employed in Switzerland and not collaborating with any Swiss-based inventor on those specific projects. These are the areas where prospective cross-border workers were required to reside for at least six months before being eligible to apply for a Permit G to work in Switzerland before the AFMP introduction. These regions remained the main residential areas for all cross-border border workers even after the AFMP. 
Table B2: Distribution of applicants and patents, by size of patent portofolio

\begin{tabular}{lccccccc}
\hline \hline & \multicolumn{3}{c}{ Applicants } & & \multicolumn{3}{c}{ Patent Applications } \\
\cline { 2 - 3 } \cline { 7 - 8 } & Number & Percentage & $\begin{array}{c}\text { Cumulated } \\
\text { Percentage }\end{array}$ & & Number & Percentage & $\begin{array}{c}\text { Cumulated } \\
\text { Percentage }\end{array}$ \\
\hline$>1000$ & 5 & 0.04 & 0.04 & & 7,371 & 10.63 & 10.63 \\
$<1000$ and $\geq 500$ & 7 & 0.05 & 0.09 & & 4,922 & 7.10 & 17.72 \\
$<500$ and $\geq 100$ & 69 & 0.54 & 0.63 & & 15,400 & 22.20 & 39.92 \\
$<100$ and $\geq 50$ & 73 & 0.57 & 1.20 & & 4,961 & 7.15 & 47.07 \\
$<50$ and $\geq 20$ & 258 & 2.01 & 3.21 & & 7,674 & 11.06 & 58.14 \\
$<20$ and $\geq 10$ & 480 & 3.74 & 6.94 & & 6,424 & 9.26 & 67.40 \\
$<10$ and $\geq 5$ & 949 & 7.39 & 14.33 & & 6,168 & 8.89 & 76.29 \\
$<5$ and $\geq 1$ & 11,003 & 85.67 & 100.00 & & 16,448 & 23.71 & 100.00 \\
\hline Total & 12,844 & 100.00 & 100.00 & & 69,368 & 100.00 & 100.00 \\
\hline \hline
\end{tabular}

Notes: The table shows the number of applicants and their associated patent filings for each applicant portfolio size bracket, based on the extracted dataset of EPO applications filed between 1990-2012 and including at least one Swiss-based inventor or an inventor residing in a G-permit-designated area and a Swiss-based applicant. For example, the first row refers to applicants with more than 1,000 patent applications. There are 5 applicants with a patent portfolio of this size and they are associated to 7,371 applications, accounting for $10.63 \%$ of all the filings the dataset. Similarly, the second row refers to the 7 applicants with a portfolio size greater or equal to 500 and smaller than 1,000 filings, which account for 4,922 patent applications. The last column shows how these two categories combined account for roughly $18 \%$ of all applications in the dataset. 
Table B3: Examples of applicants' disambiguation refinement

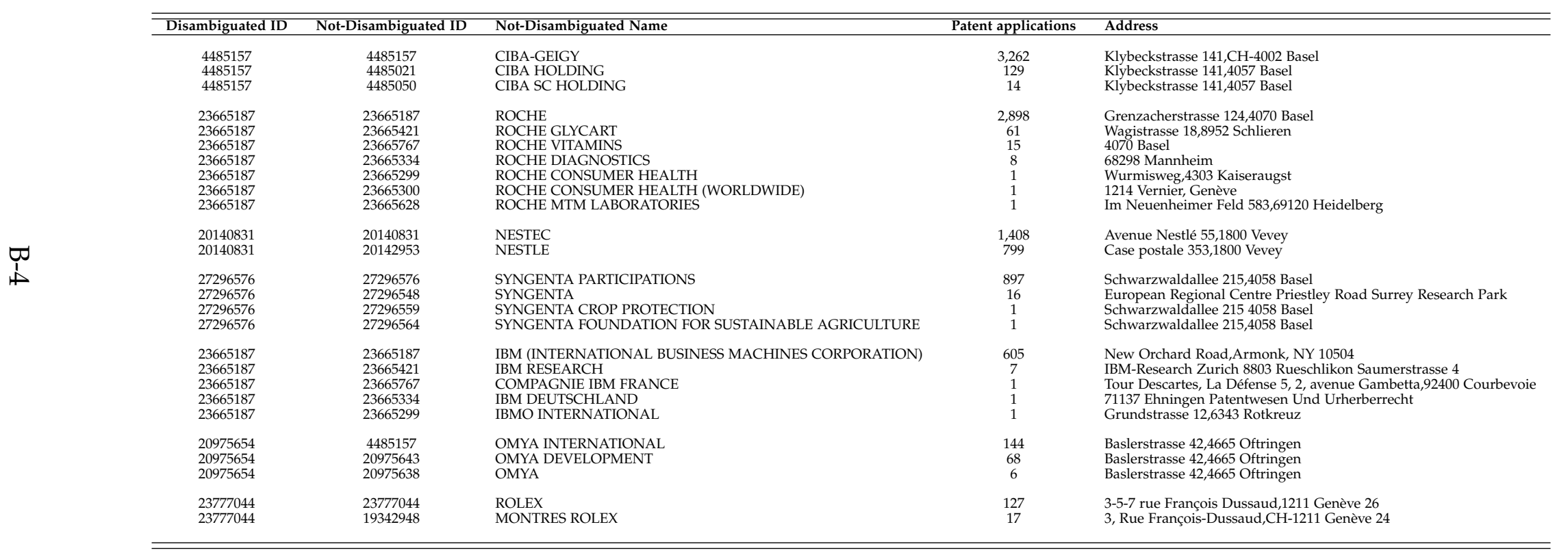

Notes: Disambiguation performed only within the Swiss-invention dataset. Multi-located applicants are taken into account and assigned to multiple location at later stage. 
Table B4: Applicant categories based on inventor-patent instances distribution

\begin{tabular}{|c|c|c|c|c|c|c|}
\hline & \multicolumn{3}{|c|}{ Applicants } & \multicolumn{3}{|c|}{ Patent Applications } \\
\hline & Number & Percentage & $\begin{array}{l}\text { Cumulated } \\
\text { Percentage }\end{array}$ & Number & Percentage & $\begin{array}{l}\text { Cumulated } \\
\text { Percentage }\end{array}$ \\
\hline Single R\&D location candidate & 8,027 & 64.80 & 64.80 & 12,653 & 18.24 & 18.24 \\
\hline Multi R\&D location candidate (hand-check definition) & 175 & 1.41 & 66.21 & 37,843 & 54.55 & 72.79 \\
\hline Multi R\&D location candidate (automatized definition) & 4,185 & 33.79 & 100.00 & 18,872 & 27.21 & 100.00 \\
\hline Total & 12,387 & 100.00 & 100.00 & 69,368 & 100.00 & 100.00 \\
\hline
\end{tabular}

Notes: The table shows the number of applicants and their associated patent filings for each applicant portfolio size bracket, based on the dataset of EPO applications filed between 1990-2012, after the inventors' and applicants' disambiguation stage. 
Figure B1: Single R\&D location candidate: concordance with applicant address MS region

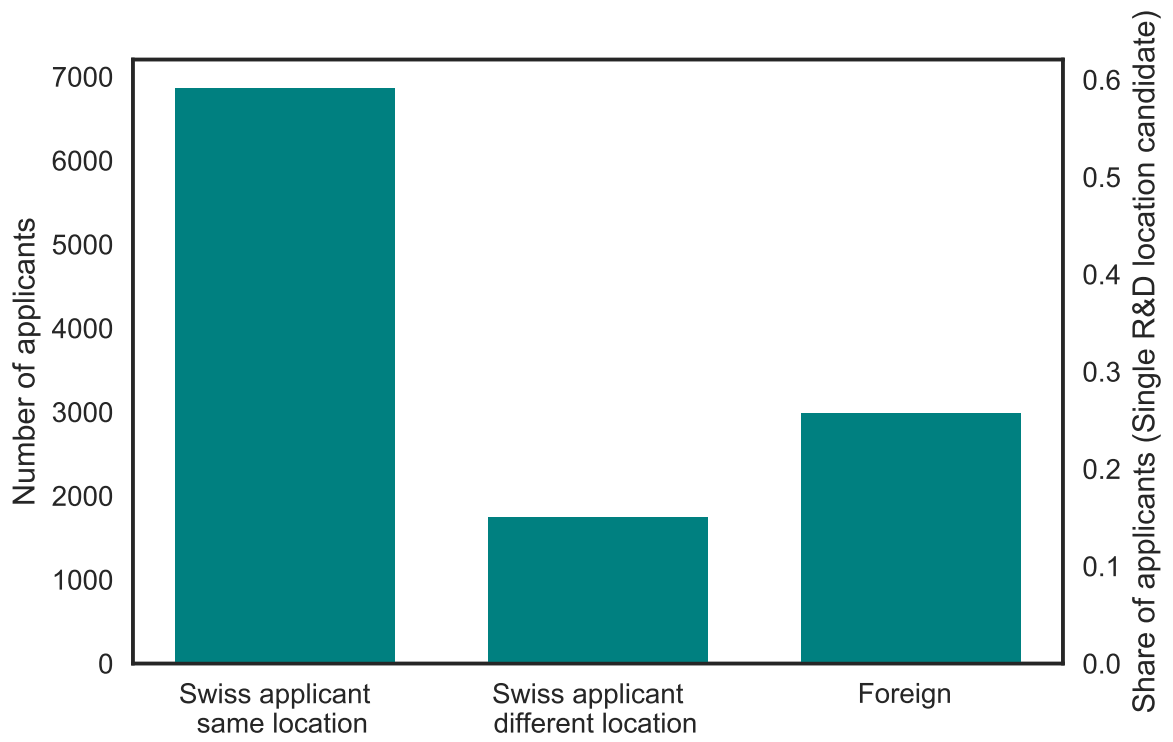

Notes: The figure focus on applicants with a single R\&D location candidate. It shows the concordance between the MS region associated to the applicant's address and the MS region of the candidate R\&D location estimated using the distribution of the applicant's inventor-patent instances across MS regions. In roughly $60 \%$ of the cases the two locations are the same. 
Table B5: Cross-border inventors potential residential districts by MS regions

\begin{tabular}{|c|c|c|c|}
\hline MS region code & MS region name & Canton & CBIs potential districts of residence \\
\hline 1 & Zurich & $\mathrm{ZH}$ & \multirow{22}{*}{$\begin{array}{l}\text { Germany: Biberach, Bodenseekreis, Breisgau-Hochschwarzwald, Freiburg, } \\
\text { Konstanz, Lörrach, Ravensburg, Sigmaringen, Schwarzwald-Baar-Kreis, } \\
\text { Tuttlingen, Waldshut-Tiengen, Kempten (Allgäu), Lindau, Oberallgäu }\end{array}$} \\
\hline 2 & Glattal-Furttal & $\mathrm{ZH}$ & \\
\hline 3 & Limmattal & $\mathrm{ZH}$ & \\
\hline 4 & Knonaueramt & $\mathrm{ZH}$ & \\
\hline 5 & Zimmerberg & $\mathrm{ZH}$ & \\
\hline 6 & Pfannenstiel & $\mathrm{ZH}$ & \\
\hline 7 & Zurcher Oberland & $\mathrm{ZH}$ & \\
\hline 8 & Winterthur & $\mathrm{ZH}$ & \\
\hline 9 & Weinland & $\mathrm{ZH}, \mathrm{SH}$ & \\
\hline 10 & Zurcher Unterland & $\mathrm{ZH}$ & \\
\hline 26 & Luzern & $\mathrm{LU}$ & \\
\hline 27 & Sursee-Seetal & LU & \\
\hline 28 & Willisau & LU & \\
\hline 29 & Entlebuch & LU & \\
\hline 30 & Uri & UR & \\
\hline 34 & Sarneraatal & $\mathrm{OW}$ & \\
\hline 35 & Nidwalden & $\mathrm{NW}, \mathrm{OW}$ & \\
\hline 38 & Zug & ZG & \\
\hline 50 & Schaffhausen & $\mathrm{SH}$ & \\
\hline 76 & Thurtal & TG & \\
\hline 77 & Untersee & TG & \\
\hline 78 & Oberthurgau & TG & \\
\hline 11 & Bern & $\overline{\mathrm{BE}}$ & \multirow{21}{*}{$\begin{array}{l}\text { France: Doubs, Haut-Rhin, Territoire de Belfort } \\
\text { Germany: Biberach, Bodenseekreis, Breisgau-Hochschwarzwald, Freiburg, } \\
\text { Konstanz, Lörrach, Ravensburg, Sigmaringen, Schwarzwald-Baar-Kreis, } \\
\text { Tuttlingen, Waldshut-Tiengen, Kempten (Allgäu), Lindau, Oberallgäu }\end{array}$} \\
\hline 12 & Erlach-Seeland & $\mathrm{BE}$ & \\
\hline 13 & Biel/Bienne & $\mathrm{BE}$ & \\
\hline 14 & Jura bernois & $\mathrm{BE}$ & \\
\hline 15 & Oberaargau & $\mathrm{BE}$ & \\
\hline 16 & Burgdorf & $\mathrm{BE}$ & \\
\hline 17 & Oberes Emmental & $\mathrm{BE}$ & \\
\hline 18 & Aaretal & $\mathrm{BE}$ & \\
\hline 19 & Schwarzwasser & $\mathrm{BE}$ & \\
\hline 20 & Thun & $\mathrm{BE}$ & \\
\hline 21 & Saanen-Obersimmental & $\mathrm{BE}$ & \\
\hline 22 & Kandertal & $\mathrm{BE}$ & \\
\hline 23 & Oberland-Ost & $\mathrm{BE}$ & \\
\hline 24 & Grenchen & $\mathrm{BE}$ & \\
\hline 25 & Laufental & $\mathrm{BL}, \mathrm{SO}$ & \\
\hline 44 & Olten & $\mathrm{SO}$ & \\
\hline 45 & Thal & $\mathrm{SO}$ & \\
\hline 46 & Solothurn & $\mathrm{SO}$ & \\
\hline 47 & Basel-Stadt & BS & \\
\hline 48 & Unteres Baselbiet & $\mathrm{BL}$ & \\
\hline 49 & Oberes Baselbiet & $\mathrm{BL}$ & \\
\hline 31 & Innerschwyz & SZ, LU & \multirow{14}{*}{$\begin{array}{l}\text { Austria: Bludenz, Bregenz, Dornbirn, Feldkirch, Landeck } \\
\text { Germany: Biberach, Bodenseekreis, Breisgau-Hochschwarzwald, Freiburg, } \\
\text { Konstanz, Lörrach, Ravensburg, Sigmaringen, Schwarzwald-Baar-Kreis, } \\
\text { Tuttlingen, Waldshut-Tiengen, Kempten (Allgäu), Lindau, Oberallgäu }\end{array}$} \\
\hline 32 & Einsiedeln & SZ & \\
\hline 33 & March & SZ & \\
\hline 36 & Glarner Unterland & GL & \\
\hline 37 & Glarner Hinterland & GL & \\
\hline 51 & Appenzell A. Rh. & AR, AI & \\
\hline 52 & Appenzell I. Rh. & AI & \\
\hline 53 & St.Gallen & SG & \\
\hline 54 & Rheintal & SG & \\
\hline 55 & Werdenberg & SG & \\
\hline 56 & Sarganserland & SG, GL & \\
\hline 57 & Linthgebiet & SG & \\
\hline 58 & Toggenburg & $\mathrm{SG}$ & \\
\hline 59 & Wil & $\mathrm{SG}, \mathrm{TG}$ & \\
\hline 39 & La Sarine & FR & \multirow{5}{*}{ France: Doubs, Haut-Rhin, Haute-Savoie, Territoire de Belfort } \\
\hline 40 & La Gruyere & FR & \\
\hline 41 & Sense & FR & \\
\hline 42 & Murten/Morat & FR, BE & \\
\hline 43 & Glane-Veveyse & FR & \\
\hline 60 & Chur & GR & \multirow{4}{*}{ Austria: Bludenz, Bregenz, Dornbirn, Feldkirch, Landeck } \\
\hline 61 & Prattigau & GR & \\
\hline 62 & Davos & GR & \\
\hline 63 & Schanfigg & GR & \\
\hline 64 & Mittelbunden & GR & \multirow{5}{*}{ Italy: Como, Sondrio } \\
\hline 65 & Viamala & GR & \\
\hline 66 & Surselva & GR & \\
\hline 68 & Oberengadin & GR & \\
\hline 69 & Mesolcina & GR & \\
\hline
\end{tabular}




\begin{tabular}{|c|c|c|c|}
\hline 67 & Engiadina Bassa & GR & $\begin{array}{l}\text { Austria: Bludenz, Bregenz, Dornbirn, Feldkirch, Landeck } \\
\text { Italy: Bolzano, Como, Sondrio }\end{array}$ \\
\hline 70 & Aarau & AG, LU & \multirow{6}{*}{$\begin{array}{l}\text { France: Haut-Rhin } \\
\text { Germany: Biberach, Bodenseekreis, Breisgau-Hochschwarzwald, Freiburg, } \\
\text { Konstanz, Lörrach, Ravensburg, Sigmaringen, Schwarzwald-Baar-Kreis, } \\
\text { Tuttlingen, Waldshut-Tiengen, Kempten (Allgäu), Lindau, Oberallgäu }\end{array}$} \\
\hline 71 & Brugg-Zurzach & AG & \\
\hline 72 & Baden & AG & \\
\hline 73 & Mutschellen & AG & \\
\hline 74 & Freiamt & AG & \\
\hline 75 & Fricktal & AG & \\
\hline 79 & Tre Valli & TI & \multirow{5}{*}{ Italy: Como, Lecco, Varese, Verbania-Cusio-Ossola } \\
\hline 80 & Locarno & $\mathrm{TT}$ & \\
\hline 81 & Bellinzona & $\mathrm{TI}$ & \\
\hline 82 & Lugano & $\mathrm{TI}$ & \\
\hline 83 & Mendrisio & TT & \\
\hline 84 & Lausanne & VD & \multirow{11}{*}{ France: Ain, Doubs, Haute-Savoie, Jura } \\
\hline 85 & Morges & VD & \\
\hline 86 & Nyon & VD & \\
\hline 87 & Vevey & VD & \\
\hline 88 & Aigle & VD & \\
\hline 89 & Pays-d'Enhaut & VD & \\
\hline 90 & Gros-de-Vaud & VD & \\
\hline 91 & Yverdon & VD & \\
\hline 92 & La Vallee & VD & \\
\hline 93 & La Broye & VD, FR & \\
\hline 105 & Geneve & GE & \\
\hline 94 & Goms & VS & \multirow{4}{*}{ Italy: Verbania-Cusio-Ossola } \\
\hline 95 & Brig & VS & \\
\hline 96 & Visp & VS & \\
\hline 97 & Leuk & VS & \\
\hline 98 & Sierre & VS & \multirow{4}{*}{$\begin{array}{l}\text { France: Haute-Savoie } \\
\text { Italy: Aosta }\end{array}$} \\
\hline 99 & Sion & VS & \\
\hline 100 & Martigny & VS & \\
\hline 101 & Monthey & VS & \\
\hline 102 & Neuchatel & $\mathrm{NE}$ & \multirow{3}{*}{ France: Doubs, Jura, Territoire de Belfort } \\
\hline 103 & La Chaux-de-Fonds & NE, BE & \\
\hline 104 & Val-de-Travers & $\mathrm{NE}$ & \\
\hline 106 & Jura & $\mathrm{JU}$ & $\begin{array}{l}\text { France: Doubs, Haut-Rhin, Territoire de Belfort } \\
\text { Germany: Biberach, Bodenseekreis, Breisgau-Hochschwarzwald, Freiburg, } \\
\text { Konstanz, Lörrach, Ravensburg, Sigmaringen, Schwarzwald-Baar-Kreis, } \\
\text { Tuttlingen, Waldshut-Tiengen }\end{array}$ \\
\hline
\end{tabular}


Table B6: MS regions driving distance to closest border crossing

\begin{tabular}{|c|c|c|c|c|}
\hline \multirow[b]{2}{*}{ MS region code } & \multirow[b]{2}{*}{ MS region name } & \multicolumn{2}{|c|}{ Driving distance (minutes) } & \multirow[b]{2}{*}{ Category } \\
\hline & & Municipalities average & Centroid & \\
\hline 54 & Rheintal & 4 & 6 & 0-20 minutes (Border Region) \\
\hline 47 & Basel-Stadt & 4.333333 & 4 & 0-20 minutes (Border Region) \\
\hline 105 & Geneve & 5.155556 & 12 & 0-20 minutes (Border Region) \\
\hline 92 & La Vallee & 6.2 & 8 & 0-20 minutes (Border Region) \\
\hline 50 & Schaffhausen & 6.269231 & 13 & 0-20 minutes (Border Region) \\
\hline 77 & Untersee & 8.047619 & 15 & 0-20 minutes (Border Region) \\
\hline 48 & Unteres Baselbiet & 9.058824 & 10 & 0-20 minutes (Border Region) \\
\hline 104 & Val-de-Travers & 9.333333 & 10 & 0-20 minutes (Border Region) \\
\hline 83 & Mendrisio & 9.588235 & 20 & 0-20 minutes (Border Region) \\
\hline 55 & Werdenberg & 10.16667 & 11 & 0-20 minutes (Border Region) \\
\hline 9 & Weinland & 11.24 & 9 & 0-20 minutes (Border Region) \\
\hline 86 & Nyon & 11.9375 & 11 & 0-20 minutes (Border Region) \\
\hline 75 & Fricktal & 11.97143 & 6 & 0-20 minutes (Border Region) \\
\hline 10 & Zurcher Unterland & 12.6 & 10 & 0-20 minutes (Border Region) \\
\hline 71 & Brugg-Zurzach & 15.55556 & 17 & 0-20 minutes (Border Region) \\
\hline 25 & Laufental & 15.61111 & 20 & 0-20 minutes (Border Region) \\
\hline 106 & Jura & 16.26316 & 19 & 0-20 minutes (Border Region) \\
\hline 76 & Thurtal & 16.67857 & 17 & 0-20 minutes (Border Region) \\
\hline 103 & La Chaux-de-Fonds & 17.10526 & 7 & 0-20 minutes (Border Region) \\
\hline 82 & Lugano & 17.42553 & 19 & 0-20 minutes (Border Region) \\
\hline 85 & Morges & 18.73913 & 19 & 0-20 minutes (Border Region) \\
\hline 49 & Oberes Baselbiet & 20.01786 & 19 & 0-20 minutes (Border Region) \\
\hline 78 & Oberthurgau & 20.06471 & 20 & 0-20 minutes (Border Region) \\
\hline 72 & Baden & 21.4375 & 24 & $>20$ minutes (Border Region) \\
\hline 101 & Monthey & 22.15385 & 26 & $>20$ minutes (Border Region) \\
\hline 51 & Appenzell A. Rh. & 22.33333 & 31 & $>20$ minutes (Border Region) \\
\hline 53 & St.Gallen & 23.27359 & 24 & $>20$ minutes (Border Region) \\
\hline 52 & Appenzell I. Rh. & 25.6 & 34 & $>20$ minutes (Border Region) \\
\hline 2 & Glattal-Furttal & 26.05 & 21 & $>20$ minutes (Border Region) \\
\hline 91 & Yverdon & 26.36735 & 27 & $>20$ minutes (Border Region) \\
\hline 56 & Sarganserland & 26.4 & 37 & $>20$ minutes (Border Region) \\
\hline 8 & Winterthur & 27.04348 & 34 & $>20$ minutes (Border Region) \\
\hline 1 & Zurich & 28 & 25 & $>20$ minutes (Border Region) \\
\hline 102 & Neuchatel & 30.29167 & 21 & $>20$ minutes (Border Region) \\
\hline 59 & Wil & 31.08696 & 31 & $>20$ minutes (Border Region) \\
\hline 88 & Aigle & 32 & 40 & $>20$ minutes (Border Region) \\
\hline 68 & Oberengadin & 32.92857 & 62 & $>20$ minutes (Border Region) \\
\hline 84 & Lausanne & 33.95833 & 35 & $>20$ minutes (Border Region) \\
\hline 3 & Limmattal & 34.18182 & 32 & $>20$ minutes (Border Region) \\
\hline 87 & Vevey & 35.625 & 32 & $>20$ minutes (Border Region) \\
\hline 73 & Mutschellen & 36.52 & 39 & $>20$ minutes (Border Region) \\
\hline 80 & Locarno & 37.62857 & 35 & $>20$ minutes (Border Region) \\
\hline 70 & Aarau & 38.58209 & 37 & $>20$ minutes (Border Region) \\
\hline 81 & Bellinzona & 39.4375 & 35 & $>20$ minutes (Border Region) \\
\hline 65 & Viamala & 40.68 & 45 & $>20$ minutes (Border Region) \\
\hline 14 & Jura bernois & 41.09678 & 49 & $>20$ minutes (Border Region) \\
\hline 67 & Engiadina Bassa & 41.4 & 46 & $>20$ minutes (Border Region) \\
\hline 58 & Toggenburg & 43.4 & 48 & $>20$ minutes (Border Region) \\
\hline 57 & Linthgebiet & 43.875 & 42 & $>20$ minutes (Border Region) \\
\hline 7 & Zurcher Oberland & 44 & 43 & $>20$ minutes (Border Region) \\
\hline 95 & Brig & 44.8 & 38 & $>20$ minutes (Border Region) \\
\hline 45 & Thal & 45 & 42 & $>20$ minutes (Border Region) \\
\hline 6 & Pfannenstiel & 46.91667 & 47 & $>20$ minutes (Border Region) \\
\hline 44 & Olten & 48.44118 & 34 & $>20$ minutes (Border Region) \\
\hline 46 & Solothurn & 58.04878 & 48 & $>20$ minutes (Border Region) \\
\hline 60 & Chur & 63.66667 & 81 & $>20$ minutes (Border Region) \\
\hline 62 & Davos & 64 & 68 & $>20$ minutes (Border Region) \\
\hline 69 & Mesolcina & 64.5 & 46 & $>20$ minutes (Border Region) \\
\hline 96 & Visp & 69.67742 & 74 & $>20$ minutes (Border Region) \\
\hline 63 & Schanfigg & 71.66666 & 114 & $>20$ minutes (Border Region) \\
\hline 94 & Goms & 74 & 75 & $>20$ minutes (Border Region) \\
\hline 97 & Leuk & 76.5 & 67 & $>20$ minutes (Border Region) \\
\hline 61 & Prattigau & 80.41666 & 82 & $>20$ minutes (Border Region) \\
\hline 90 & Gros-de-Vaud & 22.07042 & 16 & Non-border Region \\
\hline 100 & Martigny & 39.68182 & 19 & Non-border Region \\
\hline 36 & Glarner Unterland & 40.5 & 38 & Non-border Region \\
\hline 93 & La Broye & 43.10811 & 42 & Non-border Region \\
\hline 74 & Freiamt & 44.24138 & 53 & Non-border Region \\
\hline 42 & Murten/Morat & 46.5 & 44 & Non-border Region \\
\hline 4 & Knonaueramt & 46.64286 & 46 & Non-border Region \\
\hline 33 & March & 47 & 41 & Non-border Region \\
\hline
\end{tabular}




\begin{tabular}{lccc} 
Zimmerberg & 48.25 & 49 & Non-border Region \\
Erlach-Seeland & 48.58621 & 50 & Non-border Region \\
Biel/Bienne & 50.8333 & 50 & Non-border Region \\
Sursee-Seetal & 51.75 & 59 & Non-border Region \\
Willisau & 52.16667 & 56 & Non-border Region \\
Glane-Veveyse & 54.14286 & 43 & Non-border Region \\
La Sarine & 57.2973 & 55 & Non-border Region \\
Zug & 58.81818 & 64 & Non-border Region \\
Grenchen & 59.1 & 48 & Non-border Region \\
Luzern & 59.90476 & 58 & Non-border Region \\
Glarner Hinterland & 60 & 76 & Non-border Region \\
Tre Valli & 61.8 & 66 & Non-border Region \\
Mittelbunden & 62.3125 & 70 & Non-border Region \\
Sion & 64.88889 & 73 & Non-border Region \\
Einsiedeln & 65.28571 & 66 & Non-border Region \\
Bern & 65.53333 & 62 & Non-border Region \\
Oberaargau & 68.22916 & 70 & Non-border Region \\
La Gruyere & 68.36 & 51 & Non-border Region \\
Sierre & 69 & 79 & Non-border Region \\
Sense & 69.42105 & 71 & Non-border Region \\
Innerschwyz & 72 & 73 & Non-border Region \\
Pays-d'Enhaut & 72.66666 & 67 & Non-border Region \\
Burgdorf & 75.33334 & 79 & Non-border Region \\
Nidwalden & 77.58334 & 78 & Non-border Region \\
Schwarzwasser & 78.5 & 83 & Non-border Region \\
Aaretal & 79 & 76 & Non-border Region \\
Surselva & 80 & 110 & Non-border Region \\
Entlebuch & 80.14286 & 83 & Non-border Region \\
Sarneraatal & 84.66666 & 78 & Non-border Region \\
Thun & 88.22222 & 88 & Non-border Region \\
Oberes Emmental & 94.9 & 98 & Non-border Region \\
Uri & 95.65 & 104 & Non-border Region \\
Kandertal & 103.2 & 100 & Non-border Region \\
Oberland-Ost & 112.1429 & 143 & Non-border Region \\
Saanen-Obersimmental & 1221 & 37 & Non-border Region \\
\hline
\end{tabular}




\section{Additional descriptive evidence}

Figure C1: Permit G holders by department or district of residence (post-AFMP)

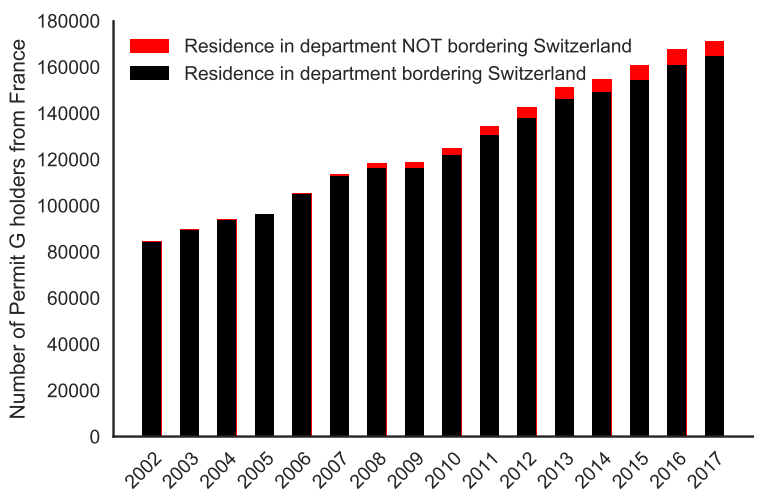

(a) French residents

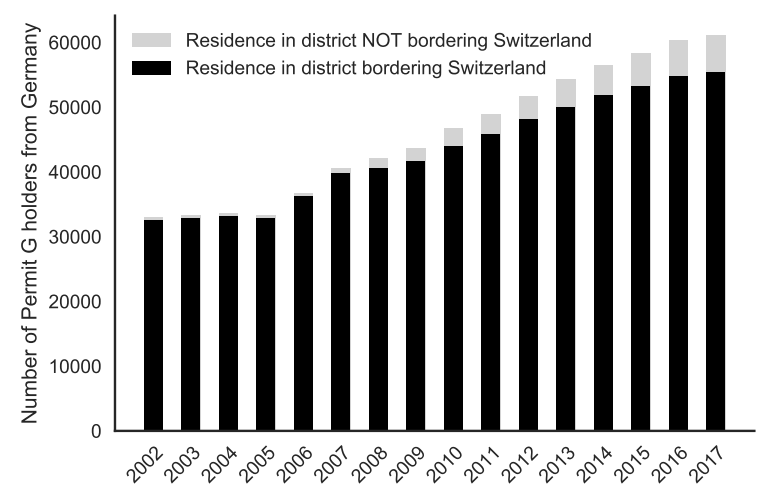

(b) German residents

Notes: The two graphs show the evolution of all Permit G holders working in Switzerland and residing in France (a) and Germany (b), distinguishing between those resident in a department ("Département", France) or district ("Landkreis", Germany) directly bordering Switzerland and those resident in departments/districts not directly bordering Switzerland. The graphs are based on official statistics from the Swiss Federal Statistical Office (FSO) and available at https://www.bfs.admin.ch/bfs/en/home/statistics/ work-income/surveys/ccs.assetdetail.7937.html (last visited: August 2020). Only information on Permit G holders residing in France and Germany was released.

Figure C2: Number of active Cross-Border Inventors (CBIs), per year. Patent-based vs. ZEMISbased definition

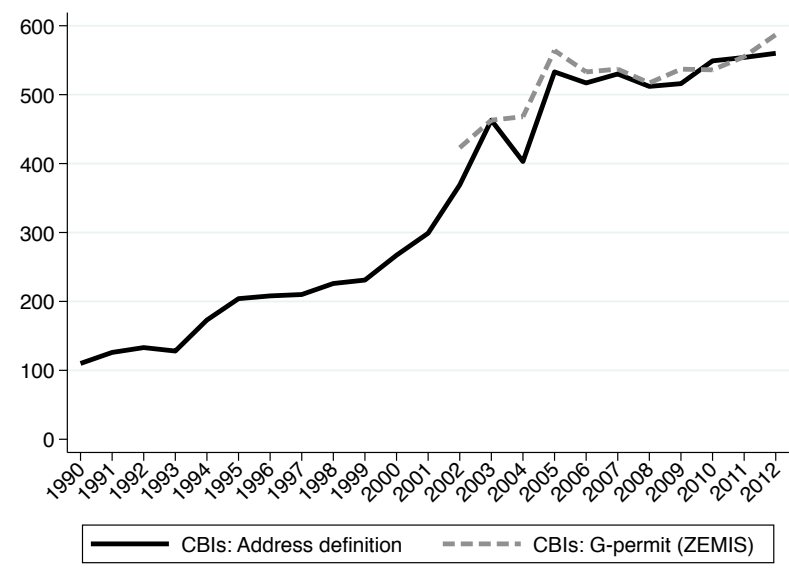

Notes: Number of CBIs active in the whole of Switzerland, as per patents filed in a given year. The patent-based definition is based on comparing each inventor's address, as reported on his/her patent, with the patent's R\&D location, as obtained by inspecting all the inventor and applicant addresses (see section 3.2). The ZEMIS-based definition is based on matching all inventors to Switzerland's entire immigration census data and retaining the positive matches to permit G holders (see section 3.3). 
Figure C3: Spatial distribution of cross-border inventors (CBIs) by municipality of residence, 1990-2012

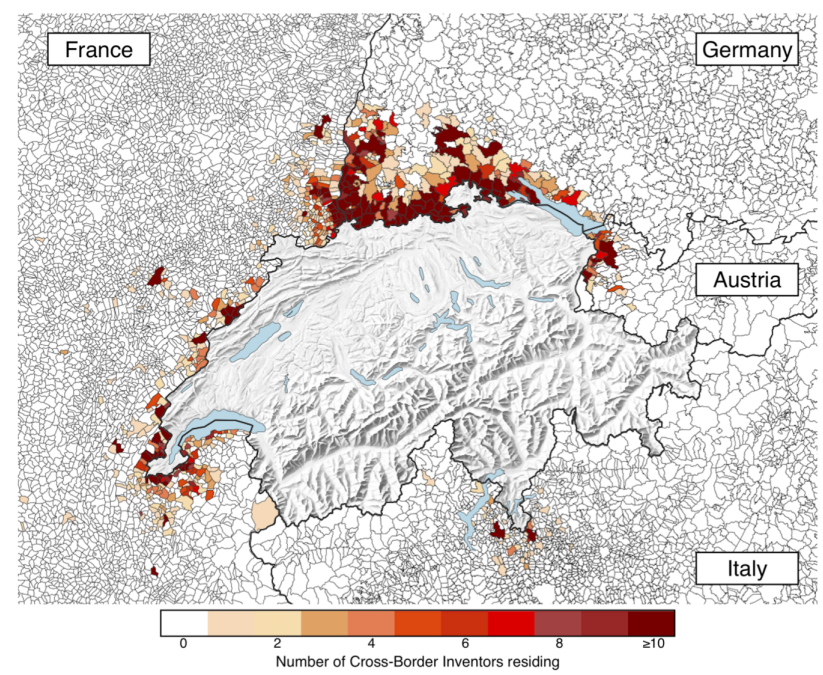

(a) Patent-based definition

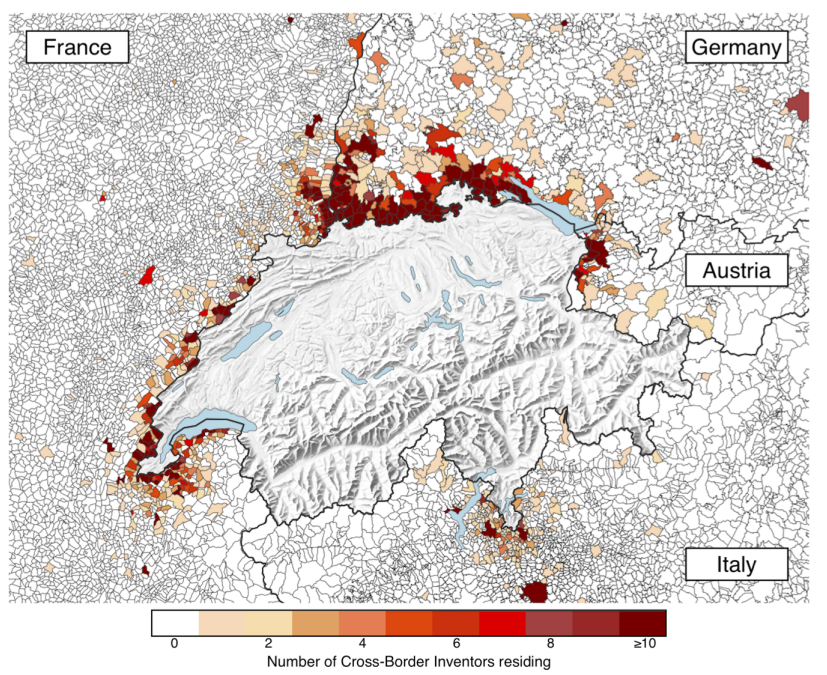

(b) ZEMIS-based definition

Notes: The two maps show the municipalities in Austria, France, Germany, and Italy where CBIs reside, comparing the geographic distribution of the patent-based (a) and the ZEMIS-based (b) CBIs' definition. 
Figure C4: Cross-border inventors (CBIs) characteristics (ZEMIS-based definition, Post-AFMP)

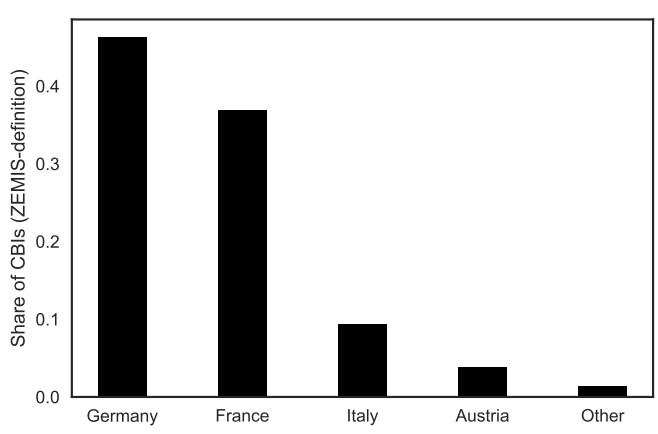

(a) CBIs Nationalities

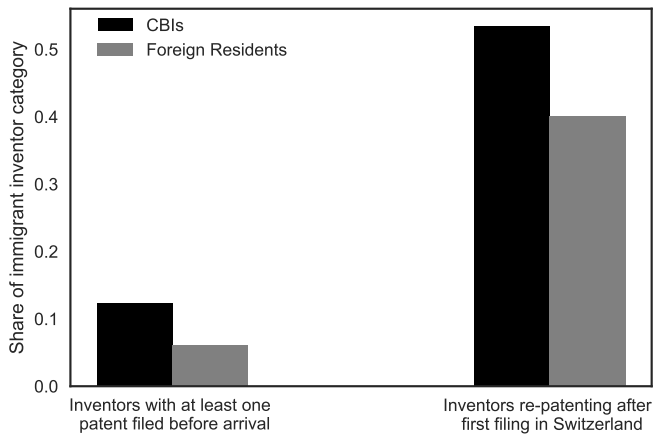

(c) "Experience-at-arrival" and patenting after first Swiss filing

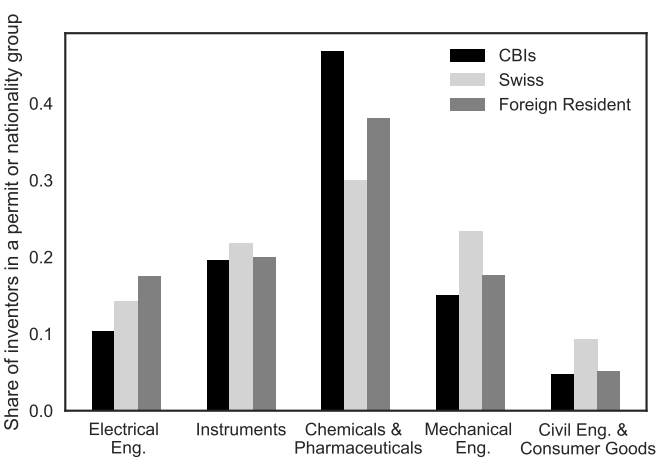

(b) Technologies

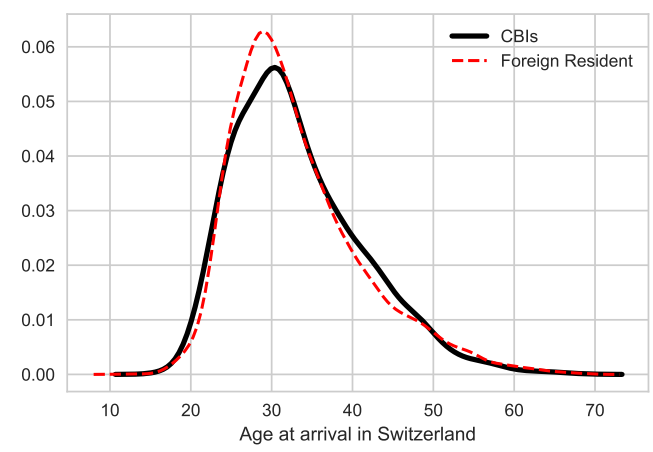

(d) Age at arrival in Switzerland

Notes: Panel (a) depicts CBIs' main nationalities. Panel (b) plots the distribution of active CBIs, Swiss inventors, and foreign resident inventors (B, C, and L permit holders) across five main technology classes (Schmoch (2008)). Panel (c) shows the share of CBIs and foreign resident inventors who filed at least one patent before entering Switzerland and the share of inventors applying for least one additional patent after their first filing in Switzerland. Panel (d) shows the distribution of age at arrival in Switzerland for CBIs and foreign resident inventors. 
Figure C5: MS regions in Switzerland: Patent filings between 1990-1999 (Pre-AFMP)

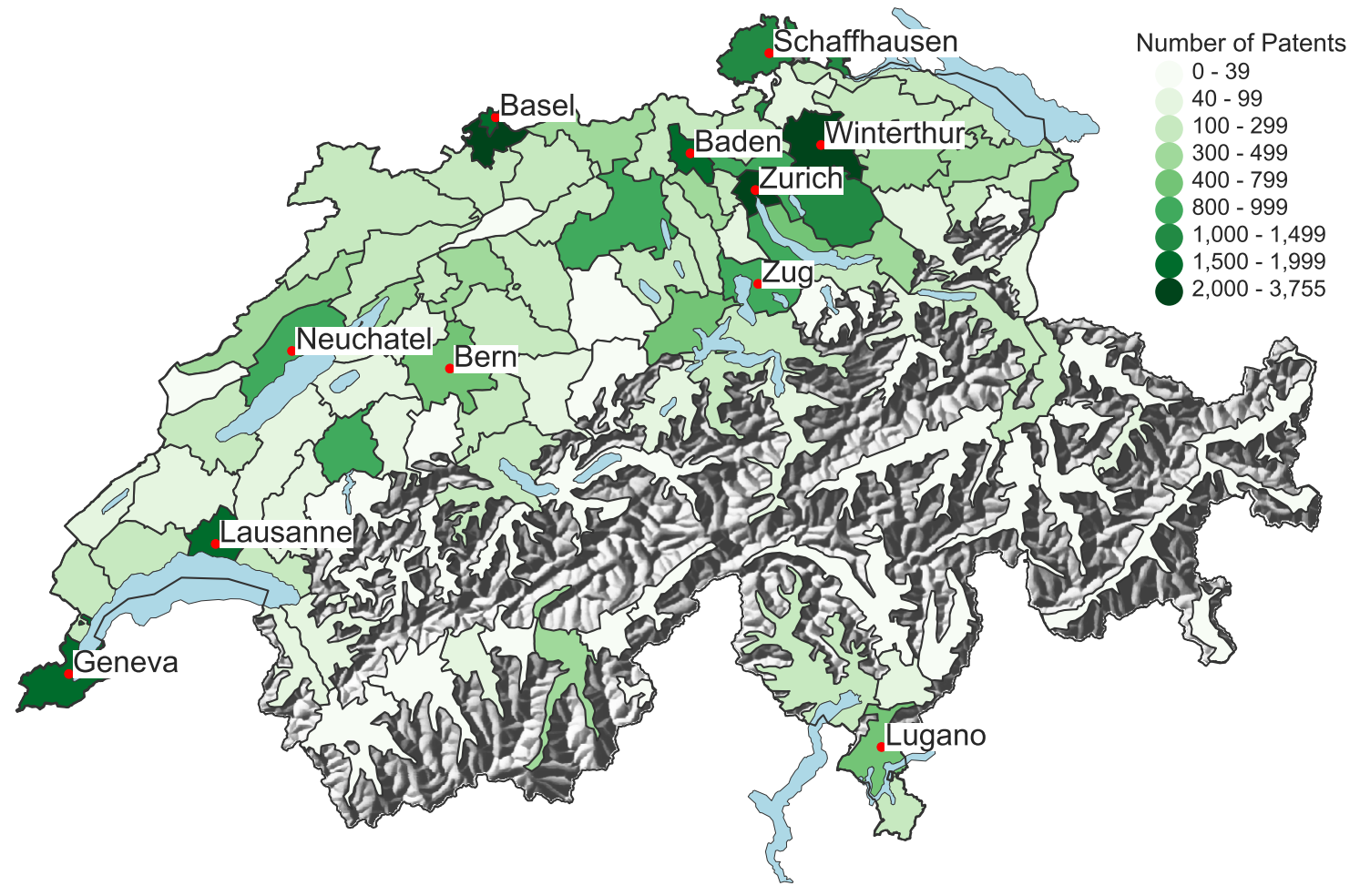

Notes: The map shows MS regions according to the number of patents filed by their R\&D locations between 1990-1999, before the AFMP was signed and introduced. MS regions are plotted in terms of their productive areas, as defined by the Swiss Federal Statistical Office (FSO). This enables a better representation of each MS region's economically active surface with respect to their purely political boundaries. It also shows how the Alps sharply separate many South-Eastern MS regions from neighbouring foreign countries, making them less accessible and more distant than an "as the crow flies" measure might suggest. 
Figure C6: Relationship between applicants inventive workforce and other firm size measures

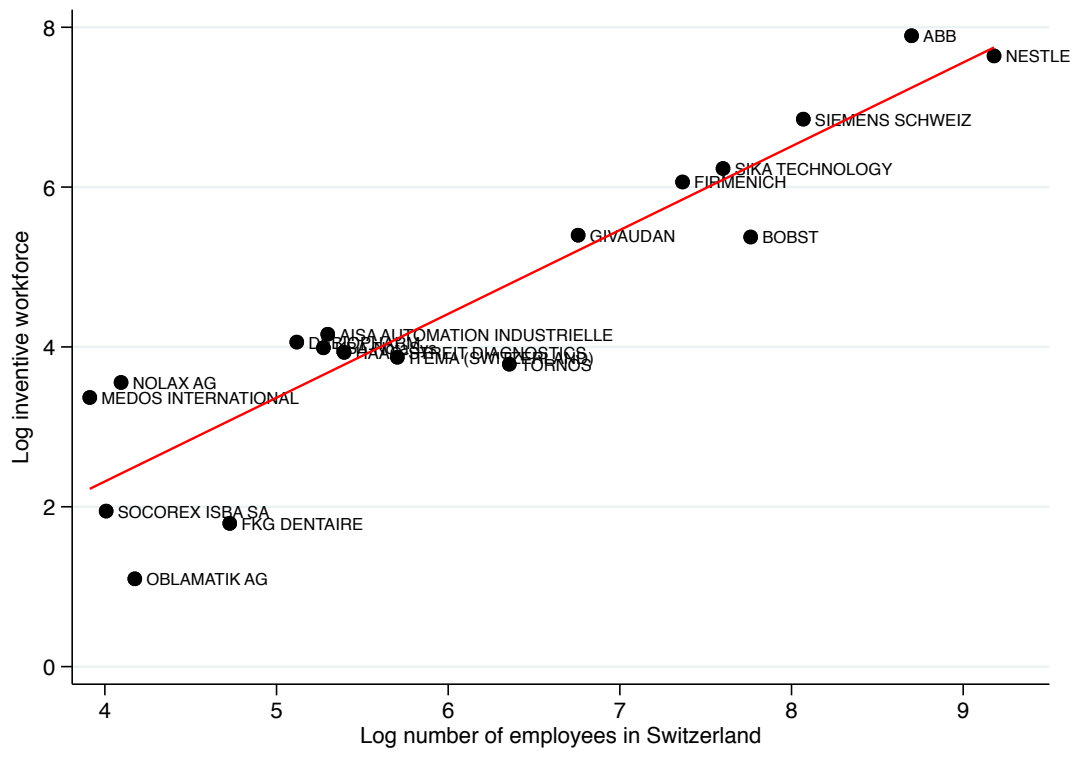

(a) Employees in Switzerland

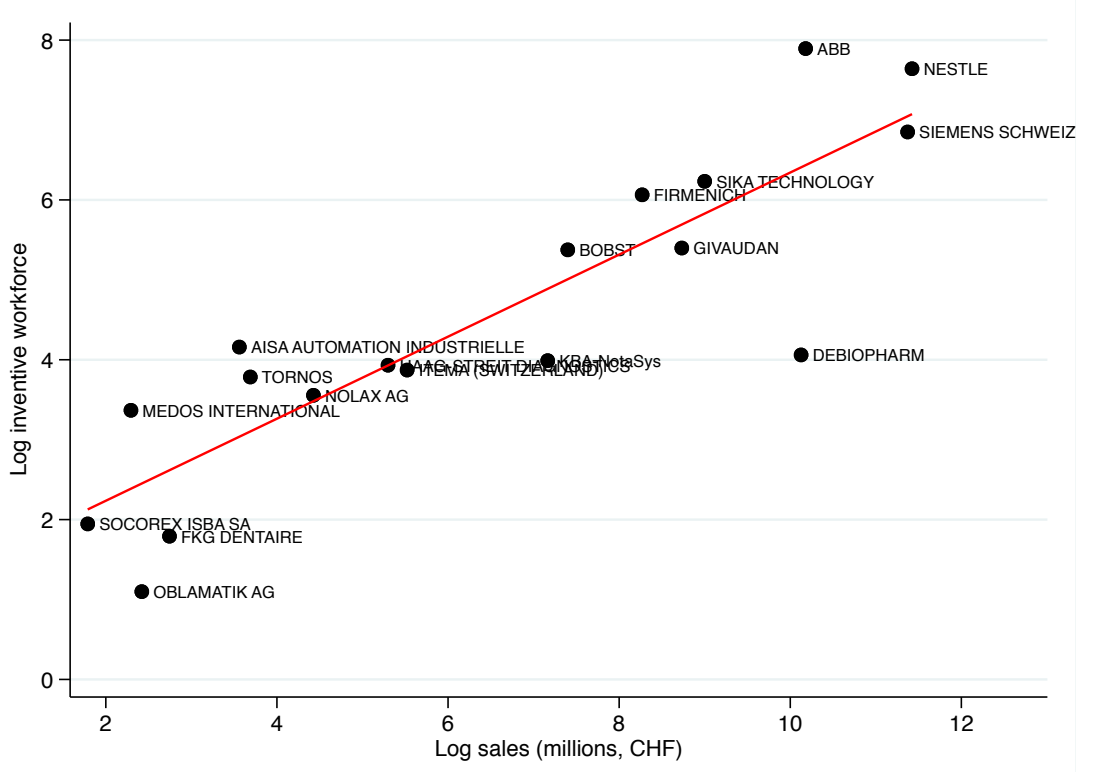

(b) Sales

Notes: Relationship between a given applicant's log inventive workforce and its employees in Switzerland or its sales (millions, CHF), superimposing a linear fit. The variables are shown as their logarithmic transformation. We randomly extracted five applicants for each applicant size category we defined. Data on employees in Switzerland comes from www.swissfirms.ch/en a portal gathering information on firms active in Switzerland obtained from Swiss Chambers of Commerce. Data on sales comes either from companies' official financial statements or from www. dnb. com. In both cases, we considered the latest figures available. 
Figure C7: Cross-border inventors collaborations
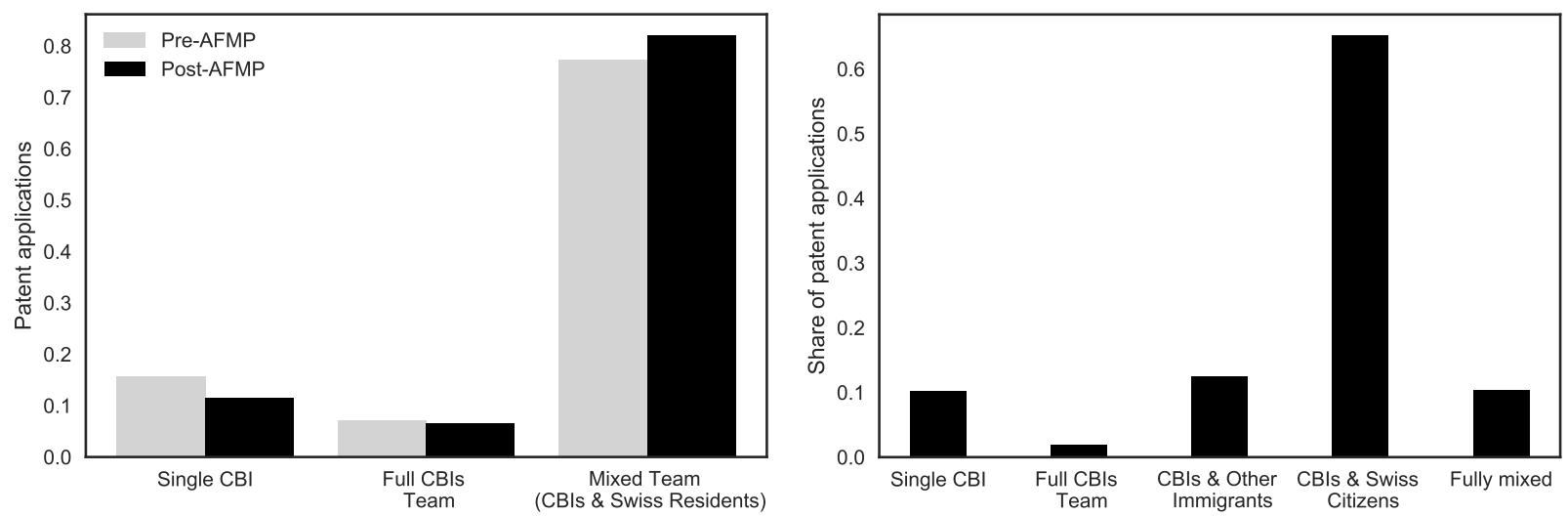

(a) Patent-based definition (Pre- \& Post-AFMP period)(b) ZEMIS-based definition (Post-AFMP period only)

Notes: The graphs show the share of patents listing CBI based on the patent inventor team composition. Panel (a) uses CBIs' patent-based definition and categorizes inventors as CBIs and Swiss Resident inventors (which includes Swiss citizens and resident immigrants). Panel (b) uses a ZEMIS-based definition and is focused only the Post-AFMP period (2000-2012). Inventors are categorized as CBIs (G-permit holders), resident immigrants (B-,C-, and L-permit holders), and Swiss citizens. 
Table C1: Persistent inventors descriptive statistics, by area and period

\begin{tabular}{|c|c|c|c|c|c|c|c|c|c|c|c|c|c|c|c|}
\hline \multirow[b]{3}{*}{$\begin{array}{l}\text { Years active } \\
\text { No. Patents } \\
\text { No. Patents (Year) } \\
\text { No. Co-inventors (Year) } \\
\text { Avg. Citations to CBI-country (Year) } \\
\text { Avg. Forward citations (Year) } \\
\text { Grant rate (Year) }\end{array}$} & \multicolumn{5}{|c|}{ Full (1990-2012) } & \multicolumn{5}{|c|}{ Pre-AFMP (1990-1999) } & \multicolumn{5}{|c|}{ Post-AFMP (2000-2012) } \\
\hline & \multicolumn{5}{|c|}{ Inventor located in 020-BRs } & \multicolumn{5}{|c|}{ Inventor located in $020-B R s$} & \multicolumn{5}{|c|}{ Inventor located in $020-B R s$} \\
\hline & $\begin{array}{l}5.40 \\
9.68 \\
1.79 \\
4.01 \\
1.56 \\
3.71 \\
0.51\end{array}$ & $\begin{array}{c}3.65 \\
10.92 \\
1.4 \\
4.02 \\
2.75 \\
5.81 \\
0.46\end{array}$ & $\begin{array}{c}4 \\
5 \\
1 \\
3 \\
1 \\
2 \\
0.5\end{array}$ & $\begin{array}{l}2 \\
2 \\
1 \\
0 \\
0 \\
0 \\
0\end{array}$ & $\begin{array}{c}21 \\
82 \\
17 \\
36 \\
46 \\
57 \\
1\end{array}$ & $\begin{array}{l}3.51 \\
3.5 \\
1.54 \\
3.20 \\
1.00 \\
3.52 \\
0.60\end{array}$ & $\begin{array}{l}1.81 \\
4.20 \\
1.01 \\
2.85 \\
1.51 \\
5.76 \\
0.46\end{array}$ & $\begin{array}{c}3 \\
2 \\
1 \\
3 \\
0.34 \\
2 \\
1\end{array}$ & $\begin{array}{l}2 \\
1 \\
1 \\
0 \\
0 \\
0 \\
0\end{array}$ & $\begin{array}{l}10 \\
45 \\
10 \\
20 \\
15 \\
57 \\
1\end{array}$ & $\begin{array}{l}4.29 \\
6.26 \\
1.97 \\
4.56 \\
1.95 \\
3.85 \\
0.44\end{array}$ & $\begin{array}{l}2.60 \\
8.92 \\
1.72 \\
4.59 \\
3.31 \\
5.84 \\
0.45\end{array}$ & $\begin{array}{c}3 \\
3 \\
1 \\
3 \\
1 \\
2 \\
0.34\end{array}$ & $\begin{array}{l}2 \\
1 \\
1 \\
0 \\
0 \\
0 \\
0\end{array}$ & $\begin{array}{c}13 \\
73 \\
17 \\
36 \\
46 \\
44.67 \\
1\end{array}$ \\
\hline & \multicolumn{5}{|c|}{ Inventor located in 20plus-BRs } & \multicolumn{5}{|c|}{ Inventor located in 20 plus-BRs } & \multicolumn{5}{|c|}{ Inventor located in 20plus-BRs } \\
\hline
\end{tabular}

Notes: The table reports descriptive statistics for peristent inventors, according to their location (those in 020-BRs vs. those in 20plus-BRs) and period (full dataset 1990-2012; pre-AFMP period; post-AFMP period). The number of peristent inventors is 2,076. Those active in 020-BRs are 777; those active in 20plus-BRs are 1,299. 
Figure C8: Average number of citations received and average grant rate, per year

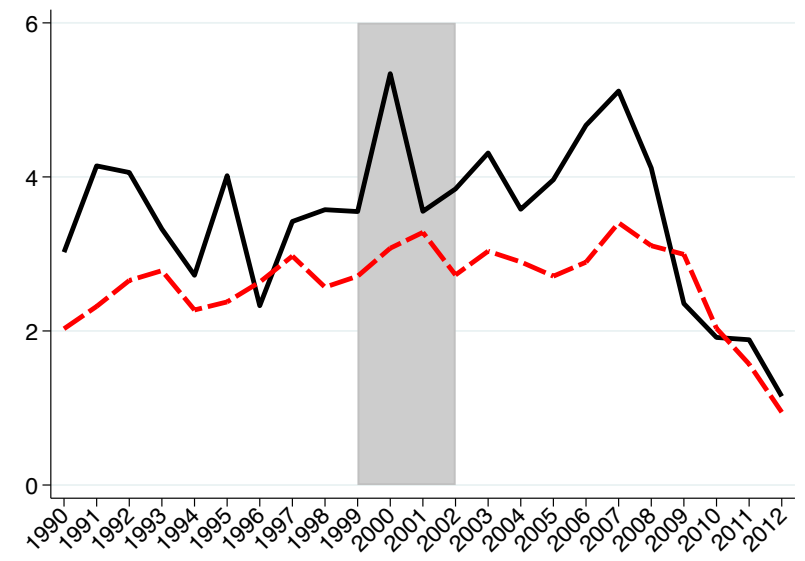

(a) Average number of forward citations (5-year)

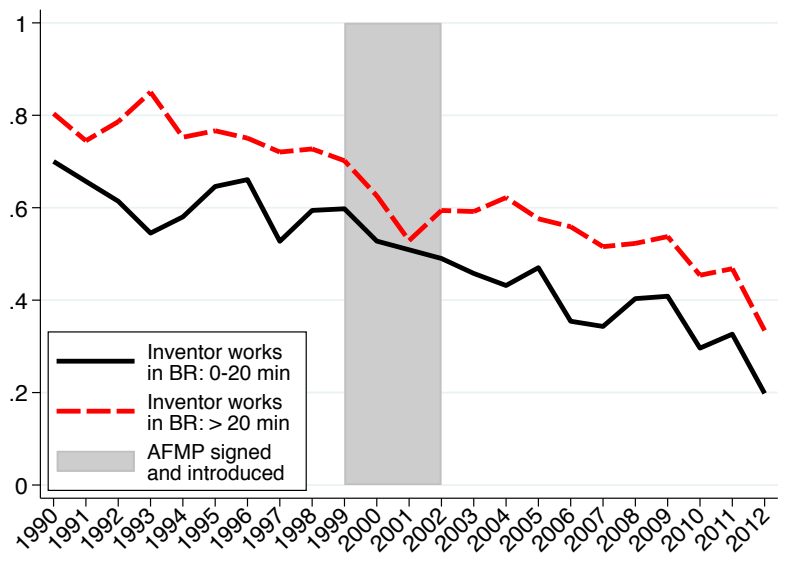

(b) Average grant rate

Notes: Panel (a) shows the average number of citations received (i.e., forward citations, 5-year window) by persistent inventors in different regions, per year. Panel (b) shows the average grant rate for patents by persistent inventors in different regions, per year. 


\section{Additional estimations and robustness checks}

Table D1: Patstat-ZEMIS matched dataset: Probability to patent again after first filing in Switzerland (five years after arrival)

\begin{tabular}{lccccc}
\hline \hline & Full & No "L" & No "C" & No "B" & Only 020-BRs \\
& $(1)$ & $(2)$ & $(3)$ & $(4)$ & $(5)$ \\
\hline CBI & $0.119^{* * *}$ & $0.113^{* * *}$ & $0.121^{* * *}$ & $0.144^{* * *}$ & $0.096^{* * *}$ \\
& $(0.0183)$ & $(0.0190)$ & $(0.0184)$ & $(0.0289)$ & $(0.0264)$ \\
& & & & & \\
& & & & & $0.008^{* *}$ \\
No. pre-migration patents & $0.014^{* * *}$ & $0.013^{* * *}$ & $0.014^{* * *}$ & $0.013^{* * *}$ & $(0.0039)$ \\
& $(0.0029)$ & $(0.0030)$ & $(0.0029)$ & $(0.0037)$ & -0.006 \\
Team size (First Swiss Patent) & 0.003 & 0.003 & 0.003 & 0.002 & $(.0050)$ \\
& $(0.0029)$ & $(0.0032)$ & $(0.0029)$ & $(0.0044)$ & 0.000 \\
Applicant inventive workforce (First Swiss Patent) & $0.00003^{* * *}$ & $0.00003^{* * *}$ & $0.00003^{* * *}$ & 0.00001 & $(0.00000)$ \\
& $(0.0000)$ & $(0.0000)$ & $(0.0000)$ & $(0.00001)$ & 1,649 \\
Observations & & & & & \\
$\mathrm{R}^{2}$ & 4,493 & 3,926 & 4,429 & 1,794 & 0.13 \\
\hline Individual-level controls & 0.10 & 0.10 & 0.10 & 0.15 & $\checkmark$ \\
MS-region dummies (First Swiss Patent) & $\checkmark$ & $\checkmark$ & $\checkmark$ & $\checkmark$ & $\checkmark$ \\
Priority year dummies (First Swiss Patent) & $\checkmark$ & $\checkmark$ & $\checkmark$ & $\checkmark$ & $\checkmark$ \\
Tech. Class dummies (First Swiss Patent) & $\checkmark$ & $\checkmark$ & $\checkmark$ & $\checkmark$ & $\checkmark$ \\
\hline \hline
\end{tabular}

Notes: ${ }^{* * *} \mathrm{p}<0.01,{ }^{* *} \mathrm{p}<0.05,{ }^{*} \mathrm{p}<0.1$. Regressions based on a cross section of all immigrant inventors entering the Swiss labor marker between 2002-2010. The dependent variable is an indicator taking value one if inventor $i$ patents at least once more in Switzerland after the first patent in the country, during the five years following inventor $i$ 's arrival in Switzerland. CBI is an indicator taking value 1 if inventor $i$ 's working-residence permit of entry in Switzerland was the "G" category (cross-border workers). Individuallevel controls include gender, nationality, age-at-first-invention in Switzerland, and a dummy variable taking value 1 if the inventor was born in Switzerland. Robust standard errors are given in parentheses. Linear Probability Models estimated by OLS. 
Table D2: Regional patent count: event-study estimations (Figure 5)

\begin{tabular}{|c|c|c|c|c|c|}
\hline & $\begin{array}{c}\text { Panel (a) } \\
(1) \\
\end{array}$ & $\begin{array}{c}\text { Panel (b) } \\
(2) \\
\end{array}$ & $\begin{array}{c}\text { Panel (c) } \\
(3) \\
\end{array}$ & $\begin{array}{c}\text { Panel (d) } \\
\text { CBI-in-team } \\
(4) \\
\end{array}$ & $\begin{array}{c}\text { Panel }(\mathrm{d}) \\
\text { Residents-only team } \\
(5)\end{array}$ \\
\hline $1990 \times$ Treated & $\begin{array}{c}0.132 \\
(0.2755)\end{array}$ & $\begin{array}{c}-0.468^{*} \\
(0.2567)\end{array}$ & $\begin{array}{c}-0.042 \\
(0.1780)\end{array}$ & $\begin{array}{c}-0.152 \\
(0.5463)\end{array}$ & $\begin{array}{c}0.200 \\
(0.2309)\end{array}$ \\
\hline $1991 \times$ Treated & $\begin{array}{c}0.156 \\
(0.2140)\end{array}$ & $\begin{array}{c}-0.211 \\
(0.1631)\end{array}$ & $\begin{array}{c}-0.020 \\
(0.1393)\end{array}$ & $\begin{array}{c}0.042 \\
(0.4137)\end{array}$ & $\begin{array}{c}0.192 \\
(0.1761)\end{array}$ \\
\hline $1992 \times$ Treated & $\begin{array}{c}0.075 \\
(0.2046)\end{array}$ & $\begin{array}{c}-0.216 \\
(0.1779)\end{array}$ & $\begin{array}{c}-0.140 \\
(0.1260)\end{array}$ & $\begin{array}{c}-0.063 \\
(0.3833)\end{array}$ & $\begin{array}{c}0.111 \\
(0.1740)\end{array}$ \\
\hline $1993 \times$ Treated & $\begin{array}{c}0.008 \\
(0.1443)\end{array}$ & $\begin{array}{c}-0.203 \\
(0.1633)\end{array}$ & $\begin{array}{c}-0.166 \\
(0.1422)\end{array}$ & $\begin{array}{c}-0.167 \\
(0.2329)\end{array}$ & $\begin{array}{c}0.050 \\
(0.1390)\end{array}$ \\
\hline $1994 \times$ Treated & $\begin{array}{c}0.052 \\
(0.1108)\end{array}$ & $\begin{array}{c}-0.039 \\
(0.1458)\end{array}$ & $\begin{array}{c}-0.172 \\
(0.1249)\end{array}$ & $\begin{array}{c}0.174 \\
(0.1970)\end{array}$ & $\begin{array}{c}0.012 \\
(0.1078)\end{array}$ \\
\hline $1995 \times$ Treated & $\begin{array}{c}0.078 \\
(0.1098)\end{array}$ & $\begin{array}{c}0.009 \\
(0.1642)\end{array}$ & $\begin{array}{c}-0.063 \\
(0.1029)\end{array}$ & $\begin{array}{c}0.223 \\
(0.1371)\end{array}$ & $\begin{array}{c}0.027 \\
(0.1022)\end{array}$ \\
\hline $1996 \times$ Treated & $\begin{array}{c}0.133 \\
(0.1121)\end{array}$ & $\begin{array}{c}0.138 \\
(0.1413)\end{array}$ & $\begin{array}{c}0.056 \\
(0.1104)\end{array}$ & $\begin{array}{c}0.138 \\
(0.1679)\end{array}$ & $\begin{array}{c}0.129 \\
(0.1054)\end{array}$ \\
\hline $1997 \times$ Treated & $\begin{array}{c}0.012 \\
(0.0897)\end{array}$ & $\begin{array}{c}-0.074 \\
(0.0985)\end{array}$ & $\begin{array}{c}0.094 \\
(0.0923)\end{array}$ & $\begin{array}{c}-0.007 \\
(0.1197)\end{array}$ & $\begin{array}{c}0.022 \\
(0.0880)\end{array}$ \\
\hline $1998 \times$ Treated & $\begin{array}{c}-0.105 \\
(0.0725)\end{array}$ & $\begin{array}{l}-0.184^{* *} \\
(0.0826)\end{array}$ & $\begin{array}{c}-0.031 \\
(0.0743)\end{array}$ & $\begin{array}{l}-0.241^{* * *} \\
(0.0869)\end{array}$ & $\begin{array}{c}-0.069 \\
(0.0738)\end{array}$ \\
\hline $2000 \times$ Treated & $\begin{array}{c}0.017 \\
(0.0651)\end{array}$ & $\begin{array}{c}-0.020 \\
(0.0802)\end{array}$ & $\begin{array}{c}0.111 \\
(0.0797)\end{array}$ & $\begin{array}{c}0.023 \\
(0.0981)\end{array}$ & $\begin{array}{c}0.017 \\
(0.0652)\end{array}$ \\
\hline $2001 \times$ Treated & $\begin{array}{c}0.111 \\
(0.0779)\end{array}$ & $\begin{array}{c}0.054 \\
(0.1015)\end{array}$ & $\begin{array}{c}0.166^{*} \\
(0.0896)\end{array}$ & $\begin{array}{c}0.128 \\
(0.1299)\end{array}$ & $\begin{array}{c}0.106 \\
(0.0774)\end{array}$ \\
\hline $2002 \times$ Treated & $\begin{array}{c}0.158^{* *} \\
(0.0749)\end{array}$ & $\begin{array}{c}0.134 \\
(0.0960)\end{array}$ & $\begin{array}{c}0.146 \\
(0.0961)\end{array}$ & $\begin{array}{l}0.332^{* * *} \\
(0.0830)\end{array}$ & $\begin{array}{c}0.103 \\
(0.0776)\end{array}$ \\
\hline $2003 \times$ Treated & $\begin{array}{l}0.346^{* * *} \\
(0.0880)\end{array}$ & $\begin{array}{l}0.402^{* * *} \\
(0.1025)\end{array}$ & $\begin{array}{l}0.332^{* * *} \\
(0.1129)\end{array}$ & $\begin{array}{l}0.730^{* * *} \\
(0.1522)\end{array}$ & $\begin{array}{l}0.202^{* * *} \\
(0.0735)\end{array}$ \\
\hline $2004 \times$ Treated & $\begin{array}{l}0.279 * * * \\
(0.0894)\end{array}$ & $\begin{array}{c}0.274^{* *} \\
(0.1113)\end{array}$ & $\begin{array}{c}0.239 * * \\
(0.1099)\end{array}$ & $\begin{array}{l}0.575^{* * *} \\
(0.1513)\end{array}$ & $\begin{array}{c}0.178^{* *} \\
(0.0999)\end{array}$ \\
\hline $2005 \times$ Treated & $\begin{array}{l}0.407^{* * *} \\
(0.0965)\end{array}$ & $\begin{array}{l}0.427^{* * *} \\
(0.1271)\end{array}$ & $\begin{array}{l}0.321^{* * *} \\
(0.0840)\end{array}$ & $\begin{array}{l}0.778^{* * *} \\
(0.1290)\end{array}$ & $\begin{array}{c}0.269^{* *} \\
(0.1052)\end{array}$ \\
\hline $2006 \times$ Treated & $\begin{array}{l}0.337^{* * *} \\
(0.1231)\end{array}$ & $\begin{array}{c}0.366^{* *} \\
(0.1618)\end{array}$ & $\begin{array}{c}0.229^{* *} \\
(0.1105)\end{array}$ & $\begin{array}{l}0.701^{* * *} \\
(0.1316)\end{array}$ & $\begin{array}{c}0.203^{* *} \\
(0.1027)\end{array}$ \\
\hline $2007 \times$ Treated & $\begin{array}{l}0.330^{* * *} \\
(0.1162)\end{array}$ & $\begin{array}{c}0.390^{* *} \\
(0.1527)\end{array}$ & $\begin{array}{c}0.257^{* *} \\
(0.1159)\end{array}$ & $\begin{array}{l}0.668^{* * *} \\
(0.1566)\end{array}$ & $\begin{array}{c}0.210 \\
(0.1293)\end{array}$ \\
\hline $2008 \times$ Treated & $\begin{array}{c}0.139 \\
(0.0968)\end{array}$ & $\begin{array}{c}0.111 \\
(0.1224)\end{array}$ & $\begin{array}{c}0.171^{*} \\
(0.0995)\end{array}$ & $\begin{array}{l}0.537^{* * *} \\
(0.1706)\end{array}$ & $\begin{array}{c}-0.010 \\
(0.0924)\end{array}$ \\
\hline $2009 \times$ Treated & $\begin{array}{c}0.075 \\
(0.1094)\end{array}$ & $\begin{array}{c}0.044 \\
(0.1279)\end{array}$ & $\begin{array}{c}0.159 \\
(0.1262)\end{array}$ & $\begin{array}{l}0.459^{* * *} \\
(0.1571)\end{array}$ & $\begin{array}{c}-0.074 \\
(0.1241)\end{array}$ \\
\hline $2010 \times$ Treated & $\begin{array}{c}0.097 \\
(0.1247)\end{array}$ & $\begin{array}{c}0.038 \\
(0.1563)\end{array}$ & $\begin{array}{c}0.195 \\
(0.1309)\end{array}$ & $\begin{array}{c}0.428^{*} \\
(0.2420)\end{array}$ & $\begin{array}{c}-0.020 \\
(0.1188)\end{array}$ \\
\hline $2011 \times$ Treated & $\begin{array}{c}0.083 \\
(0.1255)\end{array}$ & $\begin{array}{c}0.041 \\
(0.1443)\end{array}$ & $\begin{array}{c}0.150 \\
(0.1153)\end{array}$ & $\begin{array}{c}0.484^{* *} \\
(0.2243)\end{array}$ & $\begin{array}{c}-0.072 \\
(0.1223)\end{array}$ \\
\hline $2012 \times$ Treated & $\begin{array}{c}0.017 \\
(0.1336)\end{array}$ & $\begin{array}{c}-0.085 \\
(0.1652)\end{array}$ & $\begin{array}{c}0.118 \\
(0.1379)\end{array}$ & $\begin{array}{c}0.475^{* *} \\
(0.2316)\end{array}$ & $\begin{array}{c}-0.165 \\
(0.1292)\end{array}$ \\
\hline Number of MS regions & 63 & 59 & 63 & 63 & 63 \\
\hline Observations & 1,449 & 1,357 & 1,449 & 1,449 & 1,449 \\
\hline Pseudo $\mathrm{R}^{2}$ & 0.88 & 0.87 & 0.83 & 0.90 & 0.87 \\
\hline MS region FE & $\checkmark$ & $\checkmark$ & $\checkmark$ & $\checkmark$ & $\checkmark$ \\
\hline Year FE & $\checkmark$ & $\checkmark$ & $\checkmark$ & $\checkmark$ & $\checkmark$ \\
\hline
\end{tabular}

Notes: ${ }^{* * *} \mathrm{p}<0.01,{ }^{* *} \mathrm{p}<0.05,{ }^{*} \mathrm{p}<0.1$. The dependent variable is the number of patents in MS-region $m$ and year $t$. The treated group includes all MS-regions in the BR whose driving distance from the closest border crossing is below or equal to 20 minutes (BR, 0-20 min). The control group includes all MS-regions in the BR whose driving distance from the closest border crossing in above 20 minutes (BR, > $20 \mathrm{~min})$. Robust standard errors clustered at the MS-region level are given in parentheses. Estimation by Poisson pseudo-maximum-likelihood (PML). 
Figure D1: Regional patent count: event study results (including NBR in the control sample)

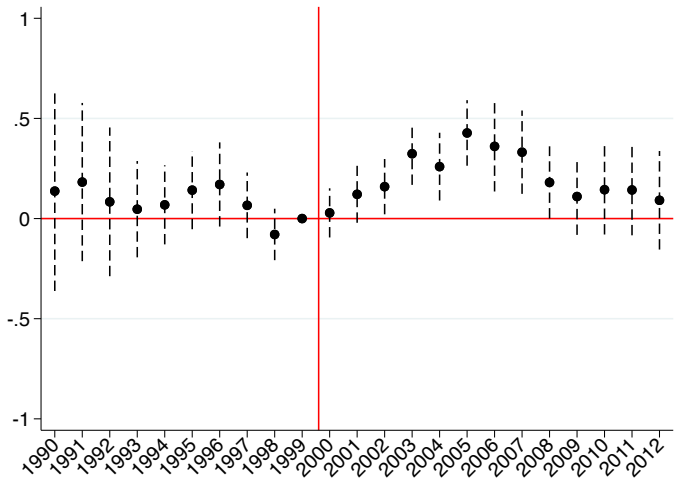

(a) Full sample

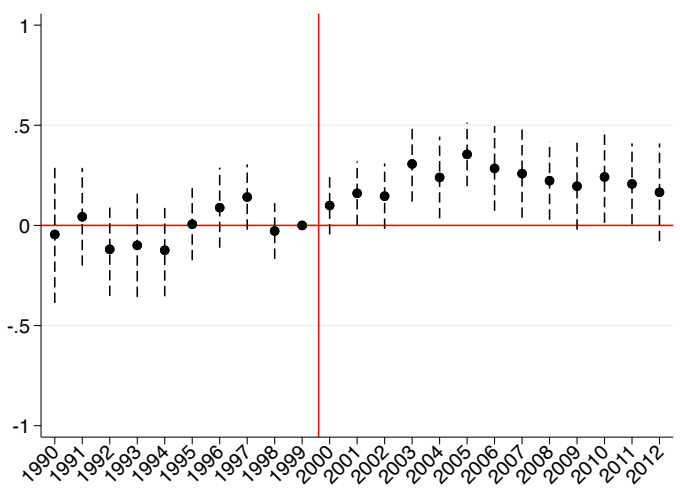

(c) No top applicants

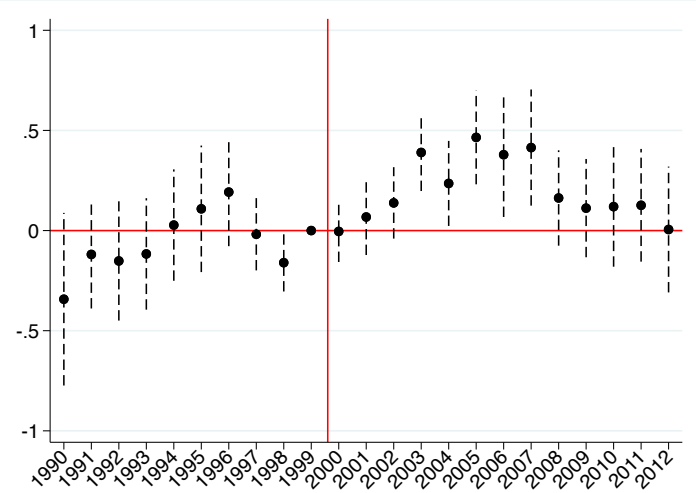

(b) Incumbent applicants only

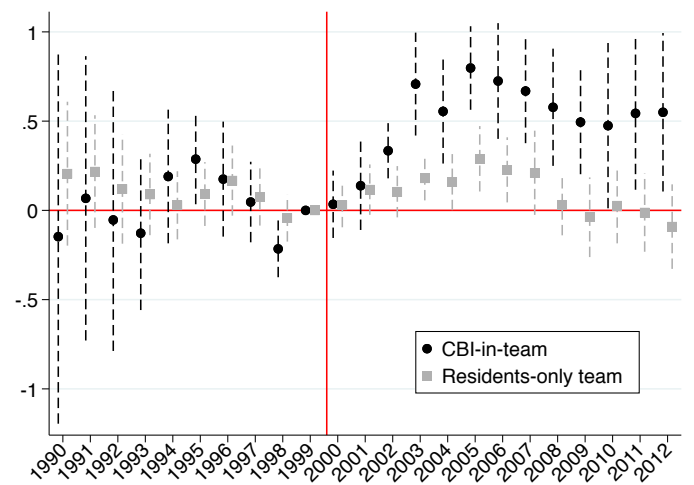

(d) CBI-in-team VS. Resident-only team patents

Notes: The dependent variable is the number of patent filings in MS-region $m$ in year $t$. The treated group includes all MS-regions in the BR whose driving distance from the closest border crossing is below or equal to 20 minutes (BR, 0-20 min). The control group includes all MS-regions in the BR whose driving distance from the closest border crossing in above 20 minutes (BR, > $20 \mathrm{~min}$ ) and all MS regions in the NBR. For the estimations in panel (a) we count all patents. For those in panel (b) we count only patents associated to "incumbent" applicants; for those in panel (c) we exclude patents associated to "top" applicants. For the estimations in panel (d) we decompose each treated MS region's yearly patent output, distinguishing between patents including at least one CBI (CBI-in-team) and patents including only resident inventors (Resident-only team) and running two separate event-study regressions. The estimated parameters related to CBI-in-team patents are shown as black circles. Those related to Resident-only team patents are shown as gray squares. All regressions include MS-region Fixed Effects and Year Fixed Effects. Vertical bars represent 95\% confidence intervals. The coefficient for our baseline year 1999 is set to zero and shown without confidence interval. Robust standard errors are clustered at the MS-region level. Estimation by Poisson pseudo-maximum-likelihood (PML). 
Table D3: Regional patent count: event-study estimations (including NBR in the control sample

\begin{tabular}{|c|c|c|c|c|c|}
\hline & $\begin{array}{c}\text { Panel (a) } \\
\text { (1) }\end{array}$ & $\begin{array}{c}\text { Panel (b) } \\
(2)\end{array}$ & $\begin{array}{c}\text { Panel (c) } \\
\text { (3) }\end{array}$ & $\begin{array}{c}\text { Panel }(\mathrm{d}) \\
\text { CBI-in-team } \\
(4)\end{array}$ & $\begin{array}{c}\text { Panel }(\mathrm{d}) \\
\text { Residents-only team } \\
\text { (5) }\end{array}$ \\
\hline $1990 \times$ Treated & $\begin{array}{c}0.137 \\
(0.2545)\end{array}$ & $\begin{array}{c}-0.343 \\
(0.2199)\end{array}$ & $\begin{array}{c}-0.045 \\
(0.1748)\end{array}$ & $\begin{array}{c}-0.147 \\
(0.5346)\end{array}$ & $\begin{array}{c}0.206 \\
(0.2057)\end{array}$ \\
\hline $1991 \times$ Treated & $\begin{array}{c}0.182 \\
(0.2016)\end{array}$ & $\begin{array}{c}-0.119 \\
(0.1377)\end{array}$ & $\begin{array}{c}0.043 \\
(0.1246)\end{array}$ & $\begin{array}{c}0.068 \\
(0.4064)\end{array}$ & $\begin{array}{c}0.217 \\
(0.1611)\end{array}$ \\
\hline $1992 \times$ Treated & $\begin{array}{c}0.086 \\
(0.1894)\end{array}$ & $\begin{array}{c}-0.152 \\
(0.1519)\end{array}$ & $\begin{array}{c}-0.119 \\
(0.1190)\end{array}$ & $\begin{array}{c}-0.054 \\
(0.3745)\end{array}$ & $\begin{array}{c}0.120 \\
(0.1562)\end{array}$ \\
\hline $1993 \times$ Treated & $\begin{array}{c}0.047 \\
(0.1227)\end{array}$ & $\begin{array}{c}-0.116 \\
(0.1419)\end{array}$ & $\begin{array}{c}-0.100 \\
(0.1315)\end{array}$ & $\begin{array}{c}-0.128 \\
(0.2196)\end{array}$ & $\begin{array}{c}0.089 \\
(0.1164)\end{array}$ \\
\hline $1994 \times$ Treated & $\begin{array}{c}0.068 \\
(0.1007)\end{array}$ & $\begin{array}{c}0.027 \\
(0.1419)\end{array}$ & $\begin{array}{c}-0.123 \\
(0.1173)\end{array}$ & $\begin{array}{c}0.190 \\
(0.1911)\end{array}$ & $\begin{array}{c}0.028 \\
(0.0974)\end{array}$ \\
\hline $1995 \times$ Treated & $\begin{array}{c}0.142 \\
(0.0996)\end{array}$ & $\begin{array}{c}0.109 \\
(0.1612)\end{array}$ & $\begin{array}{c}0.006 \\
(0.0919)\end{array}$ & $\begin{array}{c}0.288^{* *} \\
(0.1289)\end{array}$ & $\begin{array}{c}0.091 \\
(0.0912)\end{array}$ \\
\hline $1996 \times$ Treated & $\begin{array}{c}0.170 \\
(0.1072)\end{array}$ & $\begin{array}{c}0.192 \\
(0.1378)\end{array}$ & $\begin{array}{c}0.089 \\
(0.1020)\end{array}$ & $\begin{array}{c}0.175 \\
(0.1644)\end{array}$ & $\begin{array}{c}0.167^{*} \\
(0.1002)\end{array}$ \\
\hline $1997 \times$ Treated & $\begin{array}{c}0.066 \\
(0.0837)\end{array}$ & $\begin{array}{c}-0.018 \\
(0.0920)\end{array}$ & $\begin{array}{c}0.142 \\
(0.0833)\end{array}$ & $\begin{array}{c}0.047 \\
(0.1151)\end{array}$ & $\begin{array}{c}0.075 \\
(0.0819)\end{array}$ \\
\hline $1998 \times$ Treated & $\begin{array}{c}-0.079 \\
(0.0655)\end{array}$ & $\begin{array}{l}-0.160^{* *} \\
(0.0735)\end{array}$ & $\begin{array}{c}-0.028 \\
(0.0710)\end{array}$ & $\begin{array}{c}-0.216^{* * *} \\
(0.0811)\end{array}$ & $\begin{array}{c}-0.044 \\
(0.0670)\end{array}$ \\
\hline $2000 \times$ Treated & $\begin{array}{c}0.028 \\
(0.0626)\end{array}$ & $\begin{array}{c}-0.004 \\
(0.0778)\end{array}$ & $\begin{array}{c}0.099 \\
(0.0739)\end{array}$ & $\begin{array}{c}0.034 \\
(0.0963)\end{array}$ & $\begin{array}{c}0.028 \\
(0.0627)\end{array}$ \\
\hline $2001 \times$ Treated & $\begin{array}{c}0.121^{*} \\
(0.0726)\end{array}$ & $\begin{array}{c}0.068 \\
(0.0969)\end{array}$ & $\begin{array}{l}0.160^{* *} \\
(0.0812)\end{array}$ & $\begin{array}{c}0.138 \\
(0.1265)\end{array}$ & $\begin{array}{c}0.116 \\
(0.0720)\end{array}$ \\
\hline $2002 \times$ Treated & $\begin{array}{c}0.159^{* *} \\
(0.0704)\end{array}$ & $\begin{array}{c}0.138 \\
(0.0909)\end{array}$ & $\begin{array}{c}0.146^{*} \\
(0.0832)\end{array}$ & $\begin{array}{l}0.334^{* * *} \\
(0.078))\end{array}$ & $\begin{array}{c}0.105 \\
(0.0733)\end{array}$ \\
\hline $2003 \times$ Treated & $\begin{array}{l}0.324^{* * *} \\
(0.0793)\end{array}$ & $\begin{array}{l}0.390^{* * *} \\
(0.0982)\end{array}$ & $\begin{array}{l}0.307^{* * *} \\
(0.0960)\end{array}$ & $\begin{array}{l}0.708^{* * *} \\
(0.1471)\end{array}$ & $\begin{array}{l}0.180^{* * *} \\
(0.0631)\end{array}$ \\
\hline $2004 \times$ Treated & $\begin{array}{l}0.259^{* * *} \\
(0.0863)\end{array}$ & $\begin{array}{l}0.235^{* *} \\
(0.1083)\end{array}$ & $\begin{array}{l}0.240^{* *} \\
(0.1040)\end{array}$ & $\begin{array}{l}0.555^{* * *} \\
(0.1491)\end{array}$ & $\begin{array}{c}0.158^{* *} \\
(0.0801)\end{array}$ \\
\hline $2005 \times$ Treated & $\begin{array}{l}0.427^{* * *} \\
(0.0835)\end{array}$ & $\begin{array}{l}0.465^{* * *} \\
(0.1195)\end{array}$ & $\begin{array}{l}0.355^{* * *} \\
(0.0809)\end{array}$ & $\begin{array}{l}0.798^{* * *} \\
(0.1194)\end{array}$ & $\begin{array}{l}0.289^{* * *} \\
(0.0935)\end{array}$ \\
\hline $2006 \times$ Treated & $\begin{array}{l}0.360^{* * *} \\
(0.1150)\end{array}$ & $\begin{array}{c}0.379 * * \\
(0.1586)\end{array}$ & $\begin{array}{l}0.285^{* * *} \\
(0.1105)\end{array}$ & $\begin{array}{l}0.725^{* * *} \\
(0.1654)\end{array}$ & $\begin{array}{c}0.227^{* *} \\
(0.0930)\end{array}$ \\
\hline $2007 \times$ Treated & $\begin{array}{l}0.331^{* * *} \\
(0.1062)\end{array}$ & $\begin{array}{l}0.414^{* * *} \\
(0.1479)\end{array}$ & $\begin{array}{c}0.259^{* *} \\
(0.1125)\end{array}$ & $\begin{array}{l}0.669^{* * *} \\
(0.1490)\end{array}$ & $\begin{array}{c}0.211^{*} \\
(0.1203)\end{array}$ \\
\hline $2008 \times$ Treated & $\begin{array}{c}0.181^{*} \\
(0.0920)\end{array}$ & $\begin{array}{c}0.163 \\
(0.1215)\end{array}$ & $\begin{array}{c}0.223^{* *} \\
(0.0996)\end{array}$ & $\begin{array}{l}0.578^{* * *} \\
(0.1675)\end{array}$ & $\begin{array}{c}0.031 \\
(0.0873)\end{array}$ \\
\hline $2009 \times$ Treated & $\begin{array}{c}0.110 \\
(0.0977)\end{array}$ & $\begin{array}{c}0.112 \\
(0.1252)\end{array}$ & $\begin{array}{c}0.196^{*} \\
(0.1107)\end{array}$ & $\begin{array}{l}0.495^{* * *} \\
(0.1490)\end{array}$ & $\begin{array}{c}-0.038 \\
(0.1138)\end{array}$ \\
\hline $2010 \times$ Treated & $\begin{array}{c}0.144 \\
(0.1142)\end{array}$ & $\begin{array}{c}0.119 \\
(0.1530)\end{array}$ & $\begin{array}{c}0.242^{* *} \\
(0.1172)\end{array}$ & $\begin{array}{c}0.475^{* *} \\
(0.2362)\end{array}$ & $\begin{array}{c}0.026 \\
(0.1078)\end{array}$ \\
\hline $2011 \times$ Treated & $\begin{array}{c}0.142 \\
(0.1142)\end{array}$ & $\begin{array}{c}0.126 \\
(0.1436)\end{array}$ & $\begin{array}{l}0.207^{* *} \\
(0.1033)\end{array}$ & $\begin{array}{c}0.544^{* *} \\
(0.2184)\end{array}$ & $\begin{array}{c}-0.012 \\
(0.1121)\end{array}$ \\
\hline $2012 \times$ Treated & $\begin{array}{c}0.091 \\
(0.1255)\end{array}$ & $\begin{array}{c}0.005 \\
(0.1603)\end{array}$ & $\begin{array}{c}0.166 \\
(0.1244)\end{array}$ & $\begin{array}{c}0.550^{* *} \\
(0.2265)\end{array}$ & $\begin{array}{c}-0.091 \\
(0.1208)\end{array}$ \\
\hline Number of MS regions & 106 & 95 & 106 & 106 & 106 \\
\hline Observations & 2,438 & 2,185 & 2,438 & 2,438 & 2,438 \\
\hline Pseudo $\mathrm{R}^{2}$ & 0.88 & 0.87 & 0.82 & 0.88 & 0.86 \\
\hline $\begin{array}{l}\text { MS region FE } \\
\text { Year FE }\end{array}$ & $\begin{array}{l}\checkmark \\
\checkmark\end{array}$ & $\begin{array}{l}\checkmark \\
\checkmark\end{array}$ & $\begin{array}{l}\checkmark \\
\checkmark\end{array}$ & $\begin{array}{l}\checkmark \\
\checkmark\end{array}$ & $\begin{array}{l}\checkmark \\
\checkmark\end{array}$ \\
\hline
\end{tabular}

Notes: ${ }^{* * *} \mathrm{p}<0.01,{ }^{* *} \mathrm{p}<0.05,{ }^{*} \mathrm{p}<0.1$. The dependent variable is the number of patents in MS-region $m$ and year $t$. The treated group includes all MS-regions in the BR whose driving distance from the closest border crossing is below or equal to 20 minutes (BR, 0-20 min). The control group includes all MS-regions in the BR whose driving distance from the closest border crossing in above 20 minutes (BR, > $20 \mathrm{~min})$. Robust standard errors clustered at the MS-region level are given in parentheses. Estimation by Poisson pseudo-maximum-likelihood (PML). 
Table D4: Regional patent count: Fixed-effects difference-in-differences results (including NBR in the control sample)

\begin{tabular}{|c|c|c|c|c|c|c|c|c|}
\hline & \multicolumn{2}{|c|}{ Full sample } & \multicolumn{2}{|c|}{ Incumbents only } & \multicolumn{2}{|c|}{ No Top applicants } & \multicolumn{2}{|c|}{$\begin{array}{l}\text { No Top applicants } \\
\text { Incumbents only }\end{array}$} \\
\hline & $\begin{array}{c}\text { Baseline } \\
\text { (1) }\end{array}$ & $\begin{array}{c}\text { Until } 2007 \\
(2)\end{array}$ & $\begin{array}{c}\text { Baseline } \\
\text { (3) }\end{array}$ & $\begin{array}{c}\text { Until } 2007 \\
(4)\end{array}$ & $\begin{array}{c}\text { Baseline } \\
\text { (5) }\end{array}$ & $\begin{array}{l}\text { Until } 2007 \\
\text { (6) }\end{array}$ & $\begin{array}{l}\text { Baseline } \\
(7)\end{array}$ & $\begin{array}{c}\text { Until } 2007 \\
(8)\end{array}$ \\
\hline AFMP $\times$ Treated & $\begin{array}{c}0.137 \\
(0.0997)\end{array}$ & $\begin{array}{l}0.189 * * \\
(0.0908)\end{array}$ & $\begin{array}{c}0.246^{* *} \\
(0.1232)\end{array}$ & $\begin{array}{l}0.308^{* * * *} \\
(0.1136)\end{array}$ & $\begin{array}{l}0.232^{* * *} \\
(0.0812)\end{array}$ & $\begin{array}{l}0.245^{* * *} \\
(0.0787)\end{array}$ & $\begin{array}{l}0.305^{* *} \\
(0.1193)\end{array}$ & $\begin{array}{l}0.296^{* *} \\
(0.1157)\end{array}$ \\
\hline Number of MS regions & 106 & 106 & 95 & 94 & 106 & 106 & 95 & 94 \\
\hline Observations & 2,438 & 1,908 & 2,185 & 1,692 & 2,438 & 1,908 & 2,185 & 1,692 \\
\hline Pseudo $R^{2}$ & 0.88 & 0.87 & 0.86 & 0.86 & 0.82 & 0.82 & 0.78 & 0.78 \\
\hline MS region FE & $\checkmark$ & $\checkmark$ & $\checkmark$ & $\checkmark$ & $\checkmark$ & $\checkmark$ & $\checkmark$ & $\checkmark$ \\
\hline Year FE & $\checkmark$ & $\checkmark$ & $\checkmark$ & $\checkmark$ & $\checkmark$ & $\checkmark$ & $\checkmark$ & $\checkmark$ \\
\hline
\end{tabular}

Notes: ${ }^{* * *} \mathrm{p}<0.01,{ }^{* *} \mathrm{p}<0.05,{ }^{*} \mathrm{p}<0.1$. The dependent variable is the number of patents in MS-region $m$ and year $t$. The treated group includes all MS-regions in the BR whose driving distance from the closest border crossing is below or equal to 20 minutes (BR, 0-20 min). The control group includes all MS-regions in the BR whose driving distance from the closest border crossing in above 20 minutes (BR, $>20$ min) and all MS regions in the NBR. Robust standard errors clustered at the MS-region level are given in parentheses. Estimation by Poisson pseudo-maximum-likelihood (PML). Columns (1) to (4) report results for the entire dataset. Columns (5) to (8) report results excluding top applicants. Columns (3), (4), (7), and (8) report results considering only incumbent applicants' patents. In this case, the number of MS regions decreases to 95 (94 when restricting the sample to 1990-2007) since 11 (12) MS regions have no incumbent applicants observable in the post-AFMP period due to the overall low number of patent applications filed in those areas in 1990-2012. 
Table D5: Regional patent count, fixed-effects difference-in-differences results: CBI-in-team VS. Resident-only team patents, 1990-2012

\begin{tabular}{|c|c|c|c|c|}
\hline & \multicolumn{2}{|c|}{ CBI-in-Team } & \multicolumn{2}{|c|}{ Residents-only team } \\
\hline & $\begin{array}{c}\text { Baseline } \\
\text { (1) }\end{array}$ & $\begin{array}{l}\text { Until } 2007 \\
\text { (2) }\end{array}$ & $\begin{array}{c}\text { Basline } \\
\text { (3) }\end{array}$ & $\begin{array}{c}\text { Until } 2007 \\
\text { (4) }\end{array}$ \\
\hline AFMP $\times$ Treated & $\begin{array}{l}0.510^{* * *} \\
(0.1375)\end{array}$ & $\begin{array}{l}0.535^{* * *} \\
(0.1193)\end{array}$ & $\begin{array}{c}0.011 \\
(0.1241)\end{array}$ & $\begin{array}{c}0.106 \\
(0.1091)\end{array}$ \\
\hline Number of MS regions & 63 & 62 & 63 & 63 \\
\hline Observations & 1,449 & 1,116 & 1,449 & 1,134 \\
\hline Pseudo $\mathrm{R}^{2}$ & 0.89 & 0.89 & 0.86 & 0.86 \\
\hline MS region FE & $\checkmark$ & $\checkmark$ & $\checkmark$ & $\checkmark$ \\
\hline Year FE & $\checkmark$ & $\checkmark$ & $\checkmark$ & $\checkmark$ \\
\hline
\end{tabular}

Notes: ${ }^{* * *} \mathrm{p}<0.01,{ }^{* *} \mathrm{p}<0.05,{ }^{*} \mathrm{p}<0.1$. The dependent variable is the number of patent filings in MS-region $m$ in year $t$. The treated group includes all MS-regions in the BR whose driving distance from the closest border crossing is below or equal to 20 minutes (BR, 0-20 min). The control group includes all MS-regions in the BR whose driving distance from the closest border crossing in above 20 minutes (BR, > $20 \mathrm{~min}$ ). For the treated group, we decompose the each MS region's yearly patent output, distinguishing between patents including at least one CBI (i.e., CBI-in-team) and patents including only resident inventors (i.e., Resident-only team) and running two separate event-study regressions. The estimated parameters related to CBI-in-team patents are shown as black circles. Those related to Resident-only team patents are shown as gray squares. The regressions include MS-region Fixed Effects and Year Fixed Effects. Vertical bars represent 95\% confidence intervals. The coefficient for our baseline year 1999 is set to zero and shown without confidence interval. Robust standard errors are clustered at the MS-region level. Estimation by Poisson pseudo-maximum-likelihood (PML). 
Table D6: Regional patent count, fixed-effects difference-in-differences results: CBI-in-team VS. Resident-only team patents, 1990-2012 (including NBR in the control sample)

\begin{tabular}{|c|c|c|c|c|}
\hline & \multicolumn{2}{|c|}{ CBI-in-Team } & \multicolumn{2}{|c|}{ Residents-only team } \\
\hline & $\begin{array}{c}\text { Baseline } \\
\text { (1) }\end{array}$ & $\begin{array}{l}\text { Until } 2007 \\
\text { (2) }\end{array}$ & $\begin{array}{l}\text { Basline } \\
\text { (3) }\end{array}$ & $\begin{array}{c}\text { Until } 2007 \\
\text { (4) }\end{array}$ \\
\hline AFMP $\times$ Treated & $\begin{array}{l}0.507^{* * *} \\
(0.1179)\end{array}$ & $\begin{array}{l}0.511^{* * *} \\
(0.1010)\end{array}$ & $\begin{array}{c}0.008 \\
(0.1020)\end{array}$ & $\begin{array}{c}0.082 \\
(0.0888)\end{array}$ \\
\hline Number of MS regions & 106 & 105 & 106 & 106 \\
\hline Observations & 2,438 & 1,890 & 2,438 & 1,908 \\
\hline Pseudo $R^{2}$ & 0.88 & 0.87 & 0.86 & 0.86 \\
\hline MS region FE & $\checkmark$ & $\checkmark$ & $\checkmark$ & $\checkmark$ \\
\hline Year FE & $\checkmark$ & $\checkmark$ & $\checkmark$ & $\checkmark$ \\
\hline
\end{tabular}

Notes: ${ }^{* * *} \mathrm{p}<0.01,{ }^{* *} \mathrm{p}<0.05,{ }^{*} \mathrm{p}<0.1$. The dependent variable is the number of patent filings in MS-region $m$ in year $t$. The treated group includes all MS-regions in the BR whose driving distance from the closest border crossing is below or equal to 20 minutes (BR, 0-20 min). The control group includes all MS-regions in the BR whose driving distance from the closest border crossing in above 20 minutes $(\mathrm{BR},>20 \mathrm{~min})$ and all MS regions in the NBR. For the treated group, we decompose the each MS region's yearly patent output, distinguishing between patents including at least one CBI (i.e., CBI-in-team) and patents including only resident inventors (i.e., Resident-only team) and running two separate event-study regressions. The estimated parameters related to CBI-in-team patents are shown as black circles. Those related to Residentonly team patents are shown as gray squares. The regressions include MS-region Fixed Effects and Year Fixed Effects. Vertical bars represent 95\% confidence intervals. The coefficient for our baseline year 1999 is set to zero and shown without confidence interval. Robust standard errors are clustered at the MS-region level. Estimation by Poisson pseudo-maximum-likelihood (PML). 
Table D7: Active Swiss-resident inventors by region, event study estimations (Figure 6)

\begin{tabular}{|c|c|c|c|c|}
\hline & $\begin{array}{c}\text { Full sample } \\
(1) \\
\end{array}$ & $\begin{array}{c}\text { Incumbents only } \\
(2) \\
\end{array}$ & $\begin{array}{c}\text { No top applicants } \\
\text { (3) }\end{array}$ & $\begin{array}{l}\text { No top applicants } \\
\text { Incumbents only } \\
(4)\end{array}$ \\
\hline $1990 \times$ Treated & $\begin{array}{c}0.294 \\
(0.2941)\end{array}$ & $\begin{array}{c}-0.228 \\
(0.2275)\end{array}$ & $\begin{array}{c}0.004 \\
(0.1844)\end{array}$ & $\begin{array}{c}-0.247 \\
(0.2652)\end{array}$ \\
\hline $1991 \times$ Treated & $\begin{array}{c}0.206 \\
(0.2481)\end{array}$ & $\begin{array}{l}-0.188 \\
(0.1723)\end{array}$ & $\begin{array}{l}-0.008 \\
(0.1353)\end{array}$ & $\begin{array}{l}-0.161 \\
(0.1815)\end{array}$ \\
\hline $1992 \times$ Treated & $\begin{array}{c}0.125 \\
(0.1825)\end{array}$ & $\begin{array}{c}-0.086 \\
(0.1701)\end{array}$ & $\begin{array}{c}-0.123 \\
(0.1313)\end{array}$ & $\begin{array}{c}-0.188 \\
(0.1919)\end{array}$ \\
\hline $1993 \times$ Treated & $\begin{array}{c}0.096 \\
(0.1339)\end{array}$ & $\begin{array}{l}-0.046 \\
(0.1707)\end{array}$ & $\begin{array}{l}-0.081 \\
(0.1336)\end{array}$ & $\begin{array}{l}-0.204 \\
(0.1469)\end{array}$ \\
\hline $1994 \times$ Treated & $\begin{array}{c}0.136 \\
(0.1040)\end{array}$ & $\begin{array}{c}0.023 \\
(0.1631)\end{array}$ & $\begin{array}{c}-0.073 \\
(0.1145)\end{array}$ & $\begin{array}{c}-0.138 \\
(0.1597)\end{array}$ \\
\hline $1995 \times$ Treated & $\begin{array}{c}0.165 \\
(0.1226)\end{array}$ & $\begin{array}{c}0.133 \\
(0.1613)\end{array}$ & $\begin{array}{c}0.022 \\
(0.0997)\end{array}$ & $\begin{array}{c}-0.033 \\
(0.1181)\end{array}$ \\
\hline $1996 \times$ Treated & $\begin{array}{c}0.133 \\
(0.1096)\end{array}$ & $\begin{array}{c}0.123 \\
(0.1491)\end{array}$ & $\begin{array}{c}0.068 \\
(0.1044)\end{array}$ & $\begin{array}{c}0.024 \\
(0.1331)\end{array}$ \\
\hline $1997 \times$ Treated & $\begin{array}{c}-0.015 \\
(0.1036)\end{array}$ & $\begin{array}{c}-0.122 \\
(0.1063)\end{array}$ & $\begin{array}{c}0.056 \\
(0.0993)\end{array}$ & $\begin{array}{c}-0.060 \\
(0.1163)\end{array}$ \\
\hline $1998 \times$ Treated & $\begin{array}{c}-0.077 \\
(0.0759)\end{array}$ & $\begin{array}{l}-0.164^{* *} \\
(0.0759)\end{array}$ & $\begin{array}{c}-0.039 \\
(0.0819)\end{array}$ & $\begin{array}{l}-0.153^{* *} \\
(0.0777)\end{array}$ \\
\hline $2000 \times$ Treated & $\begin{array}{c}0.025 \\
(0.0560)\end{array}$ & $\begin{array}{c}-0.030 \\
(0.0748)\end{array}$ & $\begin{array}{c}0.115^{*} \\
(0.0607)\end{array}$ & $\begin{array}{c}0.091 \\
(0.0775)\end{array}$ \\
\hline $2001 \times$ Treated & $\begin{array}{c}0.087 \\
(0.0634)\end{array}$ & $\begin{array}{l}-0.007 \\
(0.0776)\end{array}$ & $\begin{array}{l}0.168^{* *} \\
(0.0839)\end{array}$ & $\begin{array}{c}0.089 \\
(0.1144)\end{array}$ \\
\hline $2002 \times$ Treated & $\begin{array}{l}0.159^{* *} \\
(0.0781)\end{array}$ & $\begin{array}{c}0.106 \\
(0.0930)\end{array}$ & $\begin{array}{c}0.155 \\
(0.0988)\end{array}$ & $\begin{array}{c}0.1017 \\
(0.1168)\end{array}$ \\
\hline $2003 \times$ Treated & $\begin{array}{l}0.225^{* * *} \\
(0.0703)\end{array}$ & $\begin{array}{c}0.205 \\
(0.0957)\end{array}$ & $\begin{array}{l}0.231^{* *} \\
(0.0976)\end{array}$ & $\begin{array}{c}0.237^{*} \\
(0.1271)\end{array}$ \\
\hline $2004 \times$ Treated & $\begin{array}{l}0.165^{* *} \\
(0.0746)\end{array}$ & $\begin{array}{c}0.157 \\
(0.1015)\end{array}$ & $\begin{array}{c}0.149 \\
(0.0987)\end{array}$ & $\begin{array}{c}0.144 \\
(0.1391)\end{array}$ \\
\hline $2005 \times$ Treated & $\begin{array}{l}0.218^{* *} \\
(0.0935)\end{array}$ & $\begin{array}{c}0.179 \\
(0.1152)\end{array}$ & $\begin{array}{l}0.189^{* *} \\
(0.0904)\end{array}$ & $\begin{array}{c}0.132 \\
(0.1234)\end{array}$ \\
\hline $2006 \times$ Treated & $\begin{array}{c}0.218^{* *} \\
(0.0944)\end{array}$ & $\begin{array}{l}0.237^{* *} \\
(0.1201)\end{array}$ & $\begin{array}{c}0.157 \\
(0.0961)\end{array}$ & $\begin{array}{c}0.178 \\
(0.1386)\end{array}$ \\
\hline $2007 \times$ Treated & $\begin{array}{c}0.151 \\
(0.1085)\end{array}$ & $\begin{array}{c}0.150 \\
(0.1584)\end{array}$ & $\begin{array}{c}0.063 \\
(0.0987)\end{array}$ & $\begin{array}{c}0.034 \\
(0.1459)\end{array}$ \\
\hline $2008 \times$ Treated & $\begin{array}{c}0.054 \\
(0.0983)\end{array}$ & $\begin{array}{c}0.018 \\
(0.1344)\end{array}$ & $\begin{array}{c}0.080 \\
(0.1065)\end{array}$ & $\begin{array}{c}0.092 \\
(0.1589)\end{array}$ \\
\hline $2009 \times$ Treated & $\begin{array}{l}-0.021 \\
(0.1036)\end{array}$ & $\begin{array}{l}-0.083 \\
(0.1399)\end{array}$ & $\begin{array}{c}0.043 \\
(0.1217)\end{array}$ & $\begin{array}{c}0.062 \\
(0.1211)\end{array}$ \\
\hline $2010 \times$ Treated & $\begin{array}{c}0.014 \\
(0.1092)\end{array}$ & $\begin{array}{c}-0.051 \\
(0.1535)\end{array}$ & $\begin{array}{c}0.099 \\
(0.1211)\end{array}$ & $\begin{array}{c}0.124 \\
(0.1786)\end{array}$ \\
\hline $2011 \times$ Treated & $\begin{array}{c}-0.027 \\
(0.1252)\end{array}$ & $\begin{array}{c}-0.086 \\
(0.1521)\end{array}$ & $\begin{array}{c}0.052 \\
(0.1244)\end{array}$ & $\begin{array}{c}0.082 \\
(0.1659)\end{array}$ \\
\hline $2012 \times$ Treated & $\begin{array}{c}-0.034 \\
(0.1334)\end{array}$ & $\begin{array}{c}-0.066 \\
(0.1747)\end{array}$ & $\begin{array}{c}0.029 \\
(0.1340)\end{array}$ & $\begin{array}{c}0.099 \\
(0.1645)\end{array}$ \\
\hline Number of MS regions & 63 & 59 & 63 & 59 \\
\hline Observations & 1,449 & 1,357 & 1,449 & 1,357 \\
\hline Pseudo $\mathrm{R}^{2}$ & 0.91 & 0.90 & 0.85 & 0.80 \\
\hline MS region FE & $\checkmark$ & $\checkmark$ & $\checkmark$ & $\checkmark$ \\
\hline
\end{tabular}

Notes: ${ }^{* * *} \mathrm{p}<0.01,{ }^{* *} \mathrm{p}<0.05,{ }^{*} \mathrm{p}<0.1$. The dependent variable is the number of Swiss-resident inventors active in MS-region $m$ and year $t$. The treated group includes all MS-regions in the BR whose driving distance from the closest border crossing is below or equal to 20 minutes (BR, 0-20 min). The control group includes all MS-regions in the BR whose driving distance from the closest border crossing in above 20 minutes (BR, > 20 min). Robust standard errors clustered at the MS-region level are given in parentheses. Estimation by Poisson pseudo-maximum-likelihood (PML). 
Table D8: Active Swiss-resident inventors by region, fixed-effects difference-in-differences results

\begin{tabular}{|c|c|c|c|c|c|c|c|c|}
\hline & \multicolumn{2}{|c|}{ Full sample } & \multicolumn{2}{|c|}{ Incumbents only } & \multicolumn{2}{|c|}{ No top applicants } & \multicolumn{2}{|c|}{$\begin{array}{l}\text { No top applicants } \\
\text { Incumbents only }\end{array}$} \\
\hline & $\begin{array}{l}\text { Baseline } \\
\text { (1) }\end{array}$ & $\begin{array}{l}\text { Until } 2007 \\
(2)\end{array}$ & $\begin{array}{c}\text { Baseline } \\
\text { (3) }\end{array}$ & $\begin{array}{l}\text { Until } 2007 \\
(4)\end{array}$ & $\begin{array}{c}\text { Baseline } \\
\text { (5) }\end{array}$ & $\begin{array}{l}\text { Until } 2007 \\
(6)\end{array}$ & $\begin{array}{l}\text { Baseline } \\
\text { (7) }\end{array}$ & $\begin{array}{l}\text { Until } 2007 \\
(8)\end{array}$ \\
\hline AFMP $\times$ Treated & $\begin{array}{c}-0.001 \\
(0.1292)\end{array}$ & $\begin{array}{c}0.068 \\
(0.1152)\end{array}$ & $\begin{array}{c}0.100 \\
(0.1443)\end{array}$ & $\begin{array}{c}0.174 \\
(0.1244)\end{array}$ & $\begin{array}{c}0.129 \\
(0.0988)\end{array}$ & $\begin{array}{l}0.167^{*} \\
(0.0892)\end{array}$ & $\begin{array}{c}0.208^{*} \\
(0.1217)\end{array}$ & $\begin{array}{l}0.221^{* *} \\
(0.1110)\end{array}$ \\
\hline
\end{tabular}

\begin{tabular}{lccccccccc} 
Number of MS regions & 63 & 63 & 59 & 59 & 63 & 63 & 59 & 59 \\
Observations & 1,449 & 1,134 & 1,357 & 1,062 & 1,449 & 1,134 & 1,357 & 1,062 \\
Pseudo R & 0.91 & 0.90 & 0.90 & 0.90 & 0.85 & 0.85 & 0.80 & 0.80 \\
\hline MS region FE & $\checkmark$ & $\checkmark$ & $\checkmark$ & $\checkmark$ & $\checkmark$ & $\checkmark$ & $\checkmark$ & $\checkmark$ \\
Year FE & $\checkmark$ & $\checkmark$ & $\checkmark$ & $\checkmark$ & $\checkmark$ & $\checkmark$ & $\checkmark$ & $\checkmark$ \\
\hline
\end{tabular}

Notes: ${ }^{* * *} \mathrm{p}<0.01, * * \mathrm{p}<0.05, * \mathrm{p}<0.1$. The dependent variable is the number of Swiss-resident inventors active in MS-region $m$ and year $t$. The treated group includes all MS-regions in the BR whose driving distance from the closest border crossing is below or equal to 20 minutes (BR, $0-20$ $\mathrm{min}$ ). The control group includes all MS-regions in the BR whose driving distance from the closest border crossing in above 20 minutes (BR, $>20$ $\mathrm{min}$ ). Robust standard errors clustered at the MS-region level are given in parentheses. Estimation by Poisson pseudo-maximum-likelihood (PML). Columns (1) to (4) report results for the entire dataset. Columns (5) to (8) report results excluding top applicants. Columns (3), (4), (7), and (8) report results considering only incumbent applicants' patents. In this case, the number of MS regions decreases to 59 since 4 MS regions have no incumbent applicants observable in the post-AFMP period due to the overall low number of patent applications filed in those areas in $1990-2012$. 
Figure D2: Active Swiss-resident inventors by region, event study results (including NBR in the control sample)

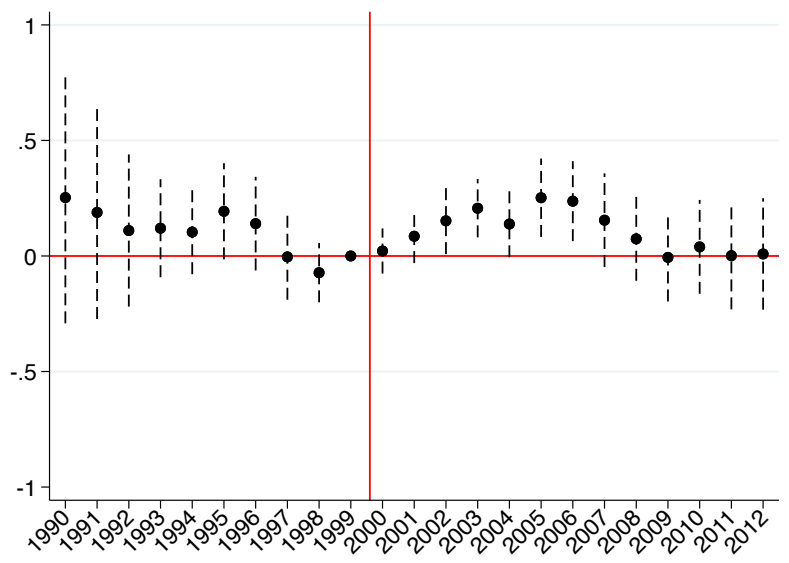

(a) Full sample

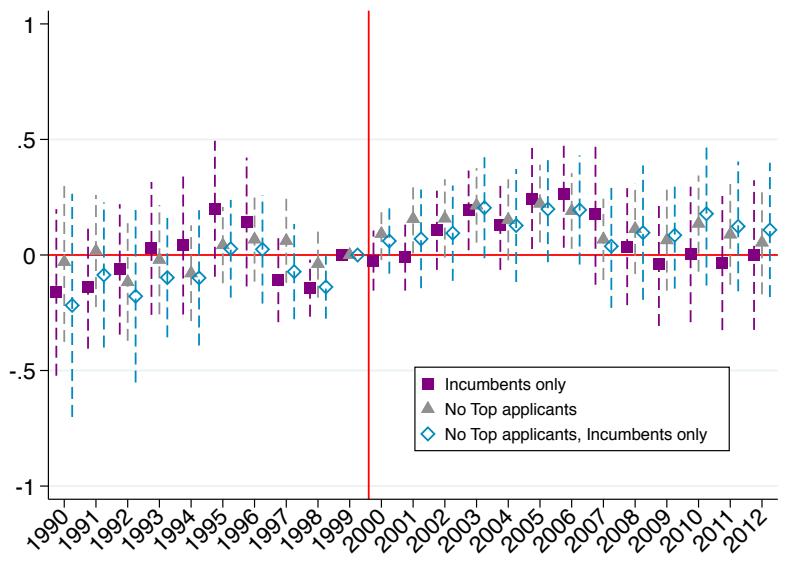

(b) Incumbents \& excluding top applicants

Notes: The dependent variable is the number of Swiss-resident inventors active in MS-region $m$ and year $t$. The treated group includes all MS-regions in the BR whose driving distance from the closest border crossing is below or equal to 20 minutes (BR, 0-20 min). The control group includes all MS-regions in the $\mathrm{BR}$ whose driving distance from the closest border crossing in above 20 minutes (BR, $>20 \mathrm{~min}$ ) and all MS regions in the NBR. Panel (a) shows estimated coefficient for the full sample. Panel (b) focuses on Incumbents and excludes top applicants. Robust standard errors clustered at the MS-region level are given in parentheses. Estimation by Poisson pseudo-maximum-likelihood (PML). 
Table D9: Active Swiss-resident inventors by region: event study estimations (Figure D2)

\begin{tabular}{|c|c|c|c|c|}
\hline & $\begin{array}{c}\text { Full sample } \\
(1) \\
\end{array}$ & $\begin{array}{c}\text { Incumbents only } \\
(2) \\
\end{array}$ & $\begin{array}{c}\text { No top applicants } \\
\text { (3) }\end{array}$ & $\begin{array}{c}\text { No top applicants } \\
\text { Incumbents only } \\
(4)\end{array}$ \\
\hline $1990 \times$ Treated & $\begin{array}{c}0.253 \\
(0.2777)\end{array}$ & $\begin{array}{c}-0.162 \\
(0.1839)\end{array}$ & $\begin{array}{c}-0.030 \\
(0.1768)\end{array}$ & $\begin{array}{c}-0.218 \\
(0.2464)\end{array}$ \\
\hline $1991 \times$ Treated & $\begin{array}{c}0.189 \\
(0.2355)\end{array}$ & $\begin{array}{c}-0.137 \\
(0.1372)\end{array}$ & $\begin{array}{c}0.017 \\
(0.1238)\end{array}$ & $\begin{array}{c}-0.087 \\
(0.1602)\end{array}$ \\
\hline $1992 \times$ Treated & $\begin{array}{c}0.110 \\
(0.1680)\end{array}$ & $\begin{array}{c}-0.063 \\
(0.1439)\end{array}$ & $\begin{array}{c}-0.117 \\
(0.1299)\end{array}$ & $\begin{array}{c}-0.179 \\
(0.1905)\end{array}$ \\
\hline $1993 \times$ Treated & $\begin{array}{c}0.120 \\
(0.1082)\end{array}$ & $\begin{array}{c}0.028 \\
(0.1467)\end{array}$ & $\begin{array}{l}-0.020 \\
(0.1207)\end{array}$ & $\begin{array}{c}-0.098 \\
(0.1318)\end{array}$ \\
\hline $1994 \times$ Treated & $\begin{array}{c}0.103 \\
(0.0930)\end{array}$ & $\begin{array}{c}0.041 \\
(0.1525)\end{array}$ & $\begin{array}{c}-0.079 \\
(0.1057)\end{array}$ & $\begin{array}{c}-0.099 \\
(0.1493)\end{array}$ \\
\hline $1995 \times$ Treated & $\begin{array}{c}0.193^{*} \\
(0.1061)\end{array}$ & $\begin{array}{c}0.200 \\
(0.1501)\end{array}$ & $\begin{array}{c}0.043 \\
(0.0843)\end{array}$ & $\begin{array}{c}0.027 \\
(0.1079)\end{array}$ \\
\hline $1996 \times$ Treated & $\begin{array}{c}0.140 \\
(0.1033)\end{array}$ & $\begin{array}{c}0.143 \\
(0.1422)\end{array}$ & $\begin{array}{c}0.068 \\
(0.0932)\end{array}$ & $\begin{array}{c}0.024 \\
(0.1197)\end{array}$ \\
\hline $1997 \times$ Treated & $\begin{array}{c}-0.004 \\
(0.0946)\end{array}$ & $\begin{array}{c}-0.109 \\
(0.0927)\end{array}$ & $\begin{array}{c}0.062 \\
(0.0928)\end{array}$ & $\begin{array}{c}-0.072 \\
(0.1051)\end{array}$ \\
\hline $1998 \times$ Treated & $\begin{array}{c}-0.072 \\
(0.0655)\end{array}$ & $\begin{array}{l}-0.144^{* *} \\
(0.0630)\end{array}$ & $\begin{array}{c}-0.038 \\
(0.0747)\end{array}$ & $\begin{array}{l}-0.138^{* *} \\
(0.0701)\end{array}$ \\
\hline $2000 \times$ Treated & $\begin{array}{c}0.022 \\
(0.0499)\end{array}$ & $\begin{array}{c}-0.024 \\
(0.0664)\end{array}$ & $\begin{array}{c}0.092 \\
(0.0583)\end{array}$ & $\begin{array}{c}0.060 \\
(0.0721)\end{array}$ \\
\hline $2001 \times$ Treated & $\begin{array}{c}0.085 \\
(0.0592)\end{array}$ & $\begin{array}{c}-0.007 \\
(0.0750)\end{array}$ & $\begin{array}{c}0.157^{* *} \\
(0.0763)\end{array}$ & $\begin{array}{c}0.070 \\
(0.1089)\end{array}$ \\
\hline $2002 \times$ Treated & $\begin{array}{l}0.152^{* *} \\
(0.0736)\end{array}$ & $\begin{array}{c}0.107 \\
(0.0874)\end{array}$ & $\begin{array}{c}0.158^{*} \\
(0.0865)\end{array}$ & $\begin{array}{c}0.094 \\
(0.1052)\end{array}$ \\
\hline $2003 \times$ Treated & $\begin{array}{l}0.207^{* * *} \\
(0.0643)\end{array}$ & $\begin{array}{c}0.193^{* *} \\
(0.0880)\end{array}$ & $\begin{array}{l}0.214^{* * *} \\
(0.0822)\end{array}$ & $\begin{array}{c}0.204^{*} \\
(0.1115)\end{array}$ \\
\hline $2004 \times$ Treated & $\begin{array}{c}0.138^{*} \\
(0 . .0735)\end{array}$ & $\begin{array}{c}0.128 \\
(0.0981)\end{array}$ & $\begin{array}{c}0.152^{*} \\
(0.0895)\end{array}$ & $\begin{array}{c}0.128 \\
(0.1247)\end{array}$ \\
\hline $2005 \times$ Treated & $\begin{array}{l}0.252^{* *} \\
(0.0865)\end{array}$ & $\begin{array}{l}0.244^{* *} \\
(0.1117)\end{array}$ & $\begin{array}{l}0.223^{* * *} \\
(0.0857)\end{array}$ & $\begin{array}{c}0.199^{*} \\
(0.1172)\end{array}$ \\
\hline $2006 \times$ Treated & $\begin{array}{l}0.237^{* * *} \\
(0.0883)\end{array}$ & $\begin{array}{c}0.263^{* *} \\
(0.1183)\end{array}$ & $\begin{array}{l}0.190^{* *} \\
(0.0836)\end{array}$ & $\begin{array}{c}0.194 \\
(0.1206)\end{array}$ \\
\hline $2007 \times$ Treated & $\begin{array}{c}0.155 \\
(0.1033)\end{array}$ & $\begin{array}{c}0.177 \\
(0.1561)\end{array}$ & $\begin{array}{c}0.068 \\
(0.0898)\end{array}$ & $\begin{array}{c}0.038 \\
(0.1361)\end{array}$ \\
\hline $2008 \times$ Treated & $\begin{array}{c}0.074 \\
(0.0927)\end{array}$ & $\begin{array}{c}0.036 \\
(0.1292)\end{array}$ & $\begin{array}{c}0.113 \\
(0.0996)\end{array}$ & $\begin{array}{c}0.097 \\
(0.1483)\end{array}$ \\
\hline $2009 \times$ Treated & $\begin{array}{c}-0.006 \\
(0.0972)\end{array}$ & $\begin{array}{c}-0.041 \\
(0.1357)\end{array}$ & $\begin{array}{c}0.064 \\
(0.1115)\end{array}$ & $\begin{array}{c}0.086 \\
(0.1180)\end{array}$ \\
\hline $2010 \times$ Treated & $\begin{array}{c}0.039 \\
(0.1036)\end{array}$ & $\begin{array}{c}0.002 \\
(0.1496)\end{array}$ & $\begin{array}{c}0.136 \\
(0.1062)\end{array}$ & $\begin{array}{c}0.178 \\
(0.1585)\end{array}$ \\
\hline $2011 \times$ Treated & $\begin{array}{c}0.001 \\
(0.1186)\end{array}$ & $\begin{array}{c}-0.035 \\
(0.1480)\end{array}$ & $\begin{array}{c}0.089 \\
(0.1114)\end{array}$ & $\begin{array}{c}0.124 \\
(0.1433)\end{array}$ \\
\hline $2012 \times$ Treated & $\begin{array}{c}0.009 \\
(0.1229)\end{array}$ & $\begin{array}{l}-0.0004 \\
(0.1651)\end{array}$ & $\begin{array}{c}0 . .054 \\
(0.1145)\end{array}$ & $\begin{array}{c}0.108 \\
(0.1483)\end{array}$ \\
\hline Number of MS regions & 106 & 95 & 106 & 85 \\
\hline Observations & 2,438 & 2,185 & 2,438 & 2,185 \\
\hline Pseudo $\mathrm{R}^{2}$ & 0.90 & 0.89 & 0.85 & 0.79 \\
\hline $\begin{array}{l}\text { MS region FE } \\
\text { Year FE }\end{array}$ & $\begin{array}{l}\checkmark \\
\checkmark\end{array}$ & $\begin{array}{l}\checkmark \\
\checkmark\end{array}$ & $\begin{array}{l}\checkmark \\
\checkmark\end{array}$ & $\begin{array}{l}\checkmark \\
\checkmark\end{array}$ \\
\hline
\end{tabular}

Notes: ${ }^{* * *} \mathrm{p}<0.01,{ }^{* *} \mathrm{p}<0.05,{ }^{*} \mathrm{p}<0.1$. The dependent variable is the number of Swiss-resident inventors active in MS-region $m$ and year $t$. The treated group includes all MS-regions in the BR whose driving distance from the closest border crossing is below or equal to 20 minutes (BR, 0-20 min). The control group includes all MS-regions in the BR whose driving distance from the closest border crossing in above 20 minutes (BR, > $20 \mathrm{~min}$ ) and all MS regions in the NBR. Robust standard errors clustered at the MS-region level are given in parentheses. Estimation by Poisson PML. 
Table D10: Active Swiss-resident inventors by region, fixed-effects difference-in-differences results (including NBR in the control sample)

\begin{tabular}{|c|c|c|c|c|c|c|c|c|}
\hline & \multicolumn{2}{|c|}{ Full sample } & \multicolumn{2}{|c|}{ Incumbents only } & \multicolumn{2}{|c|}{ No top applicants } & \multicolumn{2}{|c|}{$\begin{array}{l}\text { No top applicants } \\
\text { Incumbents only }\end{array}$} \\
\hline & $\begin{array}{c}\text { Baseline } \\
\text { (1) }\end{array}$ & $\begin{array}{c}\text { Until 2007 } \\
(2)\end{array}$ & $\begin{array}{c}\text { Baseline } \\
\text { (3) }\end{array}$ & $\begin{array}{c}\text { Until } 2007 \\
(4)\end{array}$ & $\begin{array}{l}\text { Baseline } \\
\text { (5) }\end{array}$ & $\begin{array}{l}\text { Until } 2007 \\
(6)\end{array}$ & $\begin{array}{l}\text { Baseline } \\
(7)\end{array}$ & $\begin{array}{l}\text { Until } 2007 \\
(8)\end{array}$ \\
\hline AFMP $\times$ Treated & $\begin{array}{c}0.012 \\
(0.1089)\end{array}$ & $\begin{array}{c}0.070 \\
(0.0967)\end{array}$ & $\begin{array}{c}0.095 \\
(0.1244)\end{array}$ & $\begin{array}{c}0.155 \\
(0.1059)\end{array}$ & $\begin{array}{c}0.137^{*} \\
(0.0825)\end{array}$ & $\begin{array}{l}0.164^{* *} \\
(0.0750)\end{array}$ & $\begin{array}{l}0.192^{*} \\
(0.1087)\end{array}$ & $\begin{array}{l}0.195^{*} \\
(0.1009)\end{array}$ \\
\hline Number of MS regions & 106 & 106 & 95 & 94 & 106 & 106 & 95 & 94 \\
\hline Observations & 2,438 & 1,908 & 2,185 & 1,692 & 2,438 & 2,185 & 2,185 & 1,692 \\
\hline Pseudo $R^{2}$ & 0.90 & 0.89 & 0.88 & 0.84 & 0.89 & 0.84 & 0.79 & 0.80 \\
\hline MS region FE & $\checkmark$ & $\checkmark$ & $\checkmark$ & $\checkmark$ & $\checkmark$ & $\checkmark$ & $\checkmark$ & $\checkmark$ \\
\hline Year FE & $\checkmark$ & $\checkmark$ & $\checkmark$ & $\checkmark$ & $\checkmark$ & $\checkmark$ & $\checkmark$ & $\checkmark$ \\
\hline
\end{tabular}

Notes: ${ }^{* * *} \mathrm{p}<0.01,{ }^{* *} \mathrm{p}<0.05,{ }^{*} \mathrm{p}<0.1$. The dependent variable is the number of Swiss-resident inventors active in MS-region $m$ and year $t$. The treated group includes all MS-regions in the BR whose driving distance from the closest border crossing is below or equal to 20 minutes (BR, 0-20 min). The control group includes all MS-regions in the BR whose driving distance from the closest border crossing in above 20 minutes $(\mathrm{BR},>20 \mathrm{~min})$ and all MS regions in the NBR. Robust standard errors clustered at the MS-region level are given in parentheses. Estimation by Poisson pseudo-maximum-likelihood (PML). Columns (1) to (4) report results for the entire dataset. Columns (5) to (8) report results excluding top applicants. Columns (3), (4), (7), and (8) report results considering only incumbent applicants' patents. In this case, the number of MS regions reduces to 95 (94 when restricting the sample to 1990-2007) since 11 (12) MS regions have no incumbent applicants observable in the post-AFMP period due to overall low number of patent applications filed in those areas in 1990-2012. 
Table D11: Incumbent Swiss-resident inventors' patenting probability in the post-AFMP period (including NBR in the control sample)

\begin{tabular}{lcccc}
\hline \hline & $\begin{array}{c}\text { Baseline } \\
(1)\end{array}$ & $\begin{array}{c}\text { No top applicants } \\
(2)\end{array}$ & $\begin{array}{c}\text { Pharmaceuticals } \\
(3)\end{array}$ & $\begin{array}{c}\text { Chemicals } \\
(4)\end{array}$ \\
\hline Treated & $0.377^{* * *}$ & -0.299 & 0.393 & 0.057 \\
& $(0.1198)$ & $(0.2175)$ & $(0.3022)$ & $(0.1802)$ \\
& & & & \\
& $0.105^{* * *}$ & $0.215^{* * *}$ & $0.031^{*}$ & $0.029^{* *}$ \\
Years active (pre-AFMP) & $(0.0089)$ & $(0.0128)$ & $(0.0175)$ & $(0.0115)$ \\
& & & & \\
& $0.042^{* * *}$ & $0.019^{* * *}$ & $0.044^{* * *}$ & $0.046^{* * *}$ \\
No. of co-inventors (pre-AFMP) & $(0.0043)$ & $(0.0066)$ & $(0.0070)$ & $(0.0058)$ \\
& & & & \\
& $-0.0001^{* * *}$ & 0.0002 & 0.00006 & $-0.0001^{* *}$ \\
Applicant inventive workforce (pre-AFMP) & $(0.00003)$ & $(0.0001)$ & $(0.00005)$ & $(0.00004)$ \\
& & & & \\
Observations & & & & \\
Pseudo R & & & & \\
\hline MS region dummies & 18,340 & 12,270 & 3,100 & 5,068 \\
Tech. Class dummies & 0.12 & 0.14 & $\checkmark .15$ & $\checkmark .14$ \\
\hline \hline
\end{tabular}

Notes: ${ }^{* * *} \mathrm{p}<0.01,{ }^{* *} \mathrm{p}<0.05,{ }^{*} \mathrm{p}<0.1$. Regression results for a cross section of Swiss-resident inventors active at least once in 1990-1999 and tracked until 2012. The dependent variable is a dummy variable equal to 1 if the focal inventor patents at least once after 1999, the post-AFMP period. Treated ${ }_{i}$ is a dummy equal to 1 if the focal inventor was active in BRs whose driving distance from the closest border crossing is below or equal to 20 minutes (BR, 0-20 min). The control group includes also inventors active in NBR MS regions. Column (1) reports results for the full sample. Column (2) excludes inventors associated with top applicants. Column (3) considers only inventors active in Pharmaceutical technology classes and column (4) only inventors active in Chemical technology classes (Schmoch, 2008). Robust standard errors are given in parentheses. Probit models estimated by maximum likelihood. 
Table D12: Falsification test: Individual productivity (patent count), number of co-inventors, and CBI-countries' prior-art citations: fixed-effects difference-in-differences results, 1990-2012

\begin{tabular}{|c|c|c|c|c|c|c|}
\hline & \multicolumn{2}{|c|}{ No. of patents } & \multicolumn{2}{|c|}{ No. of co-inventors } & \multicolumn{2}{|c|}{$\begin{array}{l}\text { No. of backward citations } \\
\text { to CBI-country prior art }\end{array}$} \\
\hline & $\begin{array}{c}\text { Baseline } \\
\text { (1) }\end{array}$ & $\begin{array}{l}\text { Excluding patents } \\
\text { with CBIs in team } \\
(2)\end{array}$ & $\begin{array}{c}\text { Baseline } \\
\text { (3) }\end{array}$ & $\begin{array}{l}\text { Excluding patents } \\
\text { with CBIs in team } \\
(4)\end{array}$ & $\begin{array}{c}\text { Baseline } \\
\text { (5) }\end{array}$ & $\begin{array}{l}\text { Excluding patents } \\
\text { with CBIs in team } \\
(6)\end{array}$ \\
\hline PlaceboAFMP $\times$ Treated & $\begin{array}{c}-0.063 \\
(0.0890)\end{array}$ & $\begin{array}{l}-0.140^{*} \\
(0.0822)\end{array}$ & $\begin{array}{c}-0.031 \\
(0.0948)\end{array}$ & $\begin{array}{l}-0.168 \\
(0.1121)\end{array}$ & $\begin{array}{c}-0.030 \\
(0.1139)\end{array}$ & $\begin{array}{c}-0.127 \\
(0.1348)\end{array}$ \\
\hline Number of Inventors & 960 & 913 & 926 & 884 & 729 & 668 \\
\hline Observations & 3,228 & 3,106 & 3,133 & 3,003 & 2,607 & 3,228 \\
\hline Pseudo $\mathrm{R}^{2}$ & 0.11 & 0.14 & 0.26 & 0.23 & 0.25 & 0.22 \\
\hline Inventor FE & $\checkmark$ & $\checkmark$ & $\checkmark$ & $\checkmark$ & $\checkmark$ & $\checkmark$ \\
\hline Applicant FE & $\checkmark$ & $\checkmark$ & $\checkmark$ & $\checkmark$ & $\checkmark$ & $\checkmark$ \\
\hline MS region FE & $\checkmark$ & $\checkmark$ & $\checkmark$ & $\checkmark$ & $\checkmark$ & $\checkmark$ \\
\hline Year FE & $\checkmark$ & $\checkmark$ & $\checkmark$ & $\checkmark$ & $\checkmark$ & $\checkmark$ \\
\hline
\end{tabular}

Notes: ${ }^{* * *} \mathrm{p}<0.01,{ }^{* *} \mathrm{p}<0.05,{ }^{*} \mathrm{p}<0.1$. The table reports the results of a falsification test where we restrict the sample to the pre-AFMP period

(1990-1999) testing "PlaceboAFMP", a dummy variable equal to 1 from 1995 onwards. In columns (1) and (2) the dependent variable is the number of patents filed by inventor $i$ in MS-region $m$ and year $t$ for applicant $j$. In columns (3) and (4) the dependent variable is the number of distinct co-inventors collaborating with inventor $i$ in MS-region $m$ and year $t$ for applicant $j$. In columns (5) and (6) the dependent variable is the number of citations to CBI-countries' prior art made by inventor $i$ in MS-region $m$ and year $t$ for applicant $j$, divided by the number of patents filed by the inventor in the considered year. The treated group includes "persistent" inventors working in R\&D labs located in BR MS regions whose driving distance from the closest border crossing is below or equal to 20 minutes (BR, 0-20 min). The control group includes "persistent" inventors working in R\&D labs located in BR MS regions whose driving distance from the closest border crossing is above 20 minutes (BR, > 20 min). Robust standard errors clustered at the MS region level are given in parentheses. Estimations by Poisson pseudo-maximum-likelihood (PML). The number of "persistent" inventors is slightly lower than our original sample as few observations are discarded to ensure the existence of the estimates (Silva and Tenreyro, 2011). Such "separated" observations can be safely dropped as they do not contribute useful information for the estimation algorithm (Correia et al., 2020). 
Table D13: Individual productivity (patent count), number of co-inventors, and CBI-countries' prior-art citations: fixed-effects differencein-differences results, 1990-2012 (including NBR inventors in the control sample)

\begin{tabular}{|c|c|c|c|c|c|c|}
\hline & \multicolumn{2}{|c|}{ No. of patents } & \multicolumn{2}{|c|}{ No. of co-inventors } & \multicolumn{2}{|c|}{$\begin{array}{l}\text { No. of backward citations } \\
\text { to CBI-country prior art }\end{array}$} \\
\hline & $\begin{array}{c}\text { Baseline } \\
\text { (1) }\end{array}$ & $\begin{array}{l}\text { No patents with } \\
\text { CBI in team } \\
(2)\end{array}$ & $\begin{array}{c}\text { Baseline } \\
\text { (3) }\end{array}$ & $\begin{array}{l}\text { No patents with } \\
\text { CBI in team } \\
\text { (4) }\end{array}$ & $\begin{array}{c}\text { Baseline } \\
\text { (5) }\end{array}$ & $\begin{array}{l}\text { No patents with } \\
\text { CBI in team } \\
(6)\end{array}$ \\
\hline AFMP $\times$ Treated & $\begin{array}{l}0.117^{* *} \\
(0.0579)\end{array}$ & $\begin{array}{c}0.008 \\
(0.0456)\end{array}$ & $\begin{array}{l}0.128^{* * *} \\
(0.0384)\end{array}$ & $\begin{array}{c}0.034 \\
(0.0347)\end{array}$ & $\begin{array}{l}0.238^{* * *} \\
(0.0664)\end{array}$ & $\begin{array}{c}0.075 \\
(0.0680)\end{array}$ \\
\hline Number of Inventors & 2,392 & 2,344 & 2,332 & 2,283 & 1,946 & 1,885 \\
\hline Observations & 12,087 & 11,873 & 11,755 & 11,494 & 10,369 & 10,105 \\
\hline Pseudo $\mathrm{R}^{2}$ & 0.12 & 0.14 & 0.28 & 0.24 & 0.31 & 0.26 \\
\hline Inventor FE & $\checkmark$ & $\checkmark$ & $\checkmark$ & $\checkmark$ & $\checkmark$ & $\checkmark$ \\
\hline Applicant FE & $\checkmark$ & $\checkmark$ & $\checkmark$ & $\checkmark$ & $\checkmark$ & $\checkmark$ \\
\hline MS region FE & $\checkmark$ & $\checkmark$ & $\checkmark$ & $\checkmark$ & $\checkmark$ & $\checkmark$ \\
\hline Year FE & $\checkmark$ & $\checkmark$ & $\checkmark$ & $\checkmark$ & $\checkmark$ & $\checkmark$ \\
\hline
\end{tabular}

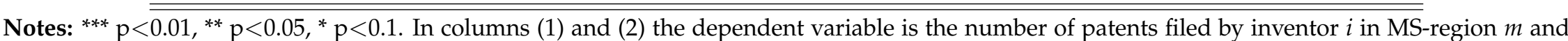
year $t$ for applicant $j$. In columns (3) and (4) the dependent variable is the number of distinct co-inventors collaborating with inventor $i$ in MS-region $m$ and year $t$ for applicant $j$. In columns (5) and (6) the dependent variable is the number of citations to CBI-countries' prior art made by inventor $i$ in MS-region $m$ and year $t$ for applicant $j$, divided by the number of patents filed by the inventor in the considered year. The treated group includes "persistent" inventors working in R\&D labs located in BR MS regions whose driving distance from the closest border crossing is below or equal to 20 minutes (BR, 0-20 min). The control group includes "persistent" inventors working in R\&D labs located in BR MS regions whose driving distance from the closest border crossing is above 20 minutes (BR, > $20 \mathrm{~min}$ ) and all those located in the NBR. Robust standard errors clustered at the MS region level are given in parentheses. Estimations by Poisson pseudo-maximum-likelihood (PML). The number of "persistent" inventors is slightly lower than our original sample as few observations are discarded to ensure the existence of the estimates (Silva and Tenreyro, 2011). Such "separated" observations can be safely dropped as they do not contribute useful information for the estimation algorithm (Correia et al., 2020). 
Table D14: Average forward citations and grant share: fixed-effects difference-in-differences results, 1990-2012

\begin{tabular}{lccccc}
\hline \hline & \multicolumn{2}{c}{ Avg. forward citations } & & \multicolumn{2}{c}{ Granted share } \\
\cline { 2 - 3 } & Baseline & $\begin{array}{c}\text { No patents with } \\
\text { CBI in team }\end{array}$ & & Baseline & $\begin{array}{c}\text { No patents with } \\
\text { CBI in team }\end{array}$ \\
& $(1)$ & $(2)$ & & $(3)$ & $(4)$ \\
\hline AFMP $\times$ Treated & -0.189 & -0.301 & & 0.034 & 0.093 \\
& $(0.2468)$ & $(0.2039)$ & & $(0.0321)$ & $(0.0653)$ \\
Number of inventors & 1,942 & 1,942 & & 1,942 & 1,942 \\
Observations & 9,887 & 9,887 & & 9,887 & 9,887 \\
$\mathrm{R}^{2}$ & 0.49 & 0.46 & & 0.49 & 0.43 \\
\hline Inventor FE & $\checkmark$ & $\checkmark$ & & $\checkmark$ & $\checkmark$ \\
Applicant FE & $\checkmark$ & $\checkmark$ & & $\checkmark$ & $\checkmark$ \\
MS region FE & $\checkmark$ & $\checkmark$ & & $\checkmark$ & $\checkmark$ \\
Year FE & $\checkmark$ & $\checkmark$ & & $\checkmark$ & $\checkmark$ \\
\hline
\end{tabular}

Notes: ${ }^{* * *} \mathrm{p}<0.01,{ }^{* *} \mathrm{p}<0.05,{ }^{*} \mathrm{p}<0.1$. In columns (1) and (2) the dependent variable is the average number of citations (5-year window) received by patents filed by inventor $i$ in MS-region $m$ and year $t$ for applicant $j$. In columns (3) and (4) the dependent variable is the share of granted patents filed by inventor $i$ in MS-region $m$ and year $t$ for applicant $j$. The treated group includes all inventor working in R\&D labs located in BR MS regions whose driving distance from the closest border crossing is below or equal to 20 minutes (BR, 0-20 min). The control group includes all inventor working in R\&D labs located in BR MS regions whose driving distance from the closest border crossing is above 20 minutes (BR, > $20 \mathrm{~min}$ ) and all those located in the NBR. Robust standard errors clustered at the MS region level are given in parentheses. Estimations by OLS. 
Table D15: Average forward citations and grant share: fixed-effects difference-in-differences results, 1990-2012 (including NBR inventors in the control sample)

\begin{tabular}{|c|c|c|c|c|}
\hline & \multicolumn{2}{|c|}{ Avg. forward citations } & \multicolumn{2}{|c|}{ Granted share } \\
\hline & $\begin{array}{c}\text { Baseline } \\
\text { (1) }\end{array}$ & $\begin{array}{l}\text { No patents with } \\
\text { CBI in team } \\
\text { (2) }\end{array}$ & $\begin{array}{c}\text { Baseline } \\
\text { (3) }\end{array}$ & $\begin{array}{l}\text { No patents with } \\
\text { CBI in team } \\
\text { (4) }\end{array}$ \\
\hline AFMP $\times$ Treated & $\begin{array}{c}0.057 \\
(0.2405)\end{array}$ & $\begin{array}{c}-0.064 \\
(0.2052)\end{array}$ & $\begin{array}{c}0.030 \\
(0.0287)\end{array}$ & $\begin{array}{c}0.088 \\
(0.0603)\end{array}$ \\
\hline Number of inventors & 2,392 & 2,392 & 2,392 & 2,392 \\
\hline Observations & 12,087 & 12,087 & 12,087 & 12,087 \\
\hline $\mathrm{R}^{2}$ & 0.46 & 0.46 & 0.48 & 0.45 \\
\hline Inventor FE & $\checkmark$ & $\checkmark$ & $\checkmark$ & $\checkmark$ \\
\hline Applicant FE & $\checkmark$ & $\checkmark$ & $\checkmark$ & $\checkmark$ \\
\hline MS region FE & $\checkmark$ & $\checkmark$ & $\checkmark$ & $\checkmark$ \\
\hline Year FE & $\checkmark$ & $\checkmark$ & $\checkmark$ & $\checkmark$ \\
\hline
\end{tabular}

Notes: ${ }^{* * *} \mathrm{p}<0.01,{ }^{* *} \mathrm{p}<0.05,{ }^{*} \mathrm{p}<0.1$. In columns (1) and (2) the dependent variable is the average number of citations (5-year window) received by patents filed by inventor $i$ in MS-region $m$ and year $t$ for applicant $j$. In columns (3) and (4) the dependent variable is the share of granted patents filed by inventor $i$ in MS-region $m$ and year $t$ for applicant $j$. The treated group includes all inventor working in R\&D labs located in BR MS regions whose driving distance from the closest border crossing is below or equal to 20 minutes (BR, 0-20 min). The control group includes all inventor working in R\&D labs located in BR MS regions whose driving distance from the closest border crossing is above 20 minutes (BR, > $20 \mathrm{~min}$ ) and all those located in the NBR. Robust standard errors clustered at the MS region level are given in parentheses. Estimations by OLS. 


\section{E. Patstat-ZEMIS matching procedure}

We match foreign inventors active in Switzerland to their immigration records by linking the Swiss Central Information Migration System database (ZEMIS) and EPO patent applications obtained from Patstat.

The ZEMIS database is the complete census of foreign individuals with a Swiss resident or work permit, a data-analysis-oriented mirror of Switzerland's Central Migration Information System. It monitors the country's foreign population aggregating immigrants' information produced by Swiss municipalities, the administrative entities tasked to issue and renew residence and work permits. The earliest ZEMIS version dates back to 2002 . Besides including information on immigrants' nationality, residence permit type, and entry date, ZEMIS contains information about individuals' background (e.g., birth year and location, parents' nationality) and work activity (e.g., type of job, employer's industrial sector).

To prepare ZEMIS immigrants' and EPO inventors' raw records for the match, we parsed individuals' full names and harmonized the information about their residence and work location. For both data sources, we split full name strings into first, last, and middle names (if any). We capitalize all strings and remove all accents. ZEMIS' residence and work locations come already classified by main administrative units (e.g., municipalities, cantons). We update all municipalities according to the latest Swiss administrative division (i.e., late 2018), accounting for communities' mergers and incorporations, and assign each municipality to the MS Region it belongs to. EPO patents provide geographic information about an inventor only in the form of address strings. In order to make them comparable to those in ZEMIS, we first submit address strings to the Google Maps Geolocation API obtaining the administrative units associated to each address and repeat the municipalities' update and addition of MS regions we performed for ZEMIS. ${ }^{25}$

The last data preparation step deals with individuals' disambiguation. ZEMIS doesn't present any problem, as a unique identifier is assigned to each person entering the database. The identifier is kept for the whole life of the record inside the database, even

\footnotetext{
${ }^{25}$ For more information on Google Maps Geolocation API: https://developers.google.com/maps/ documentation/geolocation/intro
} 
if it temporarily exits and subsequently re-enters it (i.e., a foreign individual leaving Switzerland and re-entering the country with a residence or work permit after a number of years). Patstat however offers only a basic inventor disambiguation, based on perfect similarity of names' spelling and addresses. We use the algorithm proposed by Pezzoni et al. (2014) and assign a unique identifier to the same individual appearing on different patents with different addresses or different spellings of name and/or surname.

In order to link inventors to their immigration records in ZEMIS, we implement a fuzzy match approach, based on the computation of string similarity measures between individuals' personal names and corresponding geographic and age-based information. String similarity measures are often employed to connect data sources not sharing common identifiers for their respective records. ${ }^{26}$ An important advantage of string comparisons, is the ability to overcome misspellings and the presence of additional names, which would bias the results of strict matching procedures based on perfect similarity between strings. We treat the matching as a binary classification problem and follow a supervised machine learning strategy originally developed by Feigenbaum (2016). Such approach is particularly suited to situations where a "ground-truth" training set is not readily available and has to be constructed by researchers.

We start by creating a sample of all candidate matches. To do so we compare first and last names of individuals in ZEMIS and inventors on EPO patents. To exclude false matches and limit the number of comparisons to be performed, we introduce the following blocking conditions: ${ }^{27}$

- The first two initials of first name and last name must coincide;

- The canton of residence/work must coincide;

- The potential match's age at time of the patent filing must be $\geq 18$ years old and $\leq$ 75 years old;

- The potential match must have filed at least one patent during its period of residence/work in Switzerland.

\footnotetext{
${ }^{26}$ Recent works involving fuzzy matches of inventors to external data sources include Depalo and Di Addario (2014); Jung and Ejermo (2014); Toivanen and Väänänen (2016); Dorner et al. (2016) and Bell et al. (2019).

${ }^{27} \mathrm{~A}$ comparison based on the full cartesian product of ZEMIS and EPO patents individual records would require enormous computational power, almost exclusively inflated by false matches.
} 
We then produce a Jaro-Winkler (Jaro (1989); Winkler (1990)) string similarity score

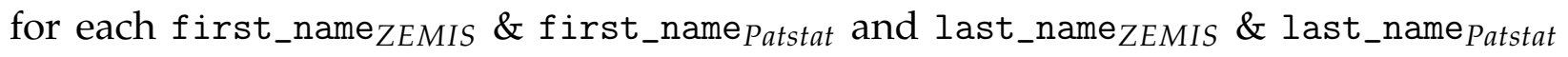
combination in the dataset. We retain only potential matches displaying similarity scores $\geq 0.8$ for both their first_name and last_name comparisons, obtaining 889,532 potential matches.

In order to tune the matching algorithm, we construct a training set by randomly extracting 6,000 candidate matches, stratifying our sampling on individuals' nationality, canton of residence (country for potential residents), and year of birth. We then manually check each record, creating a binary indicator "match" equal to 1 for those we believe referring to the same individual and equal to 0 in all other cases. ${ }^{28}$

Table E1: List of predictors to train the algorithm

\begin{tabular}{|c|c|}
\hline Variable & Description \\
\hline jw_first_name & Jaro-Winkler string similarity between first_name ZEMIS and first_name Patstat \\
\hline jw_last_name & Jaro-Winkler string similarity between last_name ${ }_{Z E M I S}$ and last_name Patstat $_{\text {. }}$ \\
\hline jw_full_name & Jaro-Winkler string similarity between full_name ZEMIS and full_name Patstat \\
\hline same_first_name & Dummy indicator equal to 1 if first_name ZEMIS perfectly matches first_name Patstat \\
\hline same_last_name & Dummy indicator equal to 1 if last_name ZEMIS perfectly matches last_name Patstat \\
\hline same_full_name & Dummy indicator equal to 1 if full_name ZEMIS perfectly matches full_name Patstat \\
\hline same_lastone_first_name & Dummy indicator equal to 1 if first_name ZEMIS's last letter perfectly matches first_name Patstat $^{\prime}$ s one \\
\hline same_lasttwo_first_name & Dummy indicator equal to 1 if first_name ZEMIS's last two letters perfectly matches first_name Patstat's ones \\
\hline same_lastthree_first_name & Dummy indicator equal to 1 if first_name ZEMIS's last three letters perfectly matches first_name Patstat's ones \\
\hline same_lastone_last_name & Dummy indicator equal to 1 if last_name ZEMIS's last letter perfectly matches last_name Patstat $_{\text {'s }}$ one \\
\hline same_lasttwo_last_name & Dummy indicator equal to 1 if last_name ZEMIS's last letter perfectly matches last_name Patstat's one \\
\hline same_lastthree_last_name & Dummy indicator equal to 1 if last_namezEMIS's last letter perfectly matches last_name patstat's one \\
\hline age_at_appln & Age at the time of invention \\
\hline age_at_first_inv & Age at first invention \\
\hline age_20_70 & Dummy indicator equal to 1 if age at the time of invention if comprised between 20 and 70 years old \\
\hline age_25_65 & Dummy indicator equal to 1 if age at the time of invention if comprised between 25 and 65 years old \\
\hline age_30_60 & Dummy indicator equal to 1 if age at the time of invention if comprised between 30 and 60 years old \\
\hline age_35_55 & Dummy indicator equal to 1 if age at the time of invention if comprised between 35 and 55 years old \\
\hline first_age_20_70 & Dummy indicator equal to 1 if age at first invention if comprised between 20 and 70 years old \\
\hline first_age_25_65 & Dummy indicator equal to 1 if age at first invention if comprised between 25 and 65 years old \\
\hline first_age_30_60 & Dummy indicator equal to 1 if age at first invention if comprised between 30 and 60 years old \\
\hline first_age_35_55 & Dummy indicator equal to 1 if age at first invention if comprised between 35 and 55 years old \\
\hline d_loc_city & Dummy indicator equal to 1 if ZEMIS residence or work municipality matches Patstat's municipality \\
\hline d_loc_region & Dummy indicator equal to 1 if ZEMIS residence or work region matches Patstat's region* \\
\hline
\end{tabular}

Notes: *For Swiss locations we use MS Regions, while for Austrian, French, German, and Italian locations we use "Politischer Bezirk", "Départements", "Landkreis", and "Province" respectively.

Following Feigenbaum (2016), we train our matching algorithm using a Probit classifier. ${ }^{29}$ We essentially run a Probit model, relating the binary indicator "match" to a series

\footnotetext{
${ }^{28}$ While the majority of non-matches stem from individuals with similar but clearly different names (e.g., Émile Zola with Emilio Zoller, Italo Calvino with Italo Castelli, or Thomas Mann with Thomas Manford), a portion of them involved homonyms. In that case we defined a match only in case of corresponding geographic information.

${ }^{29} \mathrm{He}$ demonstrates how in his case, using alternatives such as logistic or non-paramentric classifiers like random forests and support-vector-machines, do not improve the matching algorithm performance.
} 
of variables which might predict the status of match vs. non-match. Table E1 reports the predictors we use.

Based on the coefficients of the probit estimation, we estimate the predicted probability score for each candidate match in the training set. In order to tune our algorithm, we seek to find a lower bound for the score to declare a match which would simultaneously maximize precision (i.e., true positives / true positives + false positives) and recall (i.e., true positives / true positives + false negatives). Figure E1 relates these two measures to the predicted probability scores we calculated at the previous stage, evaluating the "in-sample" performance of the algorithm.

Figure E1: Precision and recall curve, training set

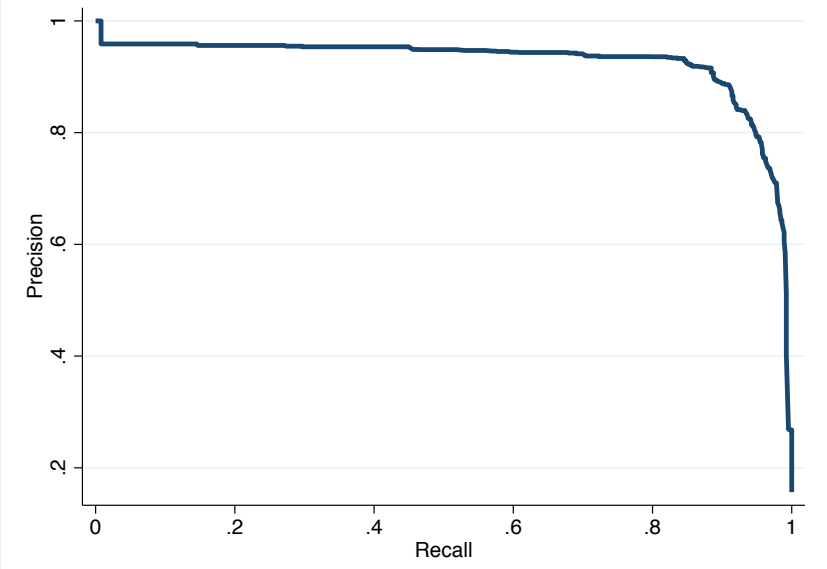

We identify the optimal score lower bound by maximising a utility function including the sum of precision and recall. Table E2 reports the results of the optimal score search under different weighting schemes for precision and recall. We opt for a weight of 1.75 on recall defining as matches all those records with a score $>0.28$. We privilege recall to obtain the highest-number of matches possible with reasonable precision rates, keeping the freedom to raise the lower bound to declare a match in subsequent stages of the analysis for robustness checks. 
Table E2: Grid search results according to different weighting schemes

\begin{tabular}{ccccc}
\hline \hline Weight on Precision & Weight on Recall & Score & Precision & Recall \\
\hline 3 & 1 & 0.580 & 0.884 & 0.878 \\
1.75 & 1 & 0.560 & 0.880 & 0.884 \\
1 & 1 & 0.560 & 0.880 & 0.884 \\
1 & 1.75 & 0.280 & 0.813 & 0.936 \\
1 & 3 & 0.236 & 0.785 & 0.948 \\
\hline \hline
\end{tabular}

Having selected the optimal score to declare a match, we return to the full dataset of candidate matches, run the algorithm we tuned on the training set, estimate each record's predicted probability, and identify as matches all those with a score higher than 0.28 . We obtain 23,123 combinations of individuals in ZEMIS matched to Patstat inventors. As a final step, we consider all those ambiguous situations where only one individual in ZEMIS is matched to multiple Patstat inventors $(1: m)$, multiple individuals in ZEMIS are matched to a only one Patstat inventor ( $m: 1)$, and multiple individuals in ZEMIS are matched to multiple Patstat inventors $(\mathrm{m}: \mathrm{m})$. Table E3 shows how roughly 57\% of the records matched involve a unique ZEMIS individual and a unique Patstat inventor (1:1).

Table E3: Match type breakdown

\begin{tabular}{lcc}
\hline \hline Zemis : Patstat & N. Records & Percentage \\
\hline $1: 1$ & 13,280 & 57.43 \\
$1: m$ & 4,297 & 18.58 \\
$m: 1$ & 2,677 & 11.58 \\
$m: m$ & 2,869 & 12.41 \\
\hline Total & 23,123 & 100.00 \\
\hline \hline
\end{tabular}

We restore the remaining records to a 1:1 set up as follows:

- 1:m : most of these records stem from Patstat disambiguation issues not solved by the "Massacrator" algorithm. We manually check each record and assign a common identifier to inventors who are clearly the same person (i.e., same applicant, same address declared), reducing the initial 4,297 records to 2,108. For persisting 1:m links we keep the match with highest predicted score, obtaining the final 1,949 1:1 matches.

- $m: 1$ : We reduce the initial 2,677 matches to 1,003 1:1 links keeping the ZEMIS : Patstat combination with the highest predicted score.

- m:m : We first get rid of multiple matches on the Pastat side assigning a common 
identifier to inventors with the same identity, reducing the records from 2,869 to 1,984 . We subsequently take care of the duplicate matches on the ZEMIS side by selecting the links with the highest predicted score, obtaining 618 1:1 matches.

The final dataset of matched records includes 16,844 unique inventors connected to their ZEMIS immigration files.

To further assess the matching algorithm performance, we test its precision and recall on an external validation set. Such out of sample test provides a more reliable indication of the algorithm's quality than that inferred at the training stage (i.e., in-sample performance). We generate our validation set by selecting all "academic inventors" (i.e., those listed on patent applications filed or co-filed by universities and other academic institutions) active in Switzerland and listed on PCT patents, which report inventors' self-declared nationalities. We focus on academic inventors to increase the likelihood of finding information about their careers and background online, as academic researchers are more likely to have public profiles on university or personal websites than scientists involved in industrial R\&D. We manually validate each inventor's nationality and (potential) immigrant status browsing their profiles. We define as "immigrants" (i.e., records to be matched) all those whose validated nationality is not Swiss.

Implementing the same procedure we used to create the final dataset of 16,844 linked inventors, we compare the match prediction of the algorithm with the validation set by immigrant status. Table E4 provides a confusion matrix enabling the calculation of precision and recall scores for this exercise.

Table E4: Testing the Algorithm on the Validation Set: Confusion Matrix

\begin{tabular}{lccc}
\hline \hline \multirow{2}{*}{ Algorithm prediction } & \multicolumn{3}{c}{ Validation set Status } \\
\cline { 2 - 4 } Not matched & Not matched(Swiss) & Matched (Foreign national) \\
Matched & 654 & 250 & 904 \\
& 50 & 613 & 663 \\
\hline \hline
\end{tabular}

The ratio of the true positives matches (613) and the sum of true and false positives matches (663) gives us the precision rate, in this case around 93\%. The ratio of true positives matches (613) and the sum of true positives and false negatives (863) matches allows to calculate the recall rate, in this case around $71 \%$. 


\section{References in Appendix}

Bell, A., R. Chetty, X. Jaravel, N. Petkova, and J. Van Reenen (2019): “Who becomes an inventor in America? The importance of exposure to innovation," The Quarterly Journal of Economics, 134, 647-713.

Depalo, D. and S. L. Di Addario (2014): “Shedding light on inventors' returns to patents," Centro Studi Luca d'Agliano Development Studies Working Paper.

Dorner, M., D. Harhoff, T. Hinz, K. Hoisl, ANd S. Bender (2016): “Social ties for labor market access-Lessons from the migration of East German inventors," CEPR Discussion Paper No. DP11601.

Feigenbaum, J. J. (2016): “Automated census record linking: A machine learning approach," Mimeo.

JARO, M. A. (1989): “Advances in record-linkage methodology as applied to matching the 1985 census of Tampa, Florida," Journal of the American Statistical Association, 84, 414-420.

JunG, T. AND O. EJermo (2014): "Demographic patterns and trends in patenting: Gender, age, and education of inventors," Technological Forecasting and Social Change, 86, 110-124.

Pezzoni, M., F. Lissoni, and G. Tarasconi (2014): “How to kill inventors: testing the Massacrator(C) algorithm for inventor disambiguation," Scientometrics, 101, 477-504.

Scнмосн, U. (2008): "Concept of a Technology Classification for Country Comparisons," WIPO Technical Report.

ToIvanen, O. AND L. VÄÄnÄNEN (2016): “Education and invention," Review of Economics and Statistics, 98, 382-396.

WinkLer, W. E. (1990): "String Comparator Metrics and Enhanced Decision Rules in the Fellegi-Sunter Model of Record Linkage." Proceedings of the Section on Survey Research Methods, American Statistical Association, 354?359. 